Universidad de Lima

Facultad de Economía

Carrera de Economía

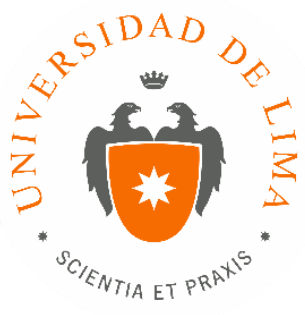

\title{
EL ENCAJE COMO INSTRUMENTO PARA EL CONTROL DE FLUJOS DE CAPITALES: UN ANÁLISIS DEL CASO PERUANO DURANTE EL PERIODO 2006-2013
}

Trabajo de investigación para optar el título profesional de Economista

\author{
Diego Andrés Escobar Izquierdo \\ Código 20090359
}

Asesor

Victor Luis Alberto Tokeshi Shirota

Lima - Perú

Junio de 2016 


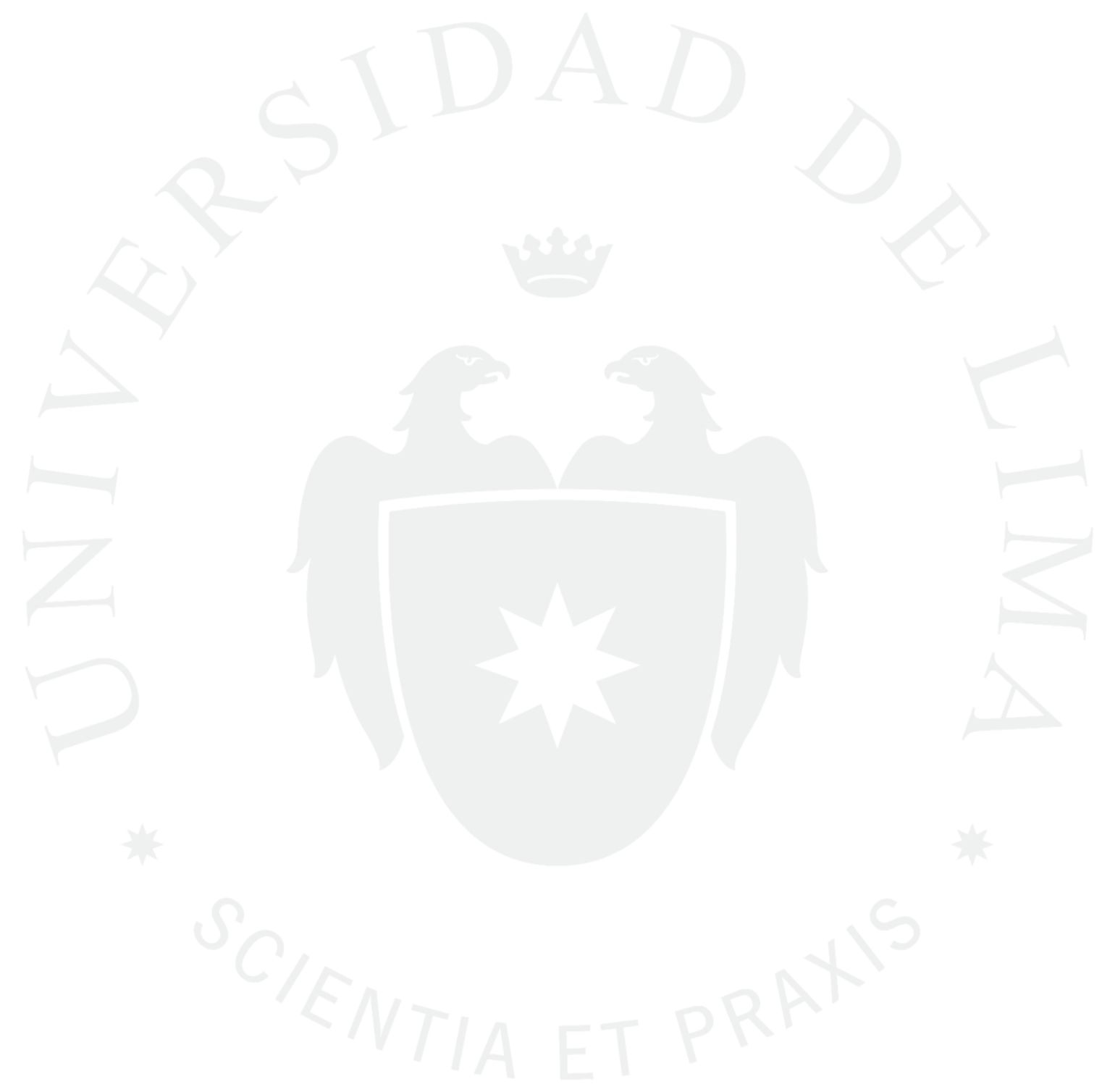




\section{EL ENCAJE COMO INSTRUMENTO PARA EL CONTROL DE FLUJOS DE CAPITALES: \\ UN ANÁLISIS DEL CASO PERUANO DURANTE EL PERIODO 2006-2013}




\section{TABLA DE CONTENIDO}

\section{CAPÍTULO I: MARCO TEÓRICO ..............................................................................4}

1.1. Mecanismos de transmisión de política monetaria ................................4

1.1.1. Canal de las tasas de interés ........................................................5

1.1.2. Canal del tipo de cambio.............................................................

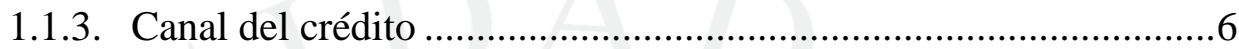

1.1.4. Canal del precio de los activos..................................................6

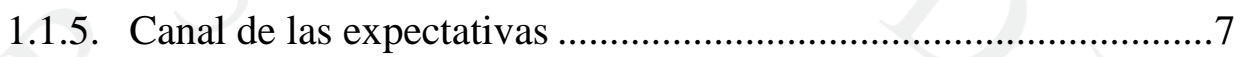

1.2. Operaciones monetarias y requerimientos de encaje .........................7

1.2.1. Operaciones de Mercado Abierto ..................................................

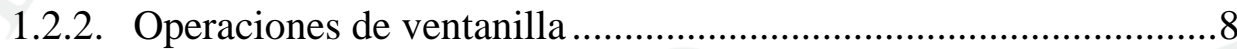

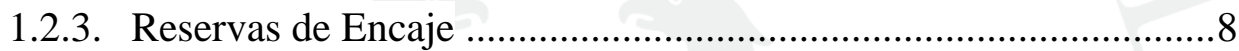

1.3. Régimen de Meta Explícita de Inflación...............................................11

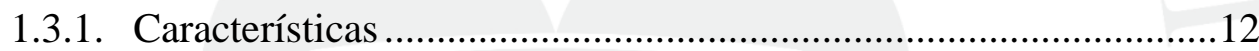

1.3.2. Determinación de la tasa de interés de política............................13

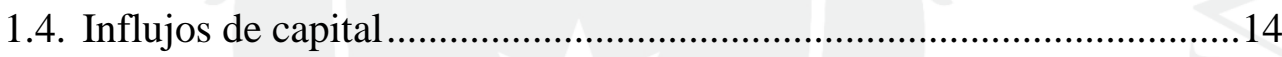

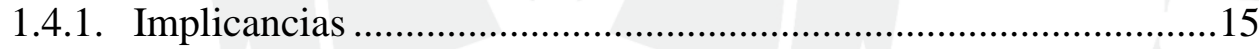

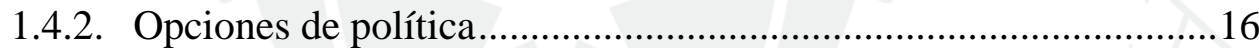

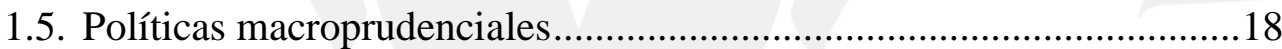

CAPÍTULO II: EVOLUCIÓN DE LAS VARIABLES..........................................20

2.1. Marco de Política Monetaria en Perú....................................................20

2.1.1. Operaciones de Mercado Abierto ..............................................25

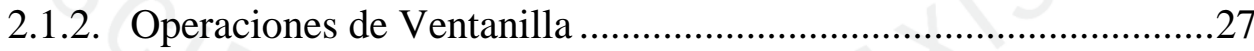

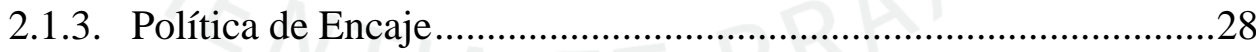

2.2. Evolución agregada de los flujos de capitales ....................................29

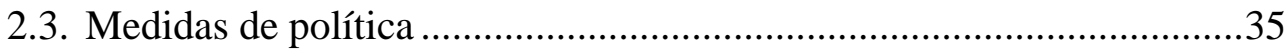

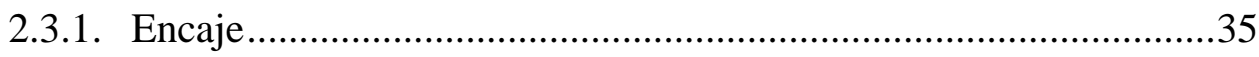

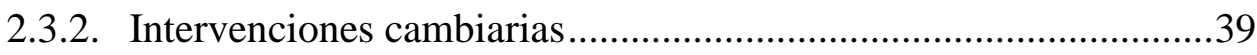

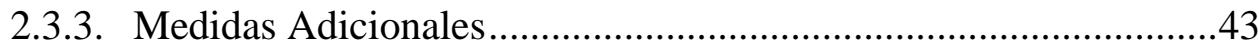

2.4. Interrelación entre encaje, flujos de capitales, crédito y tipo de cambio 


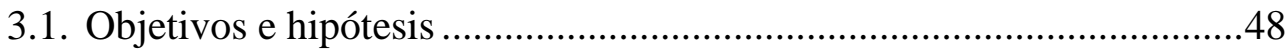

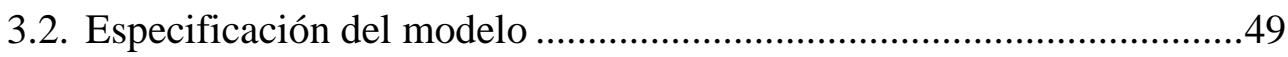

3.2.1. Descripción de Variables Base ...................................................49

3.2.2. Análisis de la relación entre el encaje y los adeudos con el exterior de corto plazo..... .50

3.2.3. Análisis de la relación entre adeudos con el exterior y el crédito en

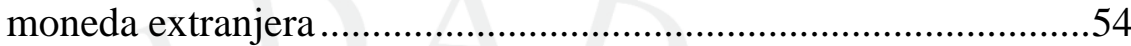

3.2.4. Descripción de Variables Finales...................................................60

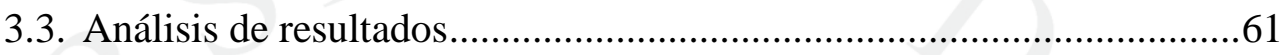

3.3.1. Impacto de la política de encaje .............................................61

3.3.2. Relación entre de los adeudos y el crédito en moneda extranjera .72

3.3.3. Simulación de la política de encaje..............................................85

3.4. Conclusiones del análisis empírico ...................................................87

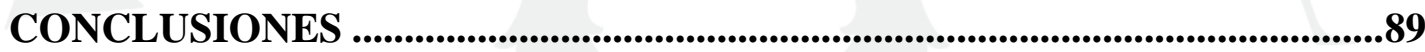

RECOMENDACIONES .........................................................................................91

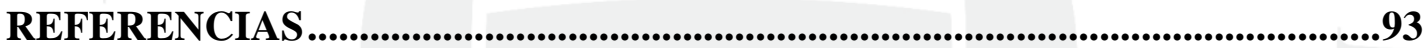




\section{ÍNDICE DE FIGURAS}

Figura 1.1. Mecanismos de Transmisión del Encaje .................................................... 10

Figura 1.2 Política Monetaria frente a Influjos de Capitales ........................................ 17

Figura 2.1 Inflación subyacente y tasa de referencia de política monetaria mensual.

Periodo 2006-2013. (En \%) .

Figura 2.2 Coeficiente de dolarización de la liquidez de las Empresas Bancarias.

Periodo 1998-2013. (En \%)

Figura 2.3 Tenencia de Bonos del Sector Público por parte de No Residente. Periodo

Julio 2010 - Diciembre 2013. (Saldo en Millones de dólares y Ratio en \%)

Figura 2.4 Inversión Extranjera de Cartera y Diferencial entre Tasa Interbancaria de

Perú en Soles y Tasa de Fondos Federales en USD. Periodo Julio 2010 - Junio 2013.

(Inversión en Millones de dólares y Tasas en \%) ............................................................. 34

Figura 2.5 Adeudos con el Exterior de Corto y de Largo Plazo. Periodo Enero 2006 -

Junio 2009. (Saldo en Millones de dólares y Ratio en \%).

Figura 2.6 Operaciones Cambiarias del BCRP y Tipo de Cambio Nominal

Interbancario. Periodo 2006 - 2013. (Operaciones en Millones de dólares y Tipo de

Cambio en soles por dólar)

Figura 2.7 Obligaciones del BCRP con No Residentes. Periodo 2007-2008. (En

Millones de dólares)

Figura 2.8 Interrelación entre Encaje, Flujos de Capitales y Crédito

Figura 3.1 Ratio de adeudos de corto plazo entre adeudos totales (eje izquierdo) y encaje a adeudos de corto plazo (eje derecho). Periodo 2006-2013. (En \%).

Figura 3.2 Tasa de crecimiento interanual de Adeudos de Corto Plazo (eje izquierdo) y del Crédito Bruto en Moneda Extranjera (eje derecho). Periodo 2006-2013. (En \%)....73 Figura 3.3 Tasa de crecimiento interanual de Adeudos Totales (eje izquierdo) y del Crédito Bruto en Moneda Extranjera (eje derecho). Periodo 2006-2013. (En \%)..........80

Figura 3.4 Ratio entre adeudos de corto plazo con el exterior y adeudos totales con el exterior - Valores simulados y observados. Periodo 2006-2013. (En \%)

Figura 3.5 Adeudos de corto plazo con el exterior - Valores simulados y observados.

Periodo 2006-2013. (En Miles de dólares)

Figura 3.6 Adeudos de largo plazo con el exterior - Valores simulados y observados.

Periodo 2006-2013. (En Miles de dólares) 


\section{ÍNDICE DE TABLAS}

Tabla 2.1 Flujos de Capitales por la Cuenta Financiera, Periodo 2006-2013. (En

Millones de dólares)

Tabla 2.2 Variación del Saldo de Crédito Bruto en Moneda Nacional y en Moneda

Extranjera. Periodos Múltiples. (En \%) .38

Tabla 2.3 Operaciones Forward de las Empresas Bancarias y Operaciones Cambiarias del BCRP en el Mercado Spot. Periodos Múltiples. (En Millones de dólares) .40

Tabla 2.4 Intervención Esterilizada en Perú. Periodos Múltiples. 41

Tabla 3.1 Categorización del Ratio entre Adeudos de Corto Plazo y Adeudos Totales según percentiles. Periodo 2006-2013.

Tabla 3.2 Ejemplo de relación lineal entre Xi y Pi en el modelo MLP .53

Tabla 3.3 Resumen de variables - relación entre encaje y adeudos

Tabla 3.4 Resumen de variables - relación entre adeudos y crédito 61

Tabla 3.5 Resultado de modelo Logit considerando como variable dependiente DU_AEC_AET_75

Tabla 3.6 Probabilidades de modelo Logit considerando como variable dependiente

DU_AEC_AET_75

Tabla 3.7 Resultado de modelo Logit considerando como variable dependiente

DU_AEC_AET_50

Tabla 3.8 Probabilidades de modelo Logit considerando como variable dependiente

DU_AEC_AET_50

Tabla 3.9 Resultado de modelo Logit considerando como variable dependiente

DU_AEC_AET_25

Tabla 3.10 Probabilidades de modelo Logit considerando como variable dependiente

DU_AEC_AET_25 .70

Tabla 3.11 Criterios de selección para escenarios de modelo logit .71

Tabla 3.12 Prueba DFA con intercepto y sin tendencia sobre

AEC_CRECIMIENTO_LN. Número de rezagos escogido según criterio de Schwarz.74

Tabla 3.13 Prueba DFA con intercepto y sin tendencia sobre

AEC_CRECIMIENTO_LN en primera diferencia. Número de rezagos escogido según

criterio de Schwarz 
Tabla 3.14 Prueba DFA con intercepto y sin tendencia sobre

CBME_CRECIMIENTO_LN. Número de rezagos escogido según criterio de Schwarz

Tabla 3.15 Prueba DFA con intercepto y sin tendencia sobre

CBME_CRECIMIENTO_LN en primera diferencia. Número de rezagos escogido

según criterio de Schwarz

Tabla 3.16 Potencial regresión cointegrante entre AEC_CRECIMIENTO_LN y

CBME_CRECIMIENTO_LN

Tabla 3.17 Prueba DFA sin intercepto ni tendencia sobre los residuos de la regresión entre adeudos de corto plazo y crédito en moneda extranjera. Número de rezagos escogido según criterio de Schwarz.

Tabla 3.18 Valores críticos de Engle y Granger para prueba DFA sobre residuos de una potencial regresión cointegrante.

Tabla 3.19 Prueba DFA sin intercepto ni tendencia sobre los residuos de la regresión entre adeudos de corto plazo y crédito en moneda extranjera. Número de rezagos escogido según criterio de Akaike

Tabla 3.20 Mecanismo de corrección de Errores entre AEC_CRECIMIENTO_LN y

CBME_CRECIMIENTO_LN

Tabla 3.21 Prueba DFA con intercepto y sin tendencia sobre

AET_CRECIMIENTO_LN. Número de rezagos escogido según criterio de Schwarz.81

Tabla 3.22 Prueba DFA con intercepto y sin tendencia sobre

AET_CRECIMIENTO_LN en primera diferencia. Número de rezagos escogido según criterio de Schwarz

Tabla 3.23 Potencial regresión cointegrante entre AET_CRECIMIENTO_LN y

CBME_CRECIMIENTO_LN

Tabla 3.24 Prueba DFA sin intercepto ni tendencia sobre los residuos de la regresión entre adeudos totales y crédito en moneda extranjera. Número de rezagos escogido según criterio de Schwarz

Tabla 3.25 Prueba DFA sin intercepto ni tendencia sobre los residuos de la regresión entre adeudos totales y crédito en moneda extranjera. Número de rezagos escogido según criterio de Schwarz

Tabla 3.26 Mecanismo de corrección de Errores entre AET_CRECIMIENTO_LN y

CBME_CRECIMIENTO_LN 
Tabla 3.27 Ratio de adeudos de corto plazo con el exterior entre adeudos con el exterior totales - Valor promedio durante dos periodos ... .85 


\section{INTRODUCCIÓN}

El rol del encaje como instrumento para el control de flujos de capitales ha sido cuestión de debate en los últimos años (León y Quispe, 2010; Carrera y Cóndor, 2011; Ghosh et. al, 2010; Choy y Chang, 2014; Castillo y Barco, 2010). Por ejemplo, León y Quispe (2010) proponen que la tasa de encaje puede ser usada como un instrumento de control de capitales extranjeros con fines especulativos, en un contexto donde las tasas de interés domésticas sean relativamente más atractivas para los inversionistas no residentes que las del resto del mundo. Sin embargo, otros autores sugieren que el encaje no sea usado con tales fines salvo casos excepcionales (Ghosh et al., 2010).

Asimismo, el impacto de los flujos de capitales sobre la economía doméstica es variado. Un ejemplo de ello es lo ocurrido durante la crisis Rusa, que tuvo lugar aproximadamente en el periodo 1998-2000. Los años previos a la crisis se caracterizaron por una notoria dependencia de la banca peruana por financiamiento con el exterior, particularmente el de corto plazo, debido a que era relativamente más barato. Cuando la crisis estalló se dio una fuga de capitales, que ocasionó una contracción abrupta del crédito; este fenómeno es conocido como credit crunch (Rossini, Quispe y Rodríguez, 2013). Este caso ilustra el impacto de los flujos de capitales por el lado de la banca sobre el crédito. A su vez, surgen algunas dudas al respecto; ¿cómo afectaron dichos flujos al crédito durante la crisis financiera internacional, que se inició a mediados del 2008 con la bancarrota del banco de inversión Lehman Brothers? Más aún, ¿existe una relación de largo plazo entre los flujos, sean estos de corto plazo o en su totalidad, con las colocaciones de la banca, o más bien el credit crunch durante la crisis rusa se trató de un hecho aislado?

La presente investigación tiene un doble objetivo. En primer lugar, evaluar el impacto del encaje sobre los adeudos con el exterior de la banca peruana. Según la Superintendencia de Banca, Seguros y Administradoras de Fondos de Pensiones (SBS, 1 de Mayo de 2016), los adeudos comprenden las obligaciones de los bancos con instituciones financieras del exterior y organismos internacionales; esta variable será utilizada para representar los flujos de capitales hacia la banca, transformados en saldos. El segundo objetivo pone énfasis en la relación entre dichos adeudos y el crédito. Para ello, se analizará si existe una relación de largo plazo entre estas variables. 
Adicionalmente, se realizará un análisis comparativo entre la crisis rusa y la crisis financiera internacional con respecto a la evolución del crédito. Se espera que el encaje haya sido un instrumento eficaz para el control de los adeudos, y que exista una relación de largo plazo entre dichos adeudos y el crédito.

El trabajo se divide de la siguiente manera. En el primer capítulo se exponen las bases teóricas de la política monetaria, con énfasis en las funciones del encaje y sus mecanismos de transmisión. Además, se estudian los posibles efectos de los flujos de capitales sobre la economía receptora, y las opciones de política sugeridas por la literatura.

En el segundo capítulo se analiza la evolución de los flujos de capitales en Perú, en el contexto de un régimen de Meta Explícita de Inflación. Si bien los objetivos de la investigación están orientados a los flujos hacia la banca, resulta útil realizar un diagnóstico más amplio de manera preliminar. Se pondrá énfasis en las medidas de políticas implementadas por el Banco Central de Reserva del Perú (BCRP) y la SBS, particularmente el uso de requerimientos de encaje e intervenciones cambiarias esterilizadas. Asimismo, en este capítulo se realizará un análisis comparativo de la evolución del crédito entre la crisis rusa y la crisis financiera internacional, con el objetivo de evaluar si ha vuelto a ocurrir un credit crunch, y qué rol han tenido las medidas de política.

El tercer capítulo está dedicado a contrastar las hipótesis de la investigación desde un enfoque econométrico. Específicamente, se realizarán dos tipos de análisis. El primero estará enfocado en evaluar el impacto del encaje sobre los adeudos con el exterior de la banca. A través de un método de categorización, ambas variables serán transformadas en binarias, las cuales serán incorporadas en un modelo logit. Posteriormente se realizará un análisis de cointegración bivariable para contrastar la existencia de una relación de largo plazo entre los adeudos y el crédito en moneda extranjera, utilizando la metodología propuesta por Engle y Granger (1987).

La investigación concluye que la política de encaje ha sido eficaz en alterar la estructura de los adeudos con el exterior de la banca, fomentando un mayor financiamiento de largo plazo en comparación al de corto plazo. Sin embargo, no se encontró una relación de cointegración entre el crédito en moneda extranjera y los adeudos; ello sugiere que el credit crunch que ocurrió durante la crisis rusa fue un 
hecho aislado, en condiciones donde la economía peruana se encontraba vulnerable al no disponer de las herramientas de política con las que cuenta ahora, principalmente el encaje a los adeudos de corto plazo. 


\section{CAPÍTULO I: MARCO TEÓRICO}

En este capítulo se exponen las bases teóricas de la política monetaria, con énfasis en las funciones del encaje y sus mecanismos de transmisión.

"La política monetaria son las decisiones que toma el Banco Central (...) en relación con el control de la oferta monetaria" (Herrarte, (s.f.)). La oferta de dinero (oferta monetaria), es la cantidad de dinero que circula en una economía en un periodo determinado. La definición de dinero varía según el grado de liquidez de los activos que abarca. Por ejemplo, la medición más básica es la Base Monetaria, el dinero que emite el Banco Central, cuya composición en una economía con encajes fraccionados, incluye el efectivo que circula en la economía (circulante) y las reservas de encaje de los bancos. El siguiente nivel comprende el circulante y los depósitos a la vista en entidades financieras (dinero bancario), comúnmente conocido como M1. Si a esta definición se agregan los depósitos a plazo en el sistema financiero, se obtiene la liquidez total en moneda nacional, o M2.

Al adoptar una política monetaria, el Banco Central de un país debe escoger entre seguir una regla o actuar discrecionalmente. Desde el punto de vista de la política monetaria, una regla puede considerarse como "un mecanismo sistemático de ajuste y respuesta del instrumento ante diversos entornos de la economía y no en una fijación arbitraria de parámetros" (Triveño y Dorich, 2000).

Por otro lado, actuar discrecionalmente implica una política monetaria flexible, que depende del juicio crítico de los hacedores de política para reaccionar ante eventos contingentes que puedan afectar el cumplimiento de una meta (Mankiw, 1997).

\subsection{Mecanismos de transmisión de política monetaria}

Los economistas han llegado a un consenso relativamente aceptado sobre los canales de transmisión de la política monetaria. A continuación, se describen los principales, en función a lo propuesto por Bofinger (2001). 


\subsubsection{Canal de las tasas de interés}

Suponiendo que la autoridad monetaria puede controlar la oferta de dinero y afectar la tasa de interés nominal a la cual las empresas bancarias realizan préstamos de corto plazo (tasa interbancaria), y que el dinero y los bonos $^{1}$ son bienes sustitutos, las variaciones en dicha tasa se traducen en cambios en las demás tasas del sistema financiero.

$$
M \downarrow \rightarrow i \uparrow \rightarrow I \downarrow, C \downarrow \rightarrow D A \downarrow
$$

Bajo este esquema, una reducción en la oferta monetaria (M) tiene como consecuencia un incremento en la tasa de interés (i), lo cual desincentiva la inversión del sector privado (I) y el consumo de las familias ( C ), y en última instancia desacelera el crecimiento de la Demanda Agregada (DA) (Villalobos, Torres y Madrigal, 1999).

\subsubsection{Canal del tipo de cambio}

Cuando las tasas de interés reales ( $\mathrm{r}$ ) domésticas disminuyen producto de una expansión en la oferta monetaria, los activos denominados en moneda nacional se vuelven menos atractivos con respecto a los activos denominados en otras divisas, ocasionando una depreciación de la moneda local (TC). Los bienes domésticos $\left(P_{B D}\right)$ se vuelven más baratos con respecto a los bienes extranjeros $\left(P_{B E}\right)$, y las exportaciones netas $(\mathrm{XN})$ aumentan, expandiéndose en última instancia la demanda agregada (DA). La siguiente relación refleja el proceso de transmisión descrito:

$$
r \downarrow \rightarrow T C \uparrow \rightarrow P_{B D}<P_{B E} \rightarrow X N \uparrow \rightarrow D A \uparrow
$$

Asimismo, las variaciones en el tipo de cambio pueden causar un efecto negativo sobre el patrimonio de las firmas cuando estas presentan descalce de moneda. Por ejemplo, si una empresa tiene más pasivos que activos en moneda extranjera, ante una depreciación del tipo de cambio producto de un choque externo (como una política monetaria expansiva de la Reserva Federal de los Estados Unidos) su deuda se incrementará más que proporcional que los recursos que gestiona; consecuentemente, habrá un

En este caso, el concepto de "bonos" incluye todos los activos financieros que representen una reserva de valor. 
deterioro en su patrimonio, lo cual afectará sus decisiones de inversión. El proceso descrito se conoce como efecto hoja de balance (Azabache, 2011).

\subsubsection{Canal del crédito}

El enfoque del crédito afirma que la política monetaria afecta la oferta de crédito por parte de las empresas bancarias, lo cual amplifica y propaga los efectos directos sobre las tasas de interés en el corto plazo.

$$
M \downarrow \rightarrow \text { Créditos } \downarrow \rightarrow I \downarrow, C \downarrow \rightarrow Y \downarrow
$$

Ante una disminución en la oferta monetaria (M), la disponibilidad de recursos para otorgar préstamos por parte de las empresas bancarias disminuye, lo cual implica menor crédito al sector privado. Si las empresas del sector privado no financiero funcionan principalmente con capital propio, una reducción del crédito bancario no tendrá efecto sobre sus decisiones de gasto o inversión. Sin embargo, si las firmas dependen del financiamiento de bancos para el curso de sus operaciones, una restricción en la oferta monetaria implicará la búsqueda de fuentes más caras. De esta manera, se reduce la inversión del sector privado (I), e indirectamente el consumo de las familias ( C ), y en última instancia la demanda agregada (DA)

\subsubsection{Canal del precio de los activos}

Un cambio en las tasas de interés afecta directamente el precio de los activos financieros.

$$
\text { Precio de Activo Financiero }=\sum_{t=1}^{\infty} \frac{\text { Flujo de caja }}{(1+i)^{t}}
$$

En la ecuación anterior se puede apreciar la relación inversa entre el precio de los activos financieros y la tasa de interés de mercado (i), que descuenta a valor presente los flujos de caja futuros que generan dichos activos, de acuerdo al periodo (t) en el que se proyecten.

Un aumento de la tasa de interés causa una disminución del precio de los activos financieros y por consiguiente una reducción en el valor de los colaterales que son garantías de los créditos; ello afecta las decisiones de 
consumo e inversión de las empresas y hogares tenedoras de dichos activos, debido a la variación en su riqueza.

\subsubsection{Canal de las expectativas}

Cuando los agentes económicos confían en la efectividad de la política monetaria, los anuncios del Banco Central tienen influencia sobre la actividad económica futura, ya que los agentes toman sus decisiones de consumo, ahorro e inversión en función a dichos anuncios. Consecuentemente, un alto nivel de credibilidad contribuye a que las políticas del ente regulador tengan un efecto sobre el sector real.

\subsection{Operaciones monetarias y requerimientos de encaje}

La mayor parte de Bancos Centrales del mundo utiliza operaciones de mercado abierto (OMA), operaciones de ventanilla y reservas de encaje como conjunto de instrumentos para implementar su política monetaria. A continuación se detallan sus principales características.

\subsubsection{Operaciones de Mercado Abierto}

Las OMA son consideradas "la herramienta más importante de la política monetaria porque son los principales determinantes de los cambios en las tasas de interés y en la base monetaria, la principal fuente de fluctuaciones en la oferta de dinero" (Mishkin, 2008). Su finalidad es regular la oferta monetaria de la economía.

Un Banco Central suele usar el mecanismo de subastas para implementar las operaciones de mercado abierto; en caso quiera aumentar la oferta monetaria, puede comprar títulos negociables a los bancos; si la finalidad es disminuir la cantidad de dinero, el Banco Central debe emitir títulos de deuda. La efectividad de estas operaciones depende de que los intermediarios financieros acudan a las subastas donde se negocian los valores mencionados. Con la finalidad de mitigar el riesgo de impago, el 
Banco Central suele limitar las compras de títulos a un conjunto reducido de valores con baja probabilidad de default.

Las OMA tienen un efecto directo sobre las tasas de interés de corto plazo. Por ejemplo, en un escenario donde los bancos demandan dinero en el corto plazo pero hay una escasez de oferta monetaria, el precio de dicho activo, la tasa de interés, tiende a elevarse. Para evitar escenarios de iliquidez en el sistema financiero el Banco Central regula la oferta monetaria a través de las OMA. En el ejemplo descrito, dicha regulación consistiría en comprar títulos negociables para expandir la oferta monetaria y equilibrarla con la demanda de dinero de los bancos; consecuentemente, las tasas de interés regresan a niveles estables.

\subsubsection{Operaciones de ventanilla}

Las operaciones de ventanilla son facilidades brindadas por el Banco Central, con una duración usual de un día, que permiten a las empresas bancarias cambiar títulos valor por dinero, solicitar préstamos con un colateral de por medio y realizar depósitos en el Banco Central (Ibíd.).

Mediante estas operaciones el Banco Central fija un techo (tasa para préstamos) y piso (tasa de interés overnight para depósitos) a la tasa de interés interbancaria, de manera que las tasas a las cuales las empresas bancarias negocian préstamos y depósitos inter-diarios se ven acotadas a dicha banda; si las entidades financieras cobraran por encima de la tasa de préstamos, o pagaran menos que la tasa de depósitos, sería más conveniente para sus pares acudir al Banco Central.

\subsubsection{Reservas de Encaje}

Las reservas de encaje constituyen

Activos líquidos que los intermediarios financieros están obligados a mantener bajo la forma de efectivo en sus bóvedas 
y/o como depósitos en el Banco Central. Dichos fondos no pueden ser utilizados por los agentes financieros en el giro de préstamos o en algún tipo de inversión que genere rentabilidad.

(Carrera y Condor, 2011).

La tasa de encaje (o simplemente encaje) determina la cantidad de reservas que debe guardar cada entidad del sistema financiero. El encaje es uno de los instrumentos más importantes de política monetaria con que dispone un Banco Central, cuyas funciones y mecanismos de transmisión se detallan a continuación.

\section{- Funciones}

El encaje es un importante instrumento de política monetaria. $\mathrm{Su}$ principal función es regular la oferta monetaria a través de la reducción de fondos prestables del sistema financiero, lo cual afecta directamente la oferta de crédito.

Adicionalmente, la tasa de encaje tiene un rol de control de capitales extranjeros, que se vuelve más evidente cuando las tasas de interés domésticas son más elevadas que las del resto del mundo. Por ejemplo, si los bancos desean solicitar fondos con el exterior en forma de líneas de crédito debido a su menor costo, se puede encarecer dicho financiamiento a través de un encaje específico, de manera los bancos opten por otros medios para obtener fondos.

Finalmente, el encaje tiene un rol prudencial. Como señalan Carrera y Cóndor (2011), “dado que los bancos están obligados a mantener una proporción de activos líquidos (básicamente efectivo), dichos fondos pueden atender la demanda cotidiana de retiros en la ventanilla de los bancos además de estar en condiciones de enfrentar una eventual corrida bancaria".

\section{- Mecanismos de transmisión}

La Figura 1.1 resume los principales canales de transmisión a través de los cuáles el encaje tiene efectos directos e indirectos en la demanda agregada y el nivel de precios. 


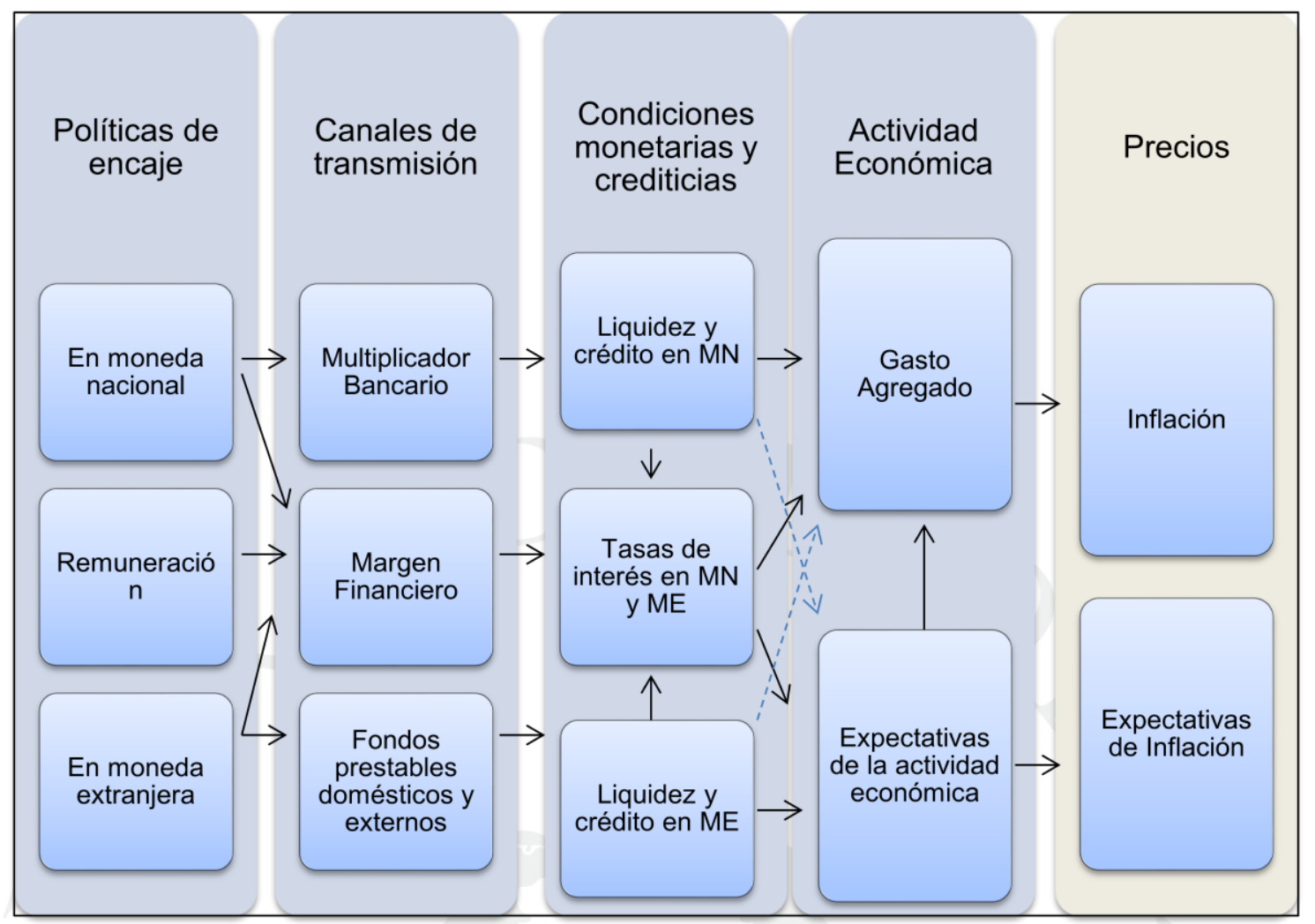

Figura 0.1. Mecanismos de Transmisión del Encaje. Adaptado de León y Quispe (2010)

Con respecto al multiplicador bancario, dicho canal permite el crecimiento de la oferta monetaria a través de la creación de dinero secundario, "el cual surge de un proceso de expansión de los activos y pasivos de las entidades financieras. El sistema financiero capta depósitos del público y con estos recursos otorga créditos reteniendo un porcentaje como reservas" (Orellana, 2011).

La ecuación matemática que representa al multiplicador bancario, considerando la definición de oferta monetaria como $\mathrm{M} 1=\mathrm{C}+\mathrm{Dv} \quad(\mathrm{C}$ circulante en poder del público y Dv depósitos vista), se presenta a continuación

$$
M B=\frac{1+c}{r+c}
$$

Donde $c$ es el ratio entre el circulante y los depósitos a la vista y $r$ es el ratio entre las reservas de encaje y los depósitos a la vista. De acuerdo a dicha ecuación, un incremento del encaje legal disminuye la oferta monetaria en moneda nacional a través de una reducción en el multiplicador bancario, evitando así un exceso de liquidez que podría traducirse en un incremento de precios domésticos o una expansión no deseada del crédito. 
Por otro lado, el margen financiero de una entidad financiera es el diferencial entre ingresos y egresos financieros provenientes de cada unidad monetaria que recibe en forma de depósitos. Se define bajo la siguiente ecuación:

$$
M F=\left(1-r_{l}\right) i_{a, t}+\left(r_{l}-r_{m l}\right) i_{e, t}-i_{p, t}
$$

Donde MF es el margen financiero, $r_{l}$ es la proporción total mantenida como encaje con respecto a una unidad monetaria de depósito, $r_{m l}$ es la tasa de encaje mínimo legal, y $i_{a, t}, i_{e, t}$ y $i_{p, t}$ representan la tasa activa que los bancos cobran, la remuneración al encaje y la tasa pasiva pagada por depósitos, respectivamente. Las reservas de encaje constituyen un desincentivo a la intermediación financiera, ya que representan un costo adicional para las entidades financieras. El dinero ocioso les representa un costo de oportunidad, que puede ser compensado con un aumento del margen financiero a través de una variación en las tasas activas y/o pasivas, decisión que dependerá de la disposición de las instituciones financieras a sacrificar parte de su rentabilidad.

Las variaciones en las tasas de interés producto de movimientos en la tasa de encaje afectan las decisiones de inversión y consumo de las empresas y hogares, así como los incentivos de las entidades financieras a otorgar nuevos créditos al sector privado debido al cambio en el perfil de riesgo de los agentes económicos; ello repercute en la demanda agregada y las expectativas futuras de la actividad económica, y en última instancia en el nivel de precios actual y esperado.

\subsection{Régimen de Meta Explícita de Inflación}

La inflación se puede definir como un incremento, del tipo continuo y generalizado, del nivel de precios (Mishkin, 2000). La experiencia de los países latinoamericanos en la década de los 80 ha demostrado que, ante procesos inflacionarios prolongados, la pérdida de valor de la moneda tiene consecuencias negativas en la actividad económica. A partir de los 90, el régimen de Mete Explícita de Inflación (MEI) ha ganado popularidad como medio para controlar la inflación. 


\subsubsection{Características}

La característica fundamental de este régimen es anunciar pública y periódicamente una meta cuantitativa de inflación, que puede ser un punto o rango, para un horizonte de tiempo fijo. El ente hacedor de política monetaria se compromete a mantener como principal objetivo al nivel de precios alineado con la meta anunciada, para lo cual proyectará la inflación y corregirá sus desviaciones con respecto a la meta usando las operaciones monetarias y los requerimientos de encaje (Ibid).

Para alcanzar la estabilidad de precios, es necesario fijar un ancla nominal,

(...) una variable nominal (..) que mantenga firmemente atado el nivel de precios (...). La adherencia a un ancla nominal que mantenga la variable nominal dentro de un rango estrecho impulsa la estabilidad de precios promoviendo en forma directa expectativas de inflación bajas.

(Triveño y Dorich, 2000).

En el régimen MEI el ancla nominal es la inflación, lo cual implica que el Banco Central tiene como unos de sus principales objetivos que los agentes económicos tomen sus decisiones de consumo, ahorro e inversión en función a la evolución de dicha variable. Si tiene éxito, será más fácil manejar las expectativas del público mediante la fijación y el cumplimiento de metas de inflación.

El Banco Central fija una tasa de interés de referencia (instrumento de política), y usa las operaciones monetarias para restringir o expandir la oferta monetaria, con la finalidad de alinear la tasa de interés interbancaria a la tasa de política fijada. De esta manera, afectará indirectamente a las demás tasas del sistema financiero, y en última instancia a la demanda agregada y el nivel de precios.

La efectividad del régimen MEI depende de que se cumplan dos condiciones: una adecuada comunicación de la meta final del Banco Central 
y las acciones tomadas para alcanzarla; y un alto grado de independencia del Banco Central, entendiendo este concepto como la potestad que tiene para escoger su meta final libre de presiones políticas, y los instrumentos que desea utilizar para alcanzar dicho fin (Montero, 2000). La mayor transparencia que se deriva del cumplimiento de estas condiciones otorga un alto grado de credibilidad a la política monetaria anunciada, lo cual permite anclar las expectativas del público a la meta anunciada.

\subsubsection{Determinación de la tasa de interés de política}

Taylor (1993) propuso una regla para fijar la tasa interés en base a un estudio empírico sobre de la política monetaria implementada en la economía estadounidense en tres periodos del tiempo: 1879-1914, 1955-1979 y 19871997. La principal conclusión a la que llegó fue que el tercer periodo ha tenido el mejor desempeño en lo que concierne a inflación y estabilidad macroeconómica, siendo el factor más importante la (mayor) respuesta de las tasas de interés a las fluctuaciones de producto e inflación. Se deriva la siguiente regla:

$$
i_{t}=\pi_{t}+r^{*}+\emptyset_{x}\left(E_{t}\left(x_{t+1}\right)-x_{t}\right)+\emptyset_{\pi}\left(E_{t}\left(\pi_{t+1}\right)-\pi^{*}\right)
$$

Donde $i_{t}$ es la tasa de interés de corto plazo que maneja el Banco Central, $r^{*}$ es la tasa de interés real de equilibrio, $E_{t}$ es un operador de expectativas, $x_{t}$ representa la brecha de producto con respecto a su nivel potencial y $\pi^{*}$ es la inflación meta. De acuerdo a esta ecuación, el Banco Central ajusta la tasa de interés de referencia en función a la brecha de producto y a la desviación de la inflación de su meta.

Debido a que la meta final de los Bancos Centrales sujetos a un régimen MEI es la inflación, es de esperar que el parámetro asociado a la brecha de inflación sea mayor que el de la brecha de producto. Esta es la idea subyacente detrás del principio de Taylor, según el cual el parámetro $\emptyset_{\pi}$ debe ser mayor a 1 para que la tasa de interés nominal reaccione más que proporcional a las desviaciones de la inflación de su meta y tenga efectos sobre la tasa de interés real; de esta manera, se afecta las decisiones de consumo, ahorro e inversión de los agentes económicos. 


\subsection{Influjos de capital}

Las entradas de capitales son muy importantes en economías emergentes, ya que permiten el financiamiento de proyectos que de otra manera no se habrían realizado, contribuyen al desarrollo de los mercados de capitales y fomentan la diversificación del riesgo dentro del sistema financiero. Sin embargo, hay flujos de capitales especulativos que tienen efectos secundarios nocivos en la estabilidad del sistema financiero y el sector real.

Existen diversas razones por las cuales puede haber entradas (y salidas) de capitales a un país. En primer lugar, los flujos de capitales pueden entrar como financiamiento a largo plazo para proyectos de inversión que ofrezcan tasas de retorno atractivas. Otra razón por la cual ingresan flujos de capitales a una economía es a través del financiamiento a los Sectores Privado y Público, de corto y largo plazo.

Los medios de entrada de capitales mencionados son, en su mayoría, beneficiosos; permiten el financiamiento de proyectos de inversión que de otra manera no se hubieran realizado. Sin embargo, existe otro tipo de influjos de carácter especulativo, que buscan un carry trade. Ello consiste en endeudarse en una moneda a una tasa relativamente baja, e invertir en otra moneda que ofrece una tasa de interés mayor (Choy y Chang, 2014).

Es importante mencionar como el carry trade puede generar efectos negativos a través de su efecto sobre el tipo de cambio. Cuando existe una diferencia entre las tasas de interés domésticas y las del mercado internacional a favor de las primeras, que compense los costos de transacción asociados, los inversionistas extranjeros buscan obtener rentabilidad adicional a la que se deriva por la brecha de tasas de interés a través del tipo de cambio. Mediante operaciones forward venta en grandes volúmenes, las empresas bancarias ven presionadas sus posiciones de cambio globales al alza, y deben ofertar dólares en el mercado spot. El exceso de oferta ocasiona una apreciación del sol con respecto al USD, y en última instancia los inversionistas que realizaron forwards inicialmente obtienen una ganancia a través del tipo de cambio (profecía auto cumplida) (Ibíd.). 
De manera específica, los flujos de capitales de no residentes pueden ingresar a una economía a través de inversión extranjera directa de largo plazo, capitales de corto plazo de portafolio, financiamiento con el exterior por parte de las empresas domésticas del sistema financiero y del sector real, y financiamiento con el exterior por parte del sector público.

Dependiendo de la manera en la cual los flujos ingresen a la economía y las condiciones de la economía receptora, las consecuencias y las medidas de política que deben ser implementadas varían.

\subsubsection{Implicancias}

Los beneficios de los influjos de capital son paralelos a los de una apertura al comercio internacional: diversificación de riesgo, financiamiento de nuevos proyectos y desarrollo del mercado de capitales. Sin embargo, estos beneficios van acompañados de una serie de implicancias negativas, que pueden darse de manera conjunta o por separado.

De Gregorio (2010) identifica dos riesgos negativos asociados a los influjos de capitales: de liquidez y crédito. Con respecto al primero, los influjos en la forma de préstamos de corto plazo a los bancos locales tenderán a aumentar su dependencia de esta fuente de financiamiento, la cual ha mostrado ser volátil y poco confiable. En cuanto al riesgo de crédito, se puede considerar como

(...) un flujo abundante de capitales en la forma de préstamos a los bancos locales y una cartera de certificados de deuda puede derivar en un aumento de la oferta de crédito ya que los intermediarios y empresas locales obtienen acceso a fuentes más elásticas y con frecuencia más baratas de financiamiento (aparte del riesgo cambiario). Esta mayor oferta de crédito en la economía local puede alimentar un auge crediticio, el que a su vez puede producir un apalancamiento excesivo en la economía y un aumento del riesgo de crédito de la banca.

(C. Reinhart y V. Reinhart, 2008). 
Los autores señalan que durante periodos de influjos de capitales a economías emergentes hay una mayor probabilidad de incurrir en ciclos de sobre-expansión del crédito al sector privado.

Por otro lado, el aumento de tenencia de divisas extranjeras ocasionado por los influjos que ingresan a la economía doméstica tiene como consecuencia una apreciación del tipo de cambio. Si esta apreciación nominal se traduce en términos reales, la pérdida de competitividad y el deterioro en la cuenta corriente afectan negativamente a la economía receptora.

Finalmente, los influjos de capitales que tengan la finalidad de especular con títulos negociables en el mercado de capitales doméstico pueden causar una burbuja de precios de los activos financieros. Si los tenedores de dichos activos solicitan nuevos préstamos para especular en el mercado de capitales, ya sea por el aumento en la riqueza percibida o usando los activos sobre-valorados como colaterales, una salida abrupta de capitales afectará el valor de su patrimonio y su capacidad de pago, en un efecto dominó que puede resultar en una crisis bancaria (Castillo y Barco, 2010). Adicionalmente, las empresas privadas (tanto del sector real como financiero) que hayan obtenido financiamiento de corto plazo en el exterior, alentadas por un menor costo, ven sus patrimonios más vulnerables ante salidas de capitales, debido a posibles descalces de moneda y plazos con respecto a sus activos.

\subsubsection{Opciones de política}

En la actualidad no hay un consenso sobre las políticas que deben tomarse para afrontar escenarios de un crecimiento considerable de los influjos de capitales de corto plazo. Estas varían de acuerdo a la situación de las economías receptoras, y la manera en que los flujos ingresan a la economía. 


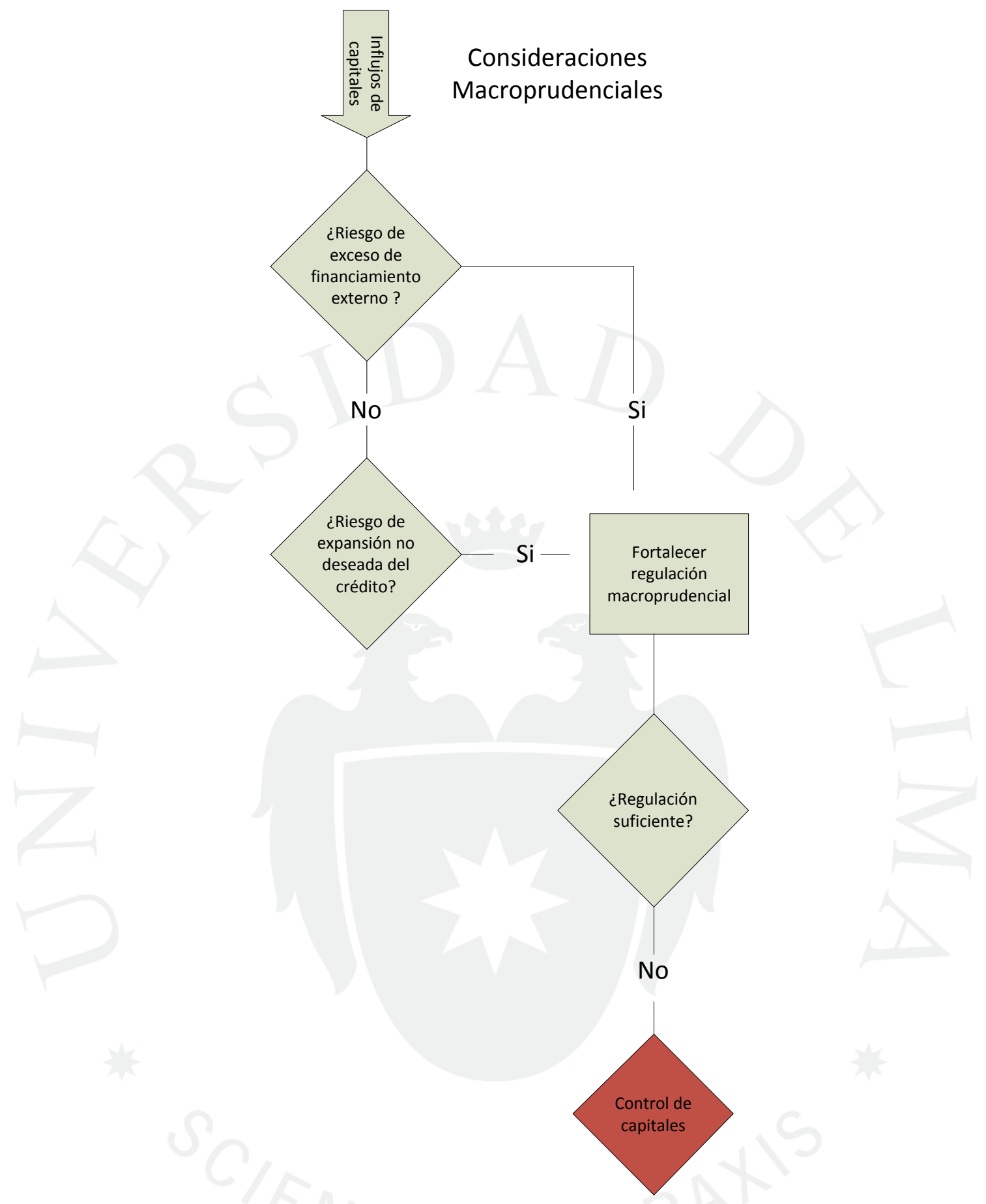

Figura 0.2 Política Monetaria frente a Influjos de Capitales. Adaptado de Ghosh et al. (2010)

La Figura 1.2 resume la postura de Ghosh. et al. (2010) con respecto a las principales políticas que deben tenerse en consideración en un escenario de influjos de capitales. De acuerdo a los autores, sólo se justifica utilizar al encaje como instrumento de control de capitales si es que hay una sobredependencia del financiamiento externo, en conjunto con un incipiente esquema regulativo para el sistema financiero y un exceso de crecimiento en el Crédito al Sector Privado Doméstico. 


\subsection{Políticas macroprudenciales}

A partir de la crisis financiera internacional que tuvo sus inicios en el segundo semestre del año 2008, se ha hecho evidente que adecuadas políticas macroeconómicas y monetarias no bastan para asegurar el equilibrio de la economía mundial; hace falta formular políticas orientadas a la estabilidad del sistema financiero. Precisamente ese es el objetivo de las políticas macroprudenciales.

De acuerdo al Fondo Monetario Internacional (IMF, 2011), la finalidad de estas políticas es controlar el riesgo sistémico (generalizado) de carácter financiero, ya sea proveniente del sector real, financiero o internacional. Si bien no hay un consenso sobre la definición de que es y que no es considerado macroprudencial, su objetivo se orienta a la estabilidad del sistema financiero.

Hay dos dimensiones en las cuales se divide el enfoque macro-prudencial (Ibíd.). En primer lugar, está la ddimensión temporal, en la cual se evalúa el riesgo financiero sistémico asociado a la parte ascendente del ciclo económico real, debido a la disminución de la aversión al riesgo de los agentes económicos y la mayor propensión de las entidades financieras a otorgar créditos. Tiene un carácter anti-cíclico, ya que se enfoca en disminuir la actividad económica en épocas de auge, y viceversa. Por otro lado se encuentra la dimensión de corte transversal, en la cual se busca atenuar el riesgo sistémico financiero en un momento determinado del tiempo. Identifica, monitorea, evalúa y controla el tamaño de las instituciones financieras, exposiciones a riesgos en común, la concentración de mercado, interconexión de los intermediarios financieros y contribución individual a la formación de riesgo de carácter sistémico.

De manera similar a la política monetaria, es importante definir una autoridad independiente, que maneje un grupo de instrumentos y reglas para cumplir con sus objetivos. Dicha institución debe cumplir con obligaciones similares a las del Banco Central: comprometerse institucionalmente al cumplimiento de metas y comunicar periódicamente el avance de resultados y las acciones tomadas para logarlos. 
Finalmente, es importante mencionar el rol de la política macroprudencial con respecto a los flujos de capitales. Como se ha señalado en el sub-aparado 1.4, los influjos de capitales pueden causar riesgos de liquidez y crédito en la banca, así como burbujas en el precio de los activos financieros. Estos riesgos deben ser tratados desde una perspectiva macroprudencial. Específicamente, se debe poner énfasis en los requisitos de liquidez que estén relacionados al financiamiento con el exterior, particularmente el de corto plazo, de manera que se atenúe el riesgo de crédito asociado a la entrada de capitales extranjeros (De Gregorio, 2010). En ese sentido, el encaje juega un rol de carácter macroprudencial, al regular el financiamiento de la banca con el exterior. 


\section{CAPÍTULO II: EVOLUCIÓN DE LAS VARIABLES}

\subsection{Marco de Política Monetaria en Perú}

La política monetaria en Perú ha tenido varios matices. A fines de los años 80, la economía peruana estaba pasando por un proceso de hiperinflación, con incrementos de precios anuales superiores a $7000 \%$ y una baja credibilidad del Banco Central. Producto de esta crisis, se implementaron varios cambios en los años posteriores.

A inicios de los 90, la nueva Ley Orgánica del Banco Central definió explícitamente que el único objetivo de dicha entidad es preservar el poder adquisitivo de la moneda local. Para lograr dicho objetivo, el BCRP tuvo que tomar decisiones cruciales en relación al régimen cambiario y la meta intermedia para su política monetaria.

Con respecto al régimen cambiario, se eligió uno flexible, ya que fijar el tipo de cambio presentaba tres inconvenientes: no habían reservas internacionales que pudieran respaldarlo; la credibilidad del Banco Central estaba mermada debido a las fallas en los programas previos de maxidevaluaciones; y la distorsión de precios relativos volvía difícil elegir un objetivo para la fijación del tipo de cambio nominal (Armas, Grippa, Quispe, y Valdivia, 2001).

Por otro lado, se escogió la emisión primaria como ancla nominal, debido a que el público percibía que la elevada inflación era producto de una excesiva creación de dinero, y consecuentemente era relativamente fácil explicar que a través de un control de la emisión se podría reducir la inflación (Ibid).

Siguiendo la misma línea, en el año 1991 se definió como meta operativa de política monetaria el saldo de la cuenta corriente de las empresas bancarias en las bóvedas del BCRP. Para controlar la emisión primaria, el ente regulador ejecutaba las operaciones monetarias para alcanzar diariamente su meta operativa. Producto de los cambios en la política monetaria se ha logrado reducir la inflación anual, que se ubicaba por encima de $7000 \%$ en la década de los 80 a sólo $3,7 \%$ en el año 2000. 
Siguiendo a Armas et. al (2001), después del éxito del antiguo régimen, en el 2002 se institucionalizó la política monetaria bajo Metas Explícitas de Inflación (MEI, en adelante), con la finalidad de anclar las expectativas del público a través de la inflación. En dicho esquema se reconoce la tasa de inflación como meta de largo plazo de la política monetaria. Asimismo, se realiza un anuncio de las metas de dicha tasa de inflación al público, con plazos de cumplimiento bien definidos. En este régimen resulta crucial la comunicación de los lineamientos generales del Banco Central; es a través de la transparencia y el constante cumplimiento de las metas que el ente gana credibilidad, y consecuentemente puede anclar las expectativas de inflación del público.

Ahora bien, surge la siguiente interrogante en relación al cambio de régimen de política monetaria: ¿Por qué se dio dicho cambio, si el anterior estaba funcionando bien? La principal razón es que el contexto de la economía peruana había cambiado, en el sentido que ya no se buscaba reducir sino mantener estable la inflación. Al respecto, Mishkin y Savastano (2000) han hallado que "las relaciones entre los agregados monetarios y la tasa de inflación pueden tornarse poco confiables al pasar a esta nueva etapa y el banco central debe estar preparado para enfrentar este potencial problema". Adicionalmente, al enfocarse en la única variable macroeconómica sobre la que el Banco Central tiene un efecto de largo plazo, será más fácil de entender para el publico las acciones del ente regulador, mejorándose la transparencia e incrementándose en última instancia la credibilidad (Armas et al., 2001).

$\mathrm{Al}$ adoptar este régimen, el BCRP estableció como meta final un rango de inflación. Hasta el 2006, dicha meta fue de $2.5 \%$ con una tolerancia de $1 \%$ tanto hacia arriba como abajo; a partir del año 2007 la meta se redujo a $2 \%$ con el mismo rango de tolerancia, acorde a la mayor estabilidad de los precios domésticos (Ibid).

En el caso peruano, la inflación se mide como la variación del Índice de Precios al Consumidor (IPC) de Lima Metropolitana. Sin embargo, el ancla nominal es la inflación subyacente, definida por el Glosario de Términos Económicos del BCRP como 
Una medida de tendencia inflacionaria que reduce la volatilidad del indicador de aumento de precios sin sub o sobre estimarlo en periodos largos. Corresponde a la variación del IPC excluyendo los alimentos perecibles, por ser productos cuyos precios están sujetos a condiciones internacionales como malas cosechas.

(BCRP, 1 de Mayo de 2016).

El uso de la inflación subyacente como ancla nominal se debe a que aísla los choques de demanda, sensibles a la política monetaria, de los choques de oferta, en los mercados de bienes y servicios, y a la vez mantiene una relación estrecha con la meta final de inflación.

Dentro del régimen MEI el BCRP fija una tasa de interés de política como meta operativa. Las operaciones monetarias que realiza están orientadas a alinear a la tasa de interés interbancaria de corto plazo con la tasa de política fijada, a través de expansiones o contracciones de los fondos en el mercado interbancario. Los cambios en la tasa interbancaria se traspasan a las demás tasas del sistema financiero, y en última instancia se afecta a la demanda agregada.

En la Figura 2.1 se ve la evolución de la inflación subyacente y la tasa de referencia de política monetaria, desde el 2006 hasta fines del 2013. Como se puede apreciar, ante presiones al alza o baja en el nivel de precios la tasa de política ha variado en la misma dirección, con la finalidad de contraer o expandir la demanda agregada según sea el caso. 


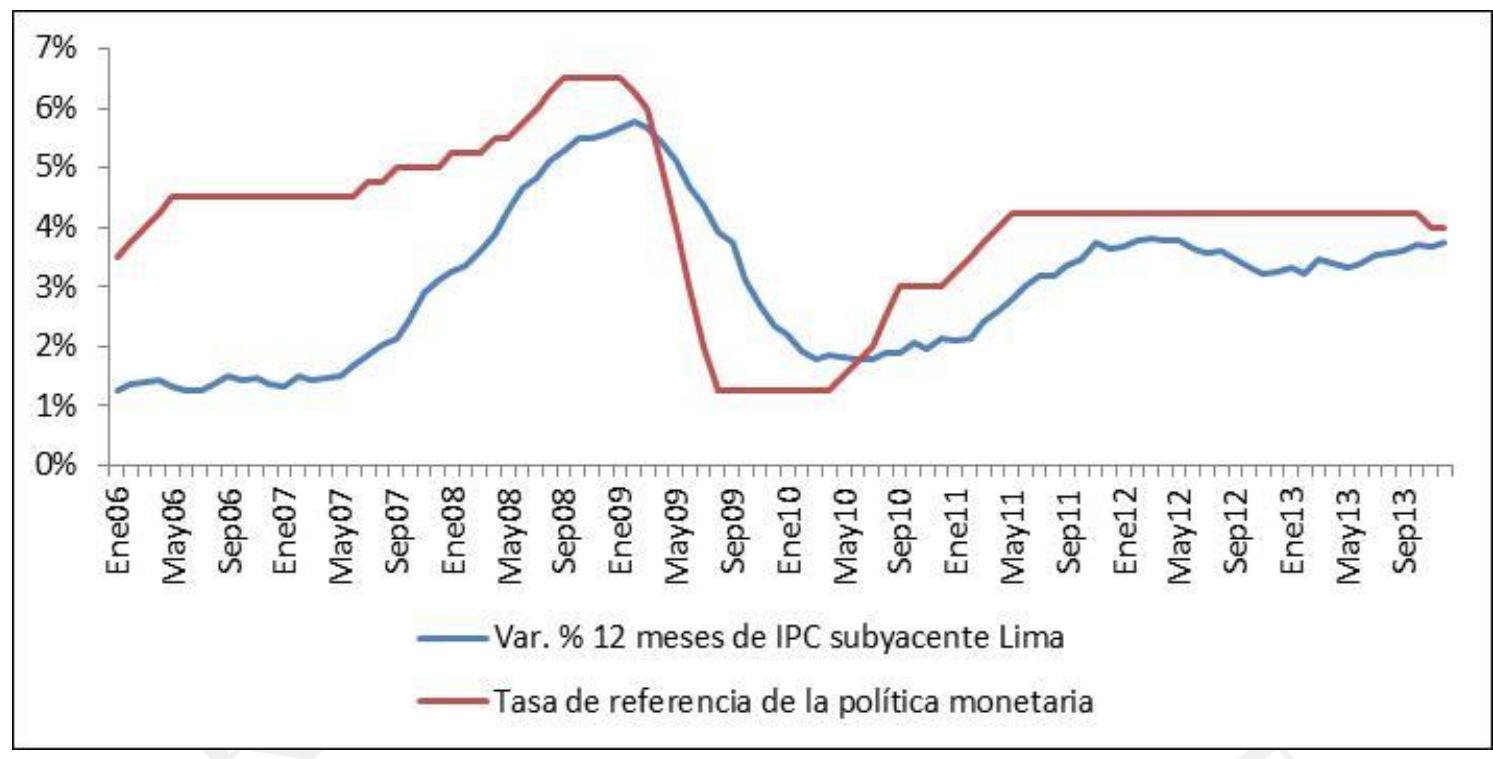

Figura 2.1 Inflación subyacente y tasa de referencia de política monetaria mensual. Periodo 2006-2013. (En \%). Fuente BCRP, Series Estadísticas Mensuales, revisado el 19 de Junio del 2014, http://estadisticas.bcrp.gob.pe/index.asp?sFrecuencia=M.

De acuerdo a los Reportes de Inflación del BCRP (BCRP, 2006-2013), se pueden identificar tres periodos de reacción activa ante cambios en la inflación. El primero se da desde Julio del 2007 hasta setiembre del 2008, cuando la tasa de política se incrementó en sucesivas ocasiones, desde $4.5 \%$ a $6.5 \%$, con la finalidad de controlar la tendencia al alza de la inflación. La presión inflacionaria se explica por el alto dinamismo de la demanda interna, factores climáticos que afectaron la oferta de alimentos en el 2008, el traspaso del precio de insumos internacionales a componentes de la inflación subyacente y el incremento de las tarifas eléctricas producto de desequilibrios internos inducidos por el sobrecalentamiento de la economía. El segundo periodo se inicia en Octubre del 2008, con una reducción en la tasa de política de $6.25 \%$ a $1.25 \%$ en un lapso de 6 meses, con la finalidad de evitar una recesión como consecuencia de la quiebra del Banco de Inversión Lehman Brothers. Finalmente, a partir de marzo del 2010 la tasa de política se elevó periódicamente hasta $4.25 \%$, en un contexto de mayor dinamismo de la demanda interna. Este nivel se mantuvo hasta Noviembre del 2013, cuando la tasa de política se redujo a $4 \%$, debido a que el crecimiento de la actividad económica se encontraba por debajo de su nivel potencial, y no había señales de presión al alza en los precios ya que las expectativas de inflación se mantenían dentro del rango meta. 
Es importante considerar que la economía peruana es parcialmente dolarizada. Los niveles de dolarización aumentaron considerablemente a fines de los 80 como consecuencia de la devaluación de la moneda local durante un proceso de hiperinflación; en la medida que se perdía la confianza en la moneda doméstica, los agentes económicos prefirieron refugiarse en el dólar estadounidense (USD, en adelante).

A pesar del notable éxito logrado en años recientes en lo que respecta a la estabilización de la inflación y la restauración de la disciplina monetaria (...), la dolarización se ha mantenido en niveles significativos, particularmente en lo que se refiere a la denominación en moneda extranjera de los activos y pasivos del sistema bancario, es decir, la dolarización financiera (DF)

(Ize, 2001)

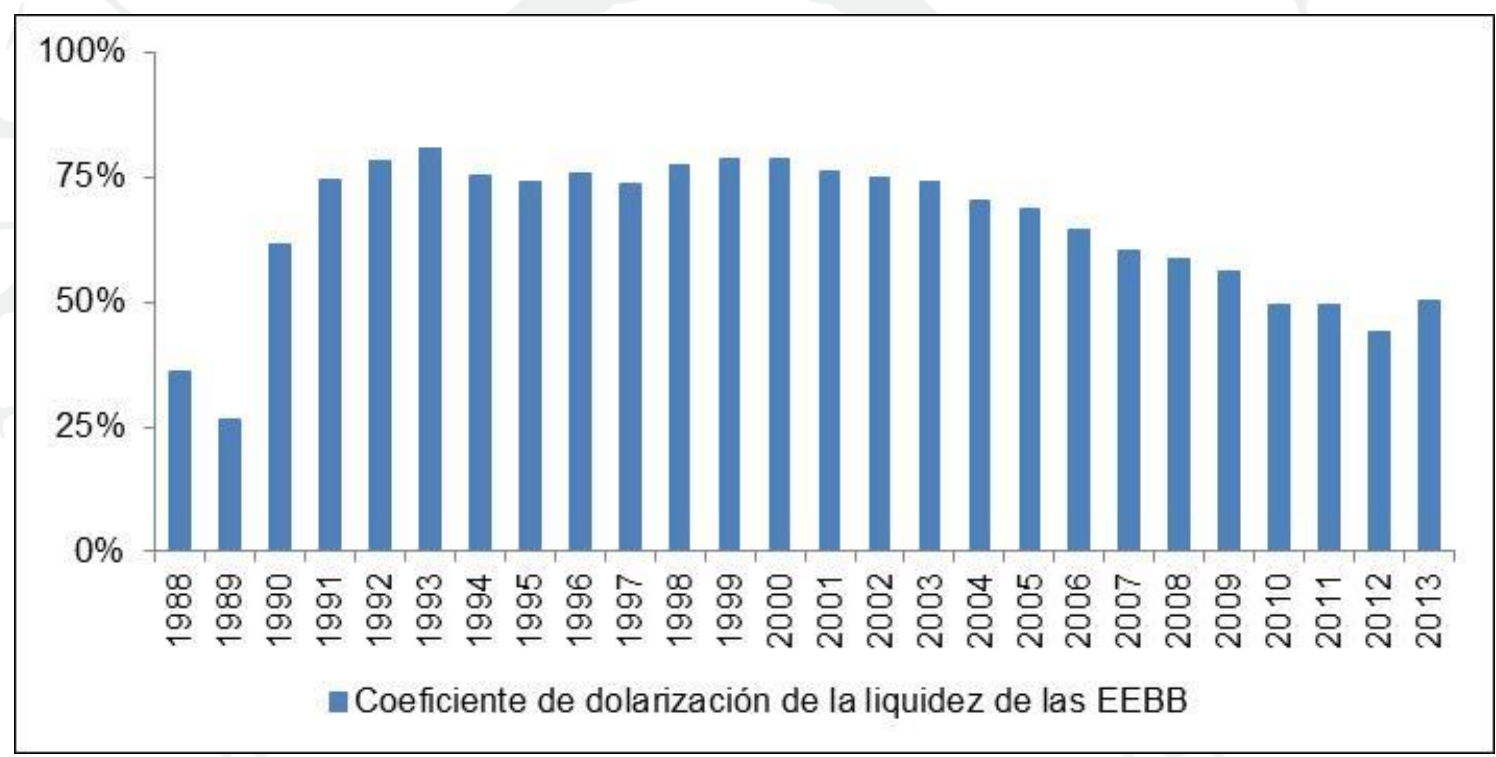

Figura 2.2 Coeficiente de dolarización de la liquidez de las Empresas Bancarias. Periodo 1998-2013. (En \%). Fuente BCRP, Series Estadísticas Anuales, revisado el 19 de Junio del 2014, http://estadisticas.bcrp.gob.pe/index.asp?sFrecuencia=A.

Como se puede apreciar en la Figura 2.2, el coeficiente de dolarización de la liquidez de los bancos ha aumentado desde la experiencia hiperinflacionaria a fines de la década de los 80 , y se ha reducido a niveles menores a $50 \%$ al año 2013. Esta tendencia indica que, si bien se ha recuperado la confianza en la moneda local, todavía persiste un alto nivel de dolarización. "La persistencia del fenómeno de la dolarización se explica en gran medida por el efecto de 
histéresis que mantiene el temor de una gran devaluación, a pesar del periodo de más de 15 años de inflación de un dígito" (Choy y Chang, 2014).

Se pueden identificar por lo menos dos riesgos sistémicos asociados a la dolarización parcial. Primero, se reduce la capacidad del Banco Central de ser un prestamista de última instancia (no puede emitir dólares), lo cual aumenta el riesgo de iliquidez en el sistema financiero, particularmente en escenarios de estrés financiero. En segundo lugar, hay un efecto indirecto sobre el riesgo cambiario crediticio para los bancos. Si el USD se aprecia con respecto al Nuevo Sol, las empresas con deuda en dólares e ingresos en soles sufren pérdidas en su patrimonio por la variación del tipo de cambio; consecuentemente, incrementa la probabilidad de que incurran en mora, y hay un deterioro en el balance de los bancos que han otorgado préstamos a dichas empresas. El proceso descrito es conocido como efecto hoja de balance, y puede ocasionar grandes pérdidas al sistema financiero. (Armas, Castillo y Vega, 2014).

Con respecto a los efectos negativos de la dolarización financiera no relacionados con riesgos financieros sistémicos, una consecuencia particular es que se reduce la efectividad de la tasa de política, dado que esta no puede influir en las tasas de interés en moneda extranjera.

En el contexto descrito, el BCRP ha diseñado un conjunto de instrumentos monetarios orientados a controlar la estabilidad de la moneda local, teniendo en consideración los riesgos provenientes de la dolarización financiera de la economía. Los principales se describen a continuación, basado en el Folleto Institucional del BCRP (BCRP, s.f.).

\subsubsection{Operaciones de Mercado Abierto}

Con excepción de la compra y venta de moneda extranjera, las operaciones de mercado abierto se implementan a través de un mecanismo de subastas, como fue descrito en el capítulo 1.

\section{- Certificado de Depósito (CD-BCRP)}

Valores denominados en soles emitidos por el BCRP a través de subastas. Tienen como finalidad la esterilización de liquidez en el sistema 
financiero. En el plazo de vencimiento, el efecto se revierte y hay una expansión de la base monetaria.

\section{- Certificados de Depósito Reajustables (CDR-BCRP)}

Valores emitidos por el BCRP a través de subastas, denominados en soles pero con valor re-ajustable en función a la variación del tipo de cambio del dólar entre la fecha de colocación y la de vencimiento, lo que resulta equivalente a poseer moneda extranjera. Tienen como finalidad esterilizar la liquidez en soles del sistema financiero y satisfacer la demanda de dólares sin necesidad de realizar ventas en el mercado spot.

- Certificados de Depósito de Liquidez en Dólares (CDLDBCRP)

Valores emitidos por el BCRP a través de subastas, denominados en soles pero que exigen un pago en dólares. Es el equivalente a realizar una compra de dólares, y esterilizar la expansión de liquidez a través de un CDBCRP. Este instrumento ha sido diseñado con la finalidad de mitigar la apreciación del nuevo sol, en un contexto donde las posiciones de cambio globales $^{2}$ de los bancos se ven presionadas al alza debido a que inversionistas extranjeros realizan operaciones forward venta de dólares en expectativa de que la moneda doméstica se aprecie y obtener una ganancia por ello.

\section{- Depósitos a plazo fijo de bancos domésticos en el BCRP}

En escenarios de importantes entradas de capitales de corto plazo, el BCRP reemplazó los CD-BCRP por depósitos a plazo, para evitar la negociación de los instrumentos emitidos en el mercado secundario.

- Compra temporal con compromiso de recompra (REPO)

2 La posición de cambio global es igual a suma de los activos netos en moneda extranjera y la posición neta en operaciones forward pactadas (compras menos ventas de dólares a futuro) 
Instrumento que permite la expansión de liquidez a través de compra de títulos $^{3}$ a empresas del sistema financiero, con el compromiso de que éstas realicen la recompra en una fecha pactada. A partir de marzo de 2007, se autorizó la realización de operaciones REPO en moneda extranjera con la finalidad de proveer liquidez en dicha moneda.

- Compra Temporal de Moneda Extranjera con Compromiso de Recompra (swaps)

Son compras de moneda extranjera en el mercado spot por parte del BCRP a las empresas bancarias, con el compromiso de recompra en una fecha pactada. Al finalizar el periodo del swap, este puede ser renovado o liquidado.

- Compra-venta de moneda extranjera en el mercado spot

Operaciones realizadas en el mercado spot, con la finalidad de evitar volatilidad en el tipo de cambio del dólar.

\subsubsection{Operaciones de Ventanilla}

- Créditos de regulación monetaria

Son préstamos a una tasa fijada por el BCRP, con la finalidad de cubrir desequilibrios transitorios de liquidez de las empresas que lo soliciten y evitar el riesgo de iliquidez en el Sistema Financiero.

\section{- Colocación directa de CD y CDR}

Consiste en la venta de estos valores fuera de las subastas, a través de una negociación directa con los intermediarios financieros que lo soliciten.

- REPO directa

Operación repo realizada a solicitud de los intermediarios financieros, fuera del mecanismo usual de subastas.

El conjunto de títulos valor que el BCRP admite para las operaciones REPO incluye CD-BCRP, CDR-BCRP, Letras y Bonos del Tesoro Público 


\section{- Depósitos overnight}

Depósitos con duración de un día, que tienen la finalidad de retirar los excedentes de liquidez del sistema financiero al cierre de las operaciones de cada día. La tasa de interés pasiva que se paga por estos depósitos, junto con la tasa de interés activa cobrada por los créditos de regulación monetaria, constituyen el corredor dentro del cual se ubica la tasa de interés interbancaria.

\subsubsection{Política de Encaje}

En Perú, los requerimientos de encaje se definen como el nivel mínimo de reservas en efectivo que las entidades del sistema financiero deben guardar en sus propias cajas y en los depósitos en cuenta corriente en el BCRP, tanto en moneda nacional como en moneda extranjera.

De manera específica, el monto que debe guardar cada entidad financiera producto del encaje se denomina encaje exigible, y tiene dos partes: encaje legal y marginal. Este encaje se calcula con periodicidad mensual.

El primer paso para determinar el encaje exigible es calcular el total de obligaciones sujetas a encaje (TOSE). Posteriormente, se calcula el saldo promedio diario de las obligaciones sujetas a encaje en un mes, el cual se denomina TOSE promedio. El encaje legal se calcula aplicando la tasa correspondiente sobre el TOSE promedio. Por otro lado, para el cálculo del encaje marginal se comparan los TOSE promedio del mes en cuestión y un periodo base; al monto excedente se aplica la tasa marginal.

Debido al contexto de dolarización financiera en que se encuentra la economía peruana, el BCRP fija un encaje en moneda extranjera, superior al encaje en moneda nacional debido al mayor riesgo asociado a la intermediación en dólares. De manera complementaria, se aplican encajes a adeudados externos de corto y largo plazo de las entidades del sistema financiero, y encajes a los depósitos de no residentes en moneda nacional, 
con la finalidad de evitar la dependencia de financiamiento con el exterior por parte de las empresas bancarias.

\subsection{Evolución agregada de los flujos de capitales}

La experiencia de Perú durante la crisis Rusa en 1998 ilustra el peligro de los flujos de corto plazo en un contexto en el que los adeudados con el exterior del sistema financiero no eran obligaciones sujetas a encaje. En ausencia de dicho encaje, los bancos locales optaban por financiarse con el exterior en forma de líneas de crédito, debido a que su costo era relativamente más barato; consecuentemente, hubo una sobre-expansión del crédito bancario. Con el estallido de la crisis se produjo una repentina salida de capitales, que además ocasionó una depreciación considerable de la moneda doméstica en relación al dólar. Como consecuencia de ello, hubo una reducción en la liquidez disponible del sistema financiero, y los intermediarios se vieron obligados a recortar el crédito al sector privado no financiero (credit crunch). Además, los prestatarios con deuda en dólares e ingresos en soles sufrieron pérdidas, incrementándose la probabilidad de cesación de pagos en el sistema bancario (efecto hoja de balance) (Rossini et al., 2013).

Para evitar que esta situación se repita, el BCRP institucionalizo un encaje específico a los adeudos con el exterior de la banca en moneda extranjera, con la finalidad de encarecer su costo y evitar la dependencia de la banca hacia dichos fondos, pues son volátiles e incrementan el riesgo de financiamiento (De Gregorio, 2010)

Durante el periodo de análisis, los flujos de capitales hacia la economía peruana han tenido una evolución muy distinta en comparación a la crisis rusa, y han supuesto una limitación a la tasa de interés como instrumento de política monetaria. Esto se debe a que parte de dichos flujos ha tenido un carácter especulativo; en caso el BCRP tenga que incrementar la tasa de política para evitar presiones inflacionarias, entrarían mas flujos en busca de rentabilidad de corto plazo, lo cual podría ocasionar un aumento en la volatilidad del tipo de cambio. 
Para analizar la evolución reciente de los flujos de capitales, resulta útil revisar la Cuenta Financiera de la Balanza de Pagos, donde se registra la mayor parte de dichos flujos. Según el portal del BCRP, sección de Preguntas Frecuentes, esta cuenta se compone ${ }^{4}$ por la Cuenta Financiera del Sector Privado, que comprende los flujos netos por inversión Directa Extranjera, los flujos netos por Inversión de Cartera Extranjera y el financiamiento de largo plazo con el exterior, neto de amortizaciones, por parte del sector privado residente; la Cuenta Financiera del Sector Público, que registra la deuda pública externa neta de amortizaciones; y la Cuenta de Capitales de Corto Plazo, que registra los flujos menores a un año (excluyendo al BCRP) de activos y pasivos de corto plazo del sector privado, y de las familias residentes.

Se pueden identificar cuatro periodos de acuerdo a la evolución de la Cuenta Financiera. El primero comprende desde el primer trimestre de 2006, hasta el tercer trimestre del 2008, y se caracteriza por la entrada neta de capitales. Luego viene un periodo de salida de capitales desde el cuarto trimestre del 2008 hasta el tercer trimestre del 2009, explicado principalmente por el estallido de la crisis financiera internacional con la quiebra del Banco de Inversión Lehman Brothers en Setiembre del 2008, seguido de una recuperación de las economías emergentes y relativamente bajos ingresos de capitales hasta el segundo trimestre del 2010; en tercer lugar, se da un resurgimiento de influjos de capitales, desde el tercer trimestre del 2010 hasta mediados del 2013; finalmente, la tendencia de los influjos se detiene desde julio del 2013 hasta diciembre de dicho año.

\footnotetext{
Adicionalmente hay un registro de "Errores y Omisiones", y cada componente de la Cuenta Financiera incluye una partida denominada "Otros Activos Externos ", ambos de menor relevancia.
} 
Tabla 2.1

Flujos de Capitales por la Cuenta Financiera, Periodo 2006-2013. (En

Millones de dólares)

\begin{tabular}{|ccccc|}
\hline Periodo & Subperiodo & CF del S. Privado & CF del S. Público & CC de Corto Plazo \\
\hline Ene2006- & & 19,026 & $-3,372$ & 4,051 \\
Set2008 & & $(578)$ & $(-102)$ & $(123)$ \\
\hline & (Oct2008- & 4,824 & -701 & $-6,123$ \\
Oct2008- & Set2009) & $(402)$ & $(-58)$ & $(-510)$ \\
\cline { 2 - 5 } Jun2010 & (Oct2009- & 4,922 & 170 & 1,426 \\
& Jun2010) & $(547)$ & $(19)$ & 467 \\
\hline Jul2010- & & 43,376 & 3463 & $(13)$ \\
Jun2013 & $(1205)$ & $(96)$ & $-2,004$ \\
\hline Julio2013- & & 5,454 & -424 & $(-334)$ \\
Dic2013 & $(909)$ & $(-71)$ & \\
\hline
\end{tabular}

Nota: Los montos sin paréntesis reflejan la sumatoria total de cada cuenta durante el periodo seleccionado. Los montos entre paréntesis son promedios mensuales. Fuente: BCRP, Cuadros Estadísticos 94, 95 y 96 de la Nota Semanal, revisado el 04 de Febrero del 2014, http://www.bcrp.gob.pe/estadisticas/cuadros-de-la-nota-semanal.html

Como se puede apreciar en la Tabla 2.1, los cuatro periodos ${ }^{5}$ de los flujos de capitales siguen evoluciones distintas. El propósito de incluir el promedio mensual de los flujos es estandarizar los volúmenes en cada periodo y poder realizar comparaciones entre los mismos.

El primer hecho a resaltar es que la Cuenta Financiera del Sector Privado tiene un peso considerablemente mayor en el resultado final de la Cuenta Financiera en comparación a las demás partidas. Según los Reportes de Inflación del BCRP (BCRP, 2006-2013), las entradas en dicha cuenta se dan a través de financiamiento de largo plazo en el mercado de capitales internacional por parte del sector privado, e inversión directa en el país, destinada principalmente al financiamiento de proyectos de inversión en el sector minero y de hidrocarburos. Las salidas de capitales a través de la misma se explican principalmente por la diversificación de activos financieros por parte de inversionistas domésticos hacia el extranjero, en especial las Administradoras de Fondos de Pensiones.

Con respecto a la Cuenta Financiera del Sector Público, los flujos de capitales reflejan principalmente la amortización de deuda pública y la emisión de nueva deuda.

$5 \quad$ El periodo Octubre 2008 - Junio 2010 se divide en dos sub-periodos, para poder distinguir la magnitud de las salidas de capitales de corto plazo en los meses posteriores a la crisis financiera internacional. 


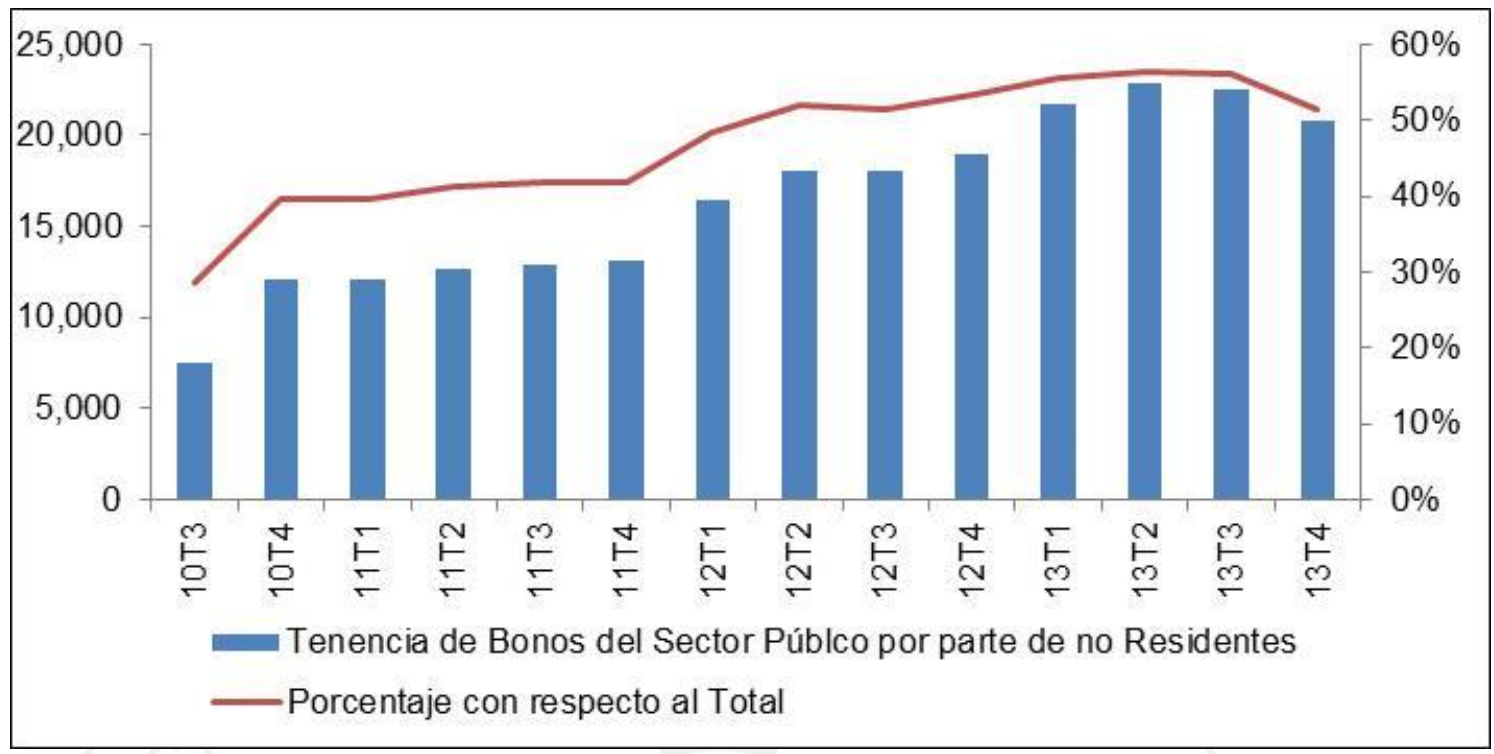

Figura 2.3 Tenencia de Bonos del Sector Público por parte de No Residente. Periodo Julio $2010-$ Diciembre 2013. (Saldo en Millones de dólares y Ratio en \%) Fuente BCRP, Cuadro Estadístico 35 de la Nota Semanal, revisado el 19 de Junio del 2014, http://www.bcrp.gob.pe/estadisticas/cuadros-de-la-notasemanal.html

Como se puede apreciar en la Figura 2.3, a partir del tercer trimestre del 2010 hay un incremento considerable en la tenencia de bonos del sector público por parte de no residentes. La entrada de capitales a través de esta vía explica el resultado de la Cuenta Financiera del Sector Público durante el periodo Julio 2010 - Junio 2013 en la Tabla 2.1.

La Cuenta de Capitales de Corto Plazo sigue una tendencia relativamente volátil. Resalta la entrada de capitales en el periodo Enero 2006 - Setiembre 2008, la cual se explica principalmente por un incremento en la tenencia de activos financieros denominados en moneda nacional por parte de no residentes, principalmente CD-BCRP. Por otro lado, la salida de 6,123 millones de USD en el periodo Octubre 2008 - Setiembre 2009 se debe a la incertidumbre global provocada por la crisis financiera internacional, y el consecuente incremento del riesgo percibido de los países en vías de desarrollo, incluido Perú, por parte de los inversionistas a nivel global.

Es importante mencionar el impacto que han tenido las políticas monetarias expansivas de las economías desarrolladas sobre la evolución de los flujos de capitales en el periodo de análisis. En Noviembre del 2008, la Reserva Federal de Estados Unidos (FED) anunció una expansión cuantitativa (QE, por sus siglas en inglés) que consistía en la compra periódica de 
instrumentos de deuda, lo cual permitió inyectar cantidades masivas de liquidez a su país. Al mes siguiente, la Reserva Federal disminuyó su tasa de interés de política a niveles muy cercanos a cero con la finalidad de expandir la demanda interna y afrontar la recesión en que se encontraba Estados Unidos. Estos eventos tuvieron un efecto a la baja en las tasas de interés de los países desarrollados, ampliando el diferencial entre dichas tasas y las de países emergentes, lo cual ocasionó un aumento la demanda de activos financieros de estos últimos por parte de inversionistas extranjeros y atenuó la salida de capitales en los primeros trimestres del $2009^{6}$.

Siguiendo la misma línea, el resurgimiento de los influjos capitales se dio a partir del tercer trimestre del 2010, hecho que coincide con la recuperación del dinamismo de la demanda interna de la economía peruana y con el segundo anuncio de expansión cuantitativa de la FED en Noviembre de dicho año. La nueva inyección de liquidez mantuvo la brecha entre las tasas de interés de países emergentes y de la economía peruana, lo cual fomentó el financiamiento de largo plazo con el exterior por parte del sector privado doméstico, debido al menor costo de fondeo. Los resultados se reflejan en los valores registrados en la Cuenta Financiera del Sector Privado durante el periodo Julio 2010 - Junio 2013 en la Tabla 2.1.

Cabe mencionar que en dicho periodo se registró una entrada creciente de flujos por concepto de inversión extranjera de cartera, con énfasis en el primer semestre del 2013.

\footnotetext{
6 De los 6,123 millones de capitales de corto plazo que salieron durante el sub-periodo Octubre 2008 - Setiembre 2009 en la Tabla 2.1, 2,653 (43\%) lo hicieron en el cuarto trimestre del 2008.
} 


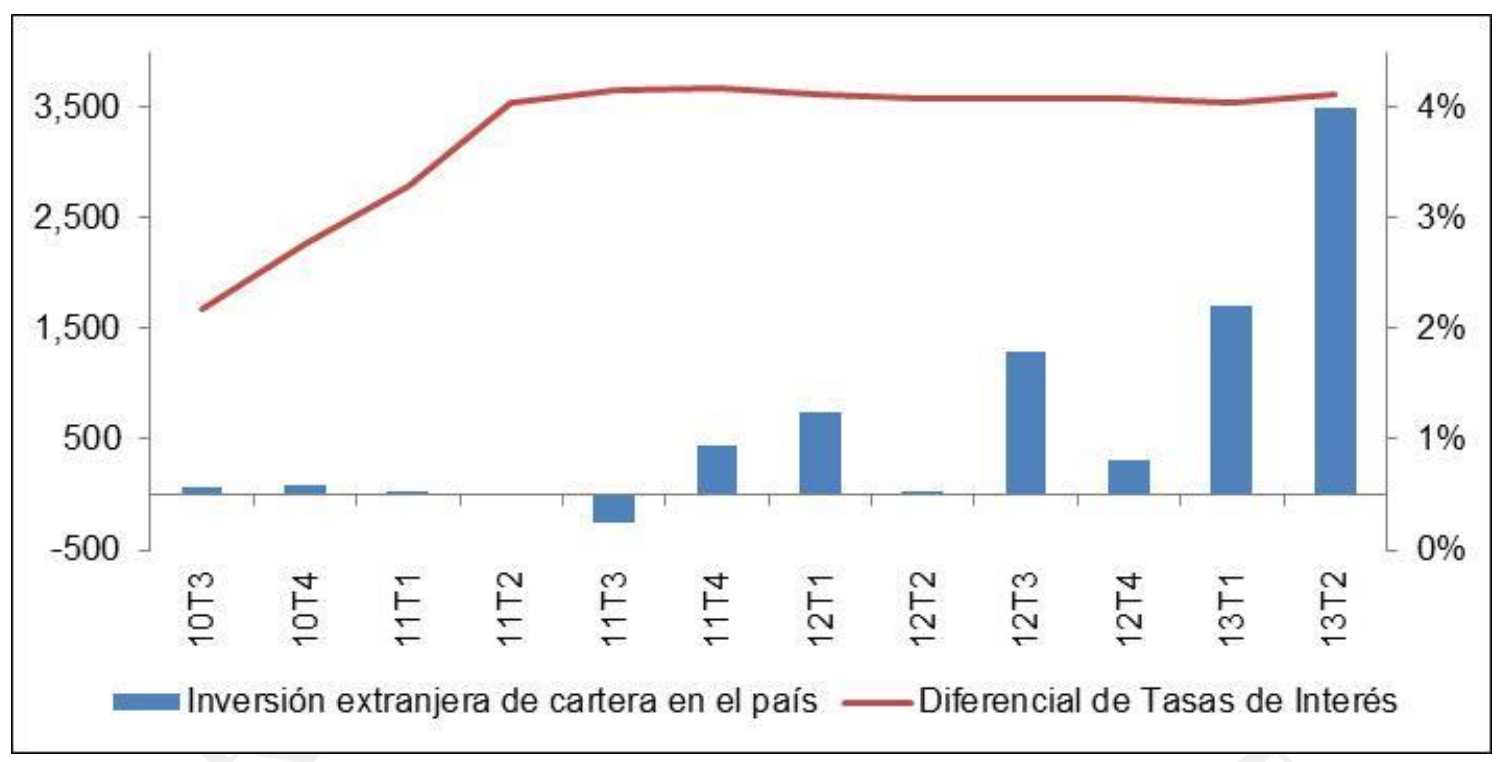

Figura 2.4 Inversión Extranjera de Cartera y Diferencial entre Tasa Interbancaria de Perú en Soles y Tasa de Fondos Federales en USD. Periodo Julio 2010 - Junio 2013. (Inversión en Millones de dólares y Tasas en \%). Fuente 1 BCRP, Cuadro Estadístico 94 de la Nota Semanal, revisado el 20 de Junio del 2014, http://www.bcrp.gob.pe/estadisticas/cuadros-de-la-nota-semanal.html. Fuente 2 BCRP, Series Estadísticas Diarias, revisado el 20 de Junio del 2014, http://estadisticas.bcrp.gob.pe/index.asp?sFrecuencia=D. Fuente 3 Federal Reserve Bank of New York, $\begin{array}{llllll}\text { revisado } & \text { el } & 20 & \text { de } & \text { Junio } & \text { del }\end{array}$ http://www.newyorkfed.org/markets/omo/dmm/historical/fedfunds/ff.cfm

En la Figura 2.4 se puede apreciar la evolución de la Inversión Extranjera de Cartera en el país, junto con el diferencial entre la tasa Interbancaria de Perú en Soles y la Tasa de Fondos Federales durante el tercer periodo de influjos de capitales. La tendencia creciente de las entradas de capitales por concepto de Inversión en Cartera se inicia en el tercer trimestre del 2012, hecho que coincide con el tercer anuncio de expansión cuantitativa de la FED, que consiste en compras mensuales de 40,000 millones de USD en bonos hipotecarios. De esta manera se mantuvieron elevados los spreads de tasas de interés entre el mercado peruano y el mercado internacional, lo cual fomento influjos de capitales especulativos a la economía.

Un último hecho a resaltar sobre la Tabla 2.1 es la salida de capitales durante el periodo Julio 2013 - Diciembre 2013, vista por el resultado negativo en la Cuenta de Capitales de Corto Plazo, la Cuenta Financiera del Sector Público y la desaceleración de influjos en la Cuenta Financiera del Sector Privado. Estos resultados se explican parcialmente por la expectativa de un posible tapering o retiro del estímulo monetario de la FED, dada la recuperación de la economía estadounidense, hecho que se materializo en 
diciembre del 2013. Producto del tapering, el diferencial de tasas de interés entre el mercado doméstico y el resto del mundo debería volver a la normalidad al cabo de pocos meses, lo cual implicaría que los activos financieros locales ya no resulten tan atractivos para los inversionistas extranjeros en comparación con el resto del mundo. Asimismo, el crecimiento de la economía peruana se estaba desacelerando durante dicho periodo; según el Instituto Nacional de Estadística e Informática (INEI), en el 2013 el crecimiento del PBI en términos reales fue de 5.02\%, menor a promedio de los últimos 8 años (6.79\%). Con ello, debería haber menores oportunidades de inversión y mayor probabilidad de una reducción en la tasa de política por parte del BCRP para reactivar la demanda interna, y consecuentemente menores posibilidades de obtener rentabilidad en el corto plazo ${ }^{7}$. Este conjunto de factores afectó la tendencia de los flujos de capitales, de entradas a salidas.

\subsection{Medidas de política}

Con la finalidad de atenuar el impacto de los flujos de capitales sobre el crédito de las empresas bancarias al sector privado y el tipo de cambio del USD, el BCRP implemento una serie de medidas de política adicionales al uso de la tasa de política.

\subsubsection{Encaje}

Las entradas de capitales producto del colapso de Lehman Brothers y previo a la segunda expansión cuantitativa de la Reserva Federal de los Estados Unidos se reflejaron en Perú a través de un aumento en la demanda de activos financieros en moneda doméstica por parte de extranjeros, principalmente los Certificados de depósito del Banco Central (CD-BCRP). Con la finalidad de contraer dichos influjos especulativos en busca de carry trade, el BCRP implementó tres medidas (Rossini et al., 2013):

- $\quad$ Una comisión de 4\% por la negociación de títulos del BCRP con no residentes. 
- Sustitución de los CD-BCRP por certificados de negociación restringida a no residentes, y posteriormente la creación de depósitos a plazo fijo, como instrumentos de esterilización de liquidez con la finalidad de evitar su negociación con no residentes.

- Aumento del encaje a los adeudos de corto plazo con no residentes, con la finalidad de disminuir la dependencia de la banca por fondos del exterior, los cuales son normalmente volátiles, implican un riesgo de financiamiento y crédito, y estuvieron relacionados con el credit crunch en la economía peruana durante la crisis rusa de 1998.

De acuerdo con el marco teórico propuesto por Ghosh et al. (2010), las medidas de control de capitales están fundamentadas en escenarios donde hay un exceso de financiamiento con el exterior por parte del sector privado financiero, en conjunto con un riesgo de sobre-expansión crediticia. Tal fue el caso de Perú en los años posteriores a la crisis Rusa, cuando se dio una contracción del crédito debido al recorte del financiamiento externo de los bancos (Rossini et al., 2013). Persiste el riesgo de que esos eventos se repitan, por lo cual el BCRP mantiene una política de encaje activa.

La principal diferencia entre la crisis financiera internacional y la crisis rusa respecto a la política encaje es que, durante la crisis reciente, el BCRP contaba con un encaje específico a los adeudos con el exterior de corto plazo, con lo cual pudo atenuar la tendencia de los bancos a fondearse con el extranjero.

Específicamente, el BCRP incrementó el encaje a los adeudos con el exterior de corto plazo de 30 a 45\%, y exoneró el encaje a préstamos de plazos mayores o iguales a 2 años de duración, políticas implementadas entre los años 2007-2008. En conjunto, dichas medidas incentivaron que las Empresas Bancarias incrementen el financiamiento externo de largo plazo, lo cual implica un menor riesgo de salidas repentinas de capitales (Armas et al., 2014). 


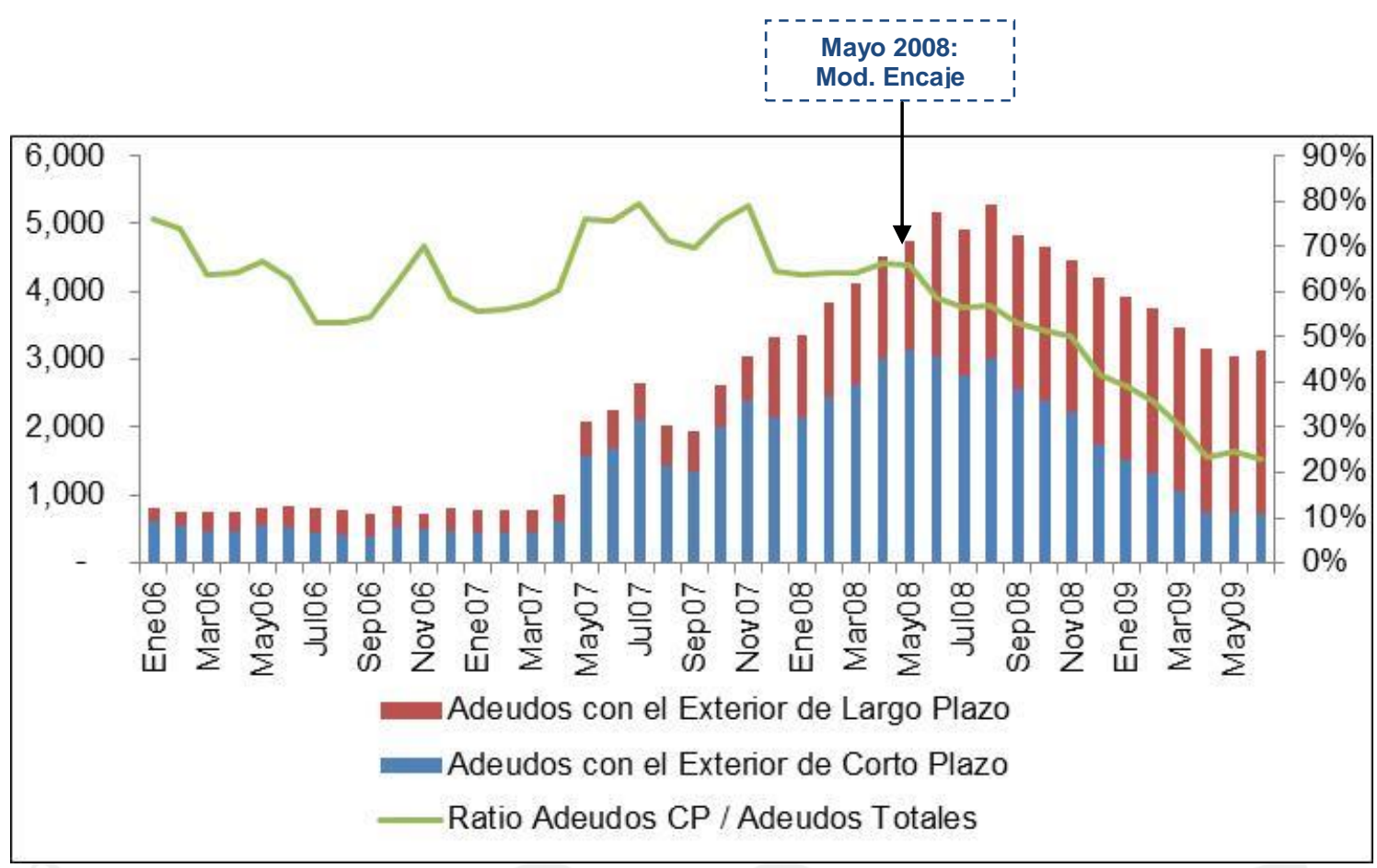

Figura 2.5 Adeudos con el Exterior de Corto y de Largo Plazo. Periodo Enero 2006 - Junio 2009. (Saldo en Millones de dólares y Ratio en \%). Saldos originales en soles, ajustados por el tipo de cambio contable de la SBS. Fuente SBS, Boletín Estadístico de la Banca Múltiple, revisado el 6 de Junio del 2015, http://www.sbs.gob.pe/app/stats/EstadisticaBoletinEstadistico.asp?p=1

Como se puede apreciar en la Figura 2.5, las medidas tomadas por el BCRP en relación a los adeudados con el exterior de la banca tuvieron un efecto directo sobre la estructura de plazos de sus pasivos, fomentando la tenencia de deuda de largo plazo de manera que su vulnerabilidad ante cortes de financiamiento externo de corto plazo disminuya; el éxito de esta política se hizo evidente cuando las salidas de capitales se materializaron después de la crisis financiera, y los bancos contaban con un mayor porcentaje de pasivos externos de largo plazo en sus balances. 
Tabla 2.2

Variación del Saldo de Crédito Bruto en Moneda Nacional y en Moneda Extranjera.

Periodos Múltiples. (En \%)

\begin{tabular}{|cccc|}
\hline \multirow{2}{*}{ Duración } & Periodo & Variación Crédito MN & Variación Crédito ME \\
\hline \multirow{2}{*}{12 meses } & AGO1998-JUL1999 (CR) & $-1 \%$ & $0 \%$ \\
\cline { 2 - 4 } & OCT2008-SEP2009 (CFI) & $16 \%$ & $-9 \%$ \\
\hline \multirow{2}{*}{24 meses } & AGO1998-JUL2000 (CR) & $-14 \%$ & $-3 \%$ \\
\cline { 2 - 4 } & OCT2008-SEP2010 (CFI) & $38 \%$ & $4 \%$ \\
\hline \multirow{2}{*}{36 meses } & ENE1998-DIC2000 (CR) & $-10 \%$ & $9 \%$ \\
\cline { 2 - 4 } & ENE2008-DIC2010 (CFI) & $98 \%$ & $38 \%$ \\
\hline
\end{tabular}

Nota 1: El Crédito Bruto se calcula a partir del Balance General de la Banca Múltiple. Se consideran los créditos vigentes, atrasados, refinanciados y reestructurados. Nota 2: CR es Crisis Rusa; CFI es Crisis Financiera Internacional. Fuente: SBS, Boletín Estadístico de la Banca Múltiple, revisado el 6 de Junio del 2015, http://www.sbs.gob.pe/app/stats/EstadisticaBoletinEstadistico.asp?p=1

En la Tabla 2.2 se incluye la variación del saldo de crédito en moneda nacional y en moneda extranjera durante seis periodos. La lectura es la siguiente: el saldo del crédito bruto en moneda nacional fue $10 \%$ inferior en diciembre el 2000 en comparación a enero de 1998, mientras dicho saldo fue 98\% mayor en diciembre del 2010 en comparación a enero del 2008. El propósito es analizar la evolución del crédito durante la crisis rusa y la crisis financiera internacional, considerando que (entre otros aspectos) se diferencian en una variable clave: durante la última crisis, el BCRP contaba con el encaje a los adeudos con el exterior. Se puede apreciar que el crédito en moneda nacional se desaceleró en menor proporción durante el primer año de la crisis financiera internacional, en comparación al primer año de la crisis rusa; no obstante, lo opuesto ocurrió al considerar el crédito en moneda extranjera en ese periodo. Sin embargo, al considerar periodos de 2 y 3 años, se puede observar que la recuperación del crédito, tanto en moneda nacional como moneda extranjera, ha sido más rápida durante la última crisis, hecho que denota menor volatilidad en las colocaciones de la banca. A partir de esta Tabla, la principal conclusión es que las medidas de encaje implementadas por el BCRP han contribuido a evitar que se repita un credit crunch similar al de la crisis rusa. 


\subsubsection{Intervenciones cambiarias}

Los flujos de capitales pueden ocasionar elevados niveles de volatilidad en el tipo de cambio, particularmente cuando estos son especulativos y de corto plazo, y están en una búsqueda constante de carry trade (Choy y Chang, 2014). Dicha volatilidad vuelve vulnerable a las empresas del sector privado con descalce de moneda.

Para controlar la volatilidad del tipo de cambio del USD, el BCRP realiza intervenciones cambiarias en el mercado spot de manera discrecional, con el único objetivo disminuir dicha volatilidad, antes que comprometerse con un nivel de tipo de cambio nominal. Bajo este sistema, el BCRP es capaz de realizar operaciones cambiarias en cualquier momento sin necesidad de previo anuncio, evitando así el compromiso con un nivel o tendencia del tipo de cambio (Rossini et al., 2013).

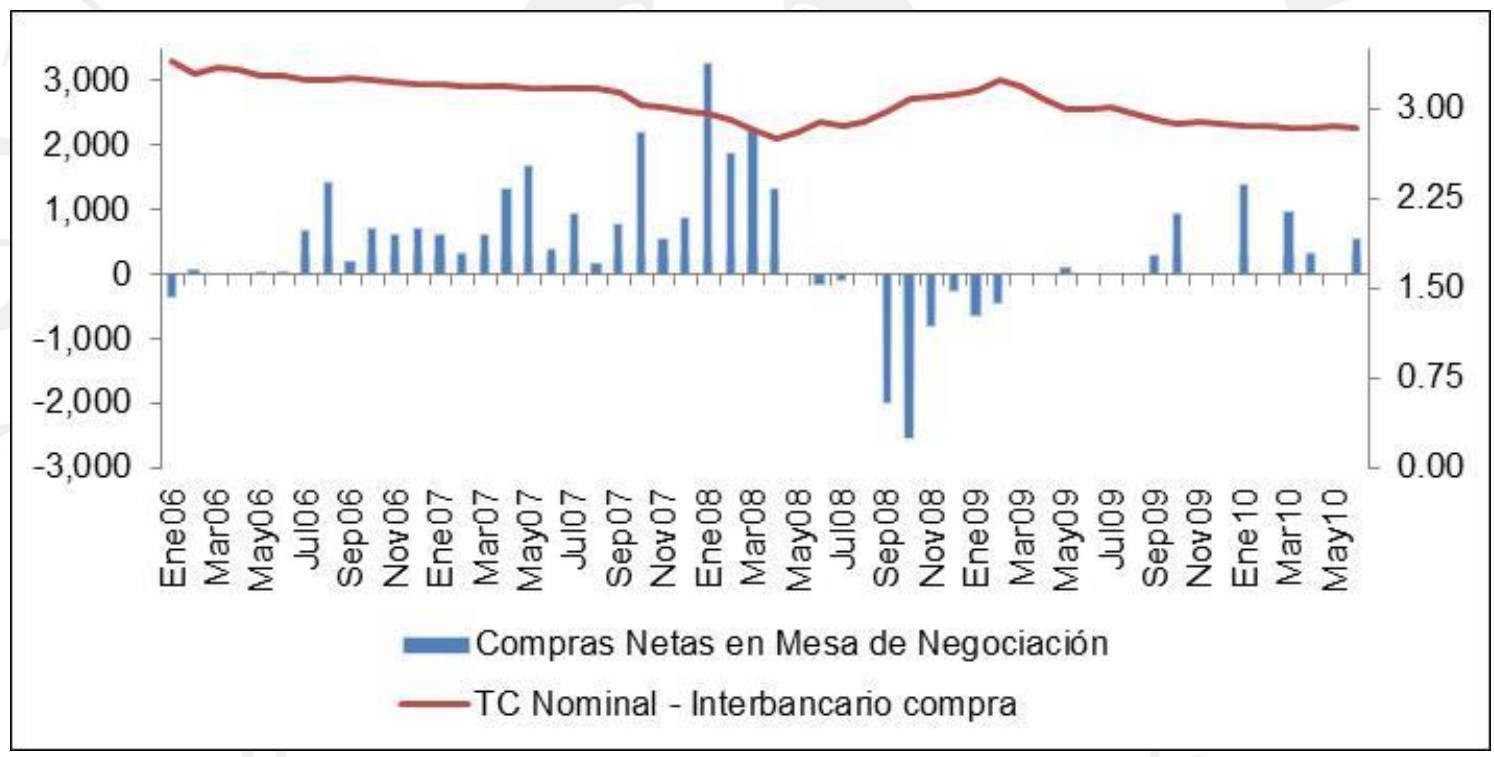

Figura 2.6 Operaciones Cambiarias del BCRP y Tipo de Cambio Nominal Interbancario. Periodo 2006 2013. (Operaciones en Millones de dólares y Tipo de Cambio en soles por dólar) Fuente BCRP, series estadísticas mensuales, revisado el 19 de Junio del 2014, http://estadisticas.bcrp.gob.pe/index.asp?sFrecuencia=M.

Al revisar la Figura 2.6 se observa que el tipo de cambio interbancario siguió una tendencia a la baja desde enero del 2006 hasta agosto del 2008. A partir de Setiembre del mismo año, la tendencia se revirtió, y el tipo de cambio llegó a depreciarse en 9.12\% a Febrero del 2009, producto de la Crisis Financiera Internacional. La reacción del BCRP fue intervenir en el mercado spot a través de ventas de dólares, aprovechando la acumulación de RIN por las compras de dólares en los años precedentes a la crisis; como 
consecuencia, en marzo del 2009 el tipo de cambio volvió a su tendencia a la baja.

En los años siguientes el BCRP continuo realizando compras de dólares, evitando así una apreciación aún más pronunciada del Tipo de Cambio. Finalmente, desde Mayo del 2013 hasta Diciembre del mismo año el dólar se apreció en 5\% con respecto al nuevo sol, principalmente por las expectativas de recuperación de la economía estadounidense y la desaceleración de las exportaciones peruanas, uno de los principales motores del crecimiento económico, hecho que contribuyo al resultado negativo de la Balanza Comercial en 364 Millones de Dólares durante dicho año, según fuentes del BCRP. Ante esta situación, el Banco Central reaccionó con ventas de dólares en el mercado spot, lo cual desaceleró la tendencia al alza del tipo de cambio.

Es importante considerar que una parte considerable de los flujos de capitales especulativos durante el periodo de análisis ingresaron a la economía doméstica a través de forwards de no residentes contra bancos peruanos. Con la finalidad de analizar el efecto dichos flujos sobre el tipo de cambio se presenta la Tabla 2.3, que incluye las Operaciones Forward de las Empresas Bancarias en tres periodos, así como el total de operaciones cambiarias realizadas por el BCRP.

Tabla 2.3

Operaciones Forward de las Empresas Bancarias y Operaciones

Cambiarias del BCRP en el Mercado Spot. Periodos Múltiples. (En

Millones de dólares)

\begin{tabular}{|ccc|}
\hline Periodo & Operaciones Forward de los Bancos (A) & Operaciones Cambiarias BCRP (B) \\
\hline ENE2007-SEP2008 & 6,681 & 16,747 \\
\hline OCT2008-MAR2009 & $-3,717$ & $-4,836$ \\
\hline ABR2009-DIC2009 & 4,756 & 1,256 \\
\hline
\end{tabular}

Nota: Un signo positivo en la columna (A) significa que los bancos han realizado en promedio más forwards compra que venta; es decir, los extranjeros han realizado forwards venta contra los bancos domésticos. Un signo negativo indica lo opuesto. Fuente 1 BCRP, Series Estadísticas Mensuales, revisado el 19 de Junio del 2014, http://estadisticas.bcrp.gob.pe/index.asp?sFrecuencia=M. Fuente 2 BCRP, Cuadro Estadístico 48 de la Nota Semanal, revisado el 19 de Junio del 2014, http://www.bcrp.gob.pe/estadisticas/cuadros-de-la-nota-semanal.html. 
Como se puede apreciar en la Tabla 2.3, las operaciones forward de las empresas Bancarias han seguido una evolución similar a las operaciones cambiarias del BCRP. Ante presiones en la posición global de la banca producto de forwards venta realizados por inversionistas extranjeros en busca de rentabilidad (profecía auto cumplida) (Choy y Chang, 2014), el BCRP contribuyó a mitigar dicha presión a través de compras de dólares, lo cual se refleja en el resultado de los periodos Ene2007-Sep2008 y Abr2009-Dic2009. Asimismo, durante la crisis financiera internacional la salida de capitales se vio parcialmente reflejada en los forward compra realizadas contra la Banca Peruana $^{8}$, ante lo cual el BCRP realizo ventas de dólares en el mercado spot con la finalidad de evitar escenarios de iliquidez en el Sistema Financiero?.

Es importante resaltar el rol de la esterilización en el proceso de intervención cambiaria. Como resultado de una compra de dólares se inyectan soles a la economía, lo cual puede causar exceso de liquidez y en última instancia inflación. Ante esta situación, el BCRP realiza emisiones de valores para retirar el exceso de liquidez; la acción conjunta se denomina intervención esterilizada.

Tabla 2.4

Intervención Esterilizada en Perú. Periodos Múltiples.

\begin{tabular}{|ccc|}
\hline Descripción & ABR 2007-MAR 2008 & ABR 2010-MAR 2011 \\
\hline $\begin{array}{c}\text { Operaciones Cambiarias (Millones de } \\
\text { dólares) }\end{array}$ & 16,185 & 7,120 \\
\hline $\begin{array}{c}\text { Flujos de Emisión Primaria por } \\
\text { Operaciones Cambiarias (Millones de } \\
\text { soles) }\end{array}$ & 37,175 & 19,742 \\
\hline $\begin{array}{c}\text { Variación Interanual en Saldo de CD- } \\
\text { BCRP (Millones de soles) }\end{array}$ & 26,738 & 2,470 \\
\hline
\end{tabular}

Fuente 1 BCRP, Series Estadísticas Mensuales, revisado el 19 de Junio del 2014, http://estadisticas.bcrp.gob.pe/index.asp?sFrecuencia=M. Fuente 2 BCRP, Cuadro Estadístico 13 de la Nota Semanal, revisado el 19 de Junio del 2014, http://www.bcrp.gob.pe/estadisticas/cuadros-de-la-notasemanal.html

La Tabla 2.4 resume el efecto de las intervenciones esterilizadas en dos periodos de igual duración de la economía peruana. En ambos casos el flujo por operaciones cambiarias ha sido positivo, lo que supuso una

$8 \quad$ Venta desde el punto de vista de los Bancos, con signo negativo

$9 \quad$ No todas las operaciones forward incluidas en la Tabla 2.3 corresponden a no residentes. Sin embargo, se asume que siguen la misma tendencia que los volúmenes reflejados en cada periodo. Es decir, si en un periodo determinado las contrapartes al Sistema Bancario realizaron principalmente compras, los no residentes también lo hicieron, y viceversa. 
inyección de liquidez en Soles a la economía, visto por el Flujo de Emisión Primaria por Operaciones Cambiarias. Asimismo, se emitieron certificados de depósito para mitigar el exceso de liquidez, lo cual se refleja en la variación interanual en saldo de CD-BCRP. Cabe resaltar que la emisión de certificados fue mayor durante el periodo Abril 2007 - Marzo 2008, hecho que es explicado en parte por el mayor volumen de compras de dólares en el mercado spot por parte del BCRP durante dicho periodo.

Un último aspecto a considerar sobre las intervenciones esterilizadas es que la emisión de CD-BCRP puede atraer flujos de capitales debido a la rentabilidad que ofrecen, particularmente en escenarios donde el spread de tasas de interés con respecto al resto del mundo es elevado a favor de la economía peruana. Ante esta situación, el BCRP creó un nuevo instrumento, los CD-BCRP de negociación restringida, a través de la Circular Número 009 del año 2008 (BCRP, 2008). Este instrumento tiene la finalidad de evitar la negociación de dichos valores con no residentes. Posteriormente, en el tercer trimestre del 2010 la tenencia de CD-BCRP por parte de no residentes se redujo a prácticamente cero, debido a la sustitución de dichos instrumentos por depósitos a plazo fijos, con la finalidad de evitar su negociación con inversionistas extranjeros con fines especulativos. 


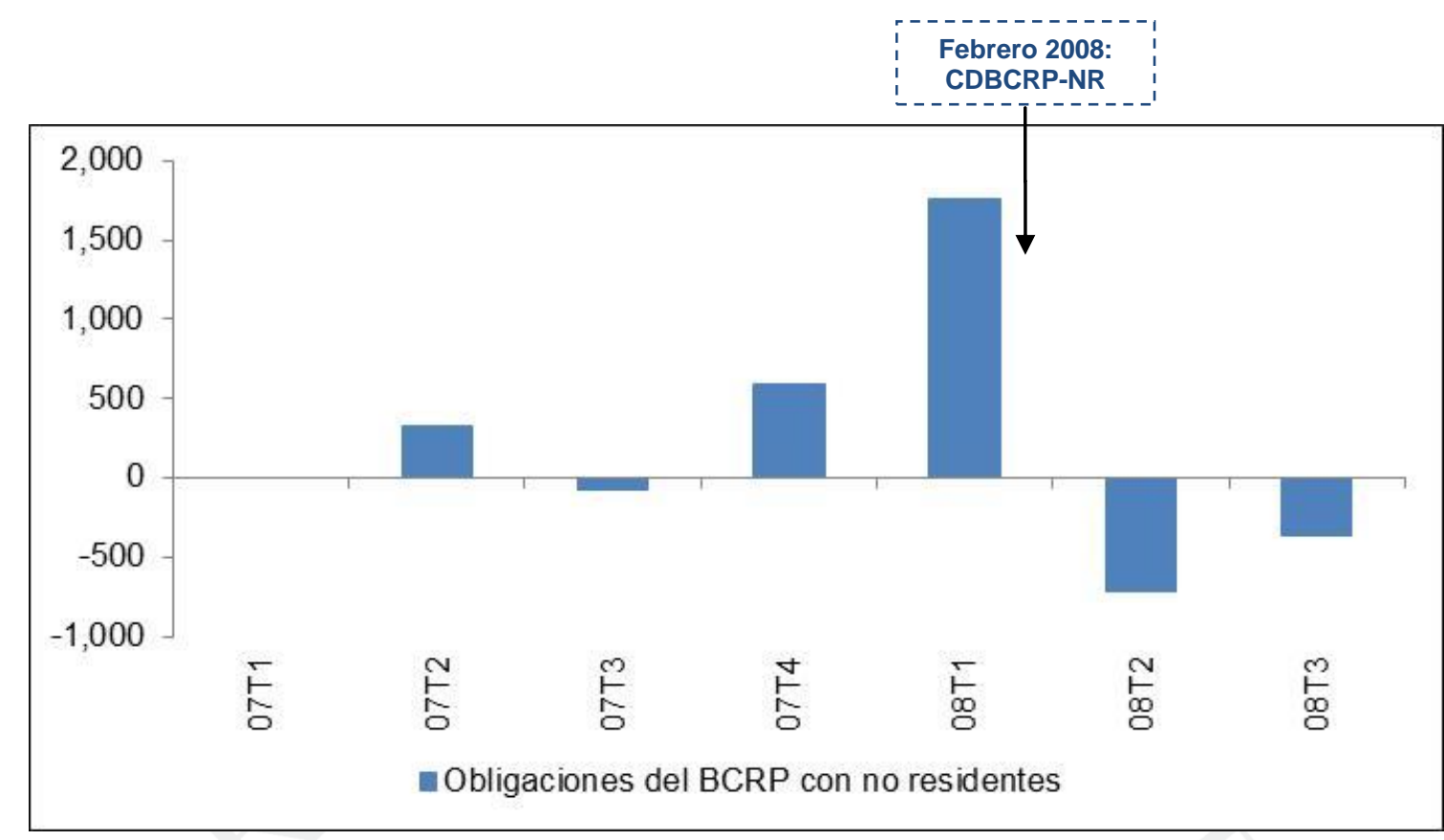

Figura 2.7 Obligaciones del BCRP con No Residentes. Periodo 2007-2008. (En Millones de dólares) Fuente BCRP, Cuadro Estadístico 96 de la Nota Semanal, revisado el 19 de Junio del 2014, http://www.bcrp.gob.pe/estadisticas/cuadros-de-la-nota-semanal.html.

\subsubsection{Medidas Adicionales}

De manera complementaria a las medidas de encaje y a las intervenciones cambiarias en el mercado spot, el BCRP, la SBS y el Ministerio de Economía y Finanzas (MEF) diseñaron un conjunto de políticas de carácter macroprudencial, orientadas (entre otros objetivos) a controlar los efectos de los flujos de capitales sobre la economía:

- Límites a la posición neta de derivados en moneda extranjera de la banca, la cual se calcula como el diferencial entre los forward compra y venta en ME pactados. Los límites han variado en tres ocasiones: en Enero del 2011 fue el mayor entre S/. 400 millones y el 40\% del Patrimonio efectivo; en Octubre del 2011, el mayor entre S/. 300 millones y el 35\% del Patrimonio efectivo; en Octubre del 2013, el mayor entre S/. 300 millones y el $20 \%$ del Patrimonio efectivo. Estas medidas permitieron amortiguar las presiones sobre el tipo de cambio producto de las operaciones forward realizadas por no residentes en busca de rentabilidad (profecía auto cumplida) (Choy y Chang, 2014).

- $\quad$ En Enero del 2011 el BCRP decidió incluir los pasivos de las sucursales del exterior de las entidades financieras locales dentro del 
total de obligaciones sujetas a encaje, en vista que el crédito que estas otorgaban a las empresas del sector privado doméstico estaban en aumento (Ibíd.).

- El BCRP ha incrementado en sucesivas ocasiones el límite de operativo de las AFP para inversiones en el exterior, fomentando así un medio de salida de dólares. Desde Octubre del 2006 hasta Diciembre del 2013, dicho límite ha pasado de $10.5 \%$ del portafolio total a $36.5 \%$ (Ibid). Esta medida ha permitido disminuir la presión del tipo de cambio hacia la baja.

\subsection{Interrelación entre encaje, flujos de capitales, crédito y tipo de cambio}

La relación entre el Encaje, los Flujos de Capitales, el Crédito y el Tipo de Cambio es compleja. La Figura 2.8 resume su interrelación y descompone los Flujos de Capitales en sus principales formas, así como el Encaje según moneda y tipología. 


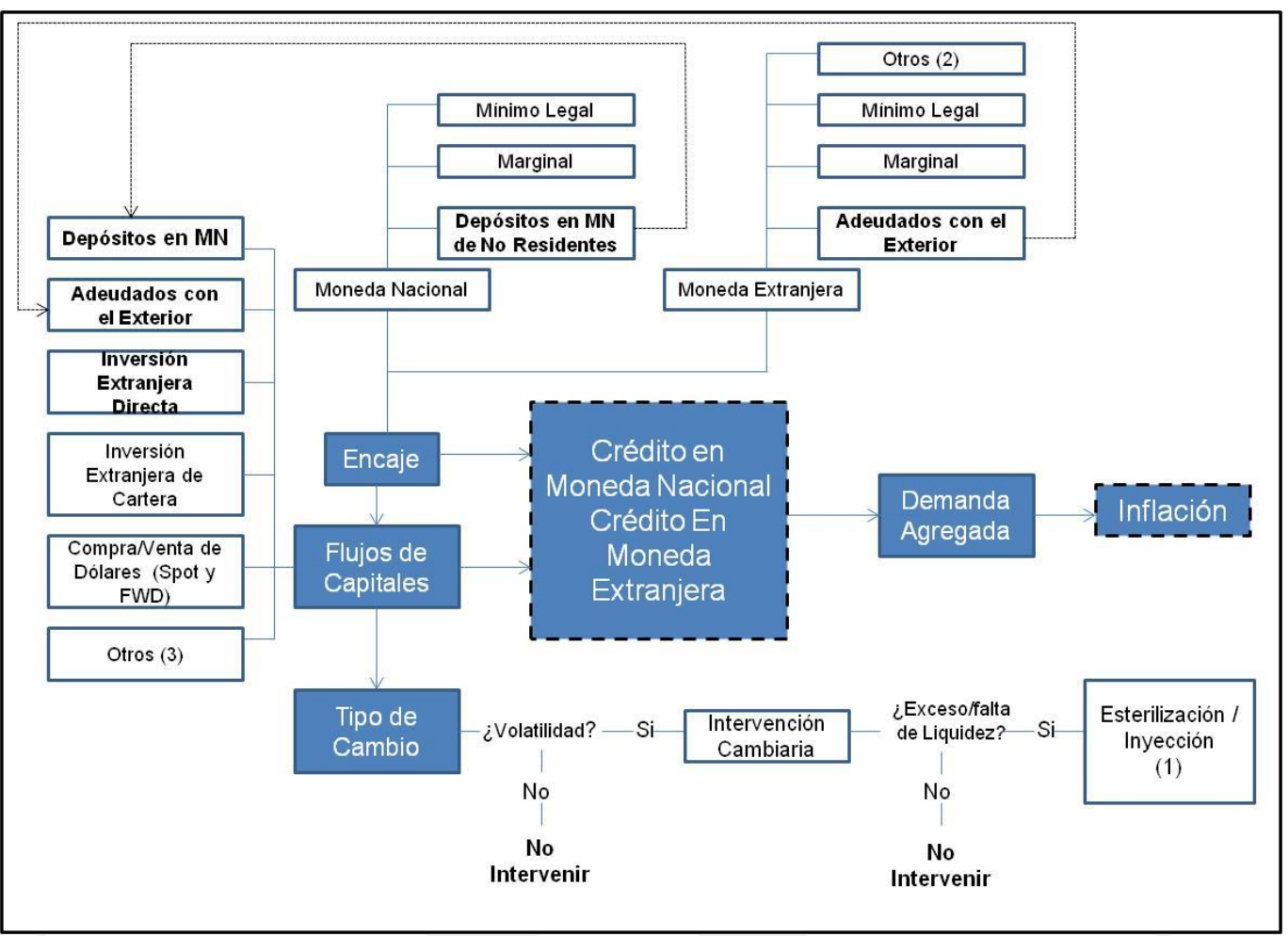

Figura 2.8 Interrelación entre Encaje, Flujos de Capitales y Crédito. Fuente Elaboración Propia. Nota 1: En escenarios de Influjos de capitales y altos diferenciales de tasas de interés con respecto al resto del mundo, se usan CD-BCRP de negociación restringida y/o Depósitos a Plazo Fijo para las intervenciones esterilizadas, con la finalidad de evitar aún más influjos de carácter especulativo. Nota 2: Incluye encajes específicos contra la dolarización financiera Nota 3: Incluye otros flujos de capitales de Corto y Largo Plazo, y la Cuenta Financiera del Sector Público

La primera relación que se puede notar en la Figura 2.8 es el efecto de los Flujos de Capitales sobre el Crédito al Sector Privado, tanto en MN como en ME. Para ver claramente este efecto, se ha distinguido cinco ${ }^{10}$ maneras en las cuáles se pueden representar los influjos. La Inversión Extranjera Directa tiene un efecto indirecto sobre el Crédito: al fomentar el desarrollo del Sector Privado no Financiero, se incentiva la demanda de préstamos en MN, tanto de consumo como para nuevas inversiones. Por otro lado, los Depósitos en MN de No Residentes y los Adeudados con el Exterior de las Empresas Bancarias tienen un efecto directo sobre la oferta de Crédito, ya que los intermediarios financieros disponen de más recursos ${ }^{11}$. Asimismo, las entradas de capitales especulativos en forma de compras de dólares (spot o forward) por parte de no residentes contra bancos domésticos ocasionan un incremento en la liquidez en moneda nacional de la banca, la cual puede traducirse en última instancia en una expansión del crédito en dicha moneda.

\footnotetext{
10 Obviando el caso "Otros"

11 En el caso de los Adeudados, un incentivo adicional es el menor costo de fondeo debido al diferencial entre las tasas de interés doméstica e internacional.
} 
En segundo lugar, un incremento en la política de Encaje del BCRP tiene un efecto directo sobre la oferta de Crédito de las Empresas Bancarias debido a la menor disponibilidad de liquidez, y representa un incentivo para las Empresas Bancarias de aumentar su margen financiero, debido al mayor costo de fondeo, lo cual afecta negativamente la demanda de Crédito del Sector Privado.

Asimismo, se ha distinguido entre los tipos de Encaje en MN y ME que implementa el BCRP, con la finalidad de identificar el efecto de los mismos sobre los Flujos de Capitales y su rol de complemento a la tasa de política. En escenarios de influjos de capitales con sobre-expansión del Crédito, un incremento de la tasa de referencia implica un aumento de las tasas activas y pasivas del sistema financiero, lo cual fomenta aún más el ingreso de capitales especulativos en busca de carry trade. Sin embargo, fijar un Encaje a los Depósitos en MN de no residentes incentiva a las Empresas Bancarias a disminuir sus tasas pasivas sólo para dicho mercado, disminuyendo así la rentabilidad del carry trade por parte de no residentes. Por otro lado, Encaje para los Adeudados con el Exterior de las Empresas Bancarias, distinguido por plazos $^{12}$, contribuye a alterar la composición de sus Pasivos, con la finalidad de evitar la dependencia del financiamiento de Corto Plazo, el cual representa un riesgo de liquidez en caso de un recorte abrupto de dicha fuente, y un riesgo de crédito en caso se use para financiar préstamos de largo plazo ${ }^{13}$.

Finalmente, es importante considerar el efecto de los flujos de capitales sobre el tipo de cambio. Tal como se puede apreciar en la Figura 2.8, las entradas/salidas de capitales que ocasionen volatilidad en el tipo de cambio, principalmente las de carácter especulativo como algunas operaciones forward de no residentes contra los bancos domésticos, justifican las intervenciones cambiarias por parte del BCRP. La compra/venta de dólares implica inyecciones o retiros de soles en la economía, respectivamente. Si el consecuente exceso o falta de Liquidez en $\mathrm{MN}$ pone en peligro el cumplimiento de la meta de inflación, se justifica el uso de operaciones

12 La distinción entre Adeudados de Corto y Largo Plazo es importante. Por ejemplo, en Octubre del 2007 se exoneró de Encaje a los Adeudados Externos de Largo Plazo de las Empresas Bancarias mayores a 2 años, mientas que el Encaje para Adeudados de Corto Plazo se mantuvo en $30 \%$.

El riesgo de crédito se refleja en el descalce de plazos 
monetarias para esterilizar o inyectar soles, tales como CD-BCRP y REPOs. Cabe mencionar que, en escenarios de influjos, las compras esterilizadas deben ser realizadas con CD-BCRP de Negociación Restringida o Depósitos a Plazo Fijo, para evitar el ingreso de más capitales especulativos. 


\section{CAPÍTULO III: CONTRASTACIÓN DE HIPÓTESIS}

En este capítulo se contrastarán las hipótesis de la investigación, utilizando las técnicas econométricas y/o estadísticas más adecuadas a cada caso. En el primer subapartado se definen los objetivos e hipótesis de manera formal. Posteriormente, se definirán las variables y la metodología que serán utilizadas. En el siguiente acápite se analizarán los resultados obtenidos. Finalmente, se presentan las conclusiones.

\subsection{Objetivos e hipótesis}

Los objetivos del presente trabajo son:

\section{Objetivo General}

Contrastar la existencia de una relación de largo plazo entre los adeudos con el exterior los bancos peruanos, particularmente los de corto plazo, y el crédito en moneda extranjera, tomando como referencia el periodo 2006-2013. De igual importancia, se desea evaluar el rol que han jugado los requerimientos de encaje sobre los adeudos.

\section{Objetivo Específico 1:}

Contrastar la existencia de una relación de largo plazo entre los adeudos con exterior de la banca, particularmente los de corto plazo, y el nivel de crédito en moneda extranjera.

\section{Objetivo Específico 2:}

Evaluar el impacto del encaje a los adeudos con el exterior de corto plazo de la banca sobre dichos adeudos.

Las hipótesis son: 


\section{Hipótesis General}

Existe una relación de largo plazo entre los adeudos con el exterior de la banca y el crédito en moneda extranjera, y los requerimientos de encaje han jugado un rol importante en suavizar la evolución de dichos adeudos.

\section{Hipótesis específica 1:}

Existe una relación de largo plazo entre los adeudos con el exterior de la banca, totales y de corto plazo, y el crédito en moneda extranjera.

\section{Hipótesis específica 2:}

El encaje a los adeudos con el exterior de corto plazo de los bancos peruanos ha sido eficaz en controlar la evolución de dichos adeudos.

\subsection{Especificación del modelo}

\subsubsection{Descripción de Variables Base}

A continuación se describen las variables base ${ }^{14}$ que serán usadas para contrastar las hipótesis planteadas en la investigación.

- Saldo de Crédito Bruto en Moneda Extranjera

Con la finalidad de contrastar la existencia de una relación de largo plazo entre los adeudos con el exterior de la banca y el crédito, se usará como variable operativa el saldo de crédito bruto en moneda extranjera ${ }^{15}$ de la banca de operaciones múltiple ${ }^{16}$.

\section{- Saldo de adeudos con el exterior de los bancos}

Según el glosario de términos financieros del portal de la SBS, los adeudos ${ }^{17}$ con el exterior de los bancos

\footnotetext{
14 Posteriormente dichas variables serán transformadas para poder realizar los análisis econométricos correspondientes

15 El Crédito Bruto se calcula a partir del Balance General de la Banca Múltiple. Se consideran los créditos vigentes, atrasados, refinanciados y reestructurados

16 La banca múltiple está compuesta por todas las entidades bancarias privadas

17 Se están usando la totalidad de los adeudos, sin distinguir entre monedas, debido a que, según la SBS, en promedio el $99 \%$ de los adeudos son en moneda extranjera.
} 
Comprenden las obligaciones de la empresa por obtención de recursos y financiamiento bajo distintas modalidades contractuales, de corto y largo plazo, contratados con las instituciones financieras del exterior que realizan intermediación financiera, similares a las empresas del sistema financiero del país, así como con organismos internacionales.

(SBS, 1 de Mayo de 2016).

Se usará como variable operativa el saldo de adeudos con el exterior de los bancos.

\section{- Encaje a los adeudados de corto plazo con el exterior de los} bancos

El encaje en cuestión es usado por el BCRP para inducir a los bancos a reducir su financiamiento con este tipo de deuda. De esta manera se minimiza el riesgo de un recorte abrupto en las fuentes de liquidez, y en última instancia la vulnerabilidad del Sistema Financiero; se utilizará la tasa de política de encaje.

\subsubsection{Análisis de la relación entre el encaje y los adeudos con el exterior de corto plazo}

Se espera que el encaje a los adeudos de corto plazo haya inducido a los bancos a reemplazar su financiamiento de corto plazo con el exterior por adeudos de largo plazo. Para ello, se utilizarán dos variables: el encaje a los adeudos de corto plazo, y el ratio entre los adeudos de corto plazo y los adeudos totales; se espera que exista una relación inversa y estadísticamente significativa entre dichas variables.

Es importante tener en consideración que el encaje es una variable de política, por lo que ha tenido pocos movimientos durante el periodo de referencia, mientras el ratio descrito constituye una serie de tiempo que varía mes a mes. Ello representa una complicación para utilizar los métodos de 
regresión lineales tradicionales, tales como Mínimos Cuadrados Ordinarios (MCO).

Una alternativa es categorizar ambas variables como binarias, y utilizar métodos de regresión de respuesta cualitativa (Molinero, 2003; Gujarati y Porter, 2010). Esto implica dos tareas: escoger los criterios para volver dicotómicas ${ }^{18}$ las variables iniciales (encaje a los adeudos de corto plazo, y el ratio entre los adeudos de corto plazo y los adeudos totales), y escoger la mejor metodología de regresión.

Con respecto al primer punto, se proponen las siguientes lógicas para realizar la categorización:

- Para el caso del encaje, la variable independiente, usar un criterio experto. En Mayo del 2008 el BCRP fijo la tasa de encaje a los adeudados de corto plazo con el exterior de en $45 \%$, lo cual coincide con el escenario de influjos de capitales previo a la crisis financiera internacional. Por ello, se escoge como punto de quiebre dicho valor para distinguir la variable dicotómica en dos categorías. Se considera que la política de encaje ha sido contractiva cuando la variable dicotómica es 1 (encaje >=45\%); caso contrario, se considera que la política de encaje ha sido laxa, en cuyo caso la variable dicotómica es 0.

- Para el ratio entre los adeudos de corto plazo y los adeudos totales, la variable dependiente, se propone dividir la variable en dos grupos usando como punto de quiebre un percentil. Con el objetivo de obtener varios escenarios y aumentar la robustez de las conclusiones, se escogen tres tipos de partición: según los percentiles 25, 50 y 75.

18 Dicotómica y binaria son sinónimos; ambas significan que la variable sólo pueda tomar dos valores; 0 o 1 
Tabla 3.1

Categorización del Ratio entre Adeudos de Corto Plazo y Adeudos Totales

según percentiles. Periodo 2006-2013.

\begin{tabular}{|ccc|}
\hline Rango $(\%)$ & Número de Meses & Cuartil \\
\hline$[15.7-26.0]$ & 24 & 1 \\
\hline$<26.0-37.1]$ & 24 & 2 \\
\hline$<37.1-57.2]$ & 24 & 3 \\
\hline$<57.2-79.5]$ & 24 & 4 \\
\hline
\end{tabular}

Fuente SBS, Boletín Estadístico de Banca Múltiple, revisado el 6 de Junio del 2015, http://sbs.gob.pe/app/stats/EstadisticaBoletinEstadistico.asp?p=1\#

En la Tabla 3.1 se ilustra la metodología de categorización para el ratio entre los adeudos de corto plazo y adeudos totales. Se ordenaron los valores del ratio de menor a mayor, y se particionaron en 4 grupos, cada uno con el mismo número de registros/meses (cuartiles). De esta manera, al hablar de una partición según el percentil 25 , lo que se quiere decir es que la variable dicotómica tomará el valor de 1 cuando el ratio en análisis se ubique en los cuartiles 2-4; caso contrario, tomará el valor de 0. La misma lógica aplica para las variables dicotómicas definidas según los percentiles 50 (cuartiles 3-4) y 75 (cuartil 4).

El segundo reto es escoger que método de regresión de respuesta cualitativa se debe utilizar. De las múltiples metodologías que existen, se realizará un análisis comparativo entre dos de las más comunes: el modelo lineal de probabilidad (MLP) y el modelo logit (Gujarati y Porter, 2010).

El MLP consiste en estimar la regresión dicotómica a través de MCO, bajo la siguiente especificación:

$$
Y_{i}=\beta_{1}+\beta_{2} X_{i}+u_{i}
$$

Donde $Y_{i}$ representa la variable dependiente, $X_{i}$ la variable independiente, $u_{i}$ es el término de error y $\beta_{1}, \beta_{2}$ son los parámetros a estimarse. El nombre del modelo se debe a que la expectativa condicional de $Y_{i}$ dado $X_{i}, E\left(Y_{i} \mid X_{i}\right)^{19}$, es equivalente a la probabilidad condicional de que el suceso ocurra dado $X_{i}$, formalmente, $P_{i}=\operatorname{Pr}\left(Y_{i}=1 \mid X_{i}\right)$ (Ibíd.).

Existen varias limitaciones técnicas en utilizar MCO en el caso de variables de respuesta cualitativa. Por ejemplo, el término de error no cumple 
el supuesto de normalidad y su varianza no es constante en el tiempo; ello implica que los estimadores son sesgados y no eficientes, es decir, no tienen varianza mínima en comparación a los demás estimadores posibles. Sin embargo, la mayor limitación del modelo MLP es que no hay certeza de que la probabilidad condicional de $\mathrm{Y}$ dado $\mathrm{X}, P i$, se ubique entre 0 y 1 ; es decir, puede estimar probabilidades negativas o mayores a 1. En estos casos, el procedimiento a seguir es el siguiente: cuando la probabilidad estimada es menor a 0 , se asume que es 0 , y cuando es mayor a 1 , se supone que es 1 (Ibid). Asimismo, otro limitante grave es que se asume un crecimiento lineal de $P i$ con respecto a $\mathrm{X}$.

Tabla 3.2

Ejemplo de relación lineal entre Xi y Pi en el modelo MLP

\begin{tabular}{|ccc|}
\hline Pi & Variación absoluta Pi & Xi \\
\hline 0.1 & - & 1 \\
\hline 0.2 & $0.1(0.2-0.1)$ & 3 \\
\hline 0.3 & $0.1(0.3-0.2)$ & $\cdots$ \\
\hline$\ldots$ & $\ldots$ & \\
\hline
\end{tabular}

Fuente Elaboración Propia

La Tabla 3.2 ilustra la gravedad del supuesto que exista una relación lineal entre $\mathrm{X}$ y $P i$. Conforme la variable independiente vaya incrementándose, se está asumiendo que $P i$ va a variar siempre en la misma proporción (en el ejemplo, 0.1 o $10 \%$ ), por lo cual no se admite crecimientos decrecientes en la probabilidad, hecho que resulta muy común en los fenómenos económicos ${ }^{20}$.

Evaluemos ahora el modelo logit. Para introducirlo, considérese la siguiente ecuación:

$$
P_{i}=\frac{1}{1+e^{-\left(\beta_{1}+\beta_{2} X_{i}+u_{i}\right)}}
$$

Donde $P_{i}$ es la probabilidad condicional de que la variable dependiente $Y_{i}$ sea igual a 1 dada la variable $X_{i}$. Después de algunas transformaciones algebraicas, se puede re-expresar la función anterior de la siguiente manera:

20 Por ejemplo, la probabilidad de adquirir una casa no se incrementa en la misma proporción cuando el ingreso de una persona crece de 10,000 a 20,000 en comparación a un crecimiento de $1,000,000$ a $1,010,000$ 


$$
L_{i}=\ln \left(\frac{P_{i}}{1-P_{i}}\right)=\beta_{1}+\beta_{2} X_{i}+u_{i}
$$

La ecuación anterior representa el modelo logit; en este caso, lo que se va a modelar es el logaritmo de la razón de probabilidades. Las principales características de este modelo son las siguientes (Ibíd.):

- Si bien el logaritmo del ratio de probabilidades no está acotado entre 0 y 1 , las probabilidades sí lo están por definición.

- $\quad$ Aunque el logaritmo es lineal en X, las probabilidades no lo son. De manera puntual, se admiten crecimientos decrecientes en la probabilidad $P_{i}$, a diferencia del modelo MLP.

Por lo antes expuesto, se concluye que el modelo logit es más útil para regresiones con variable dependiente binaria, en comparación al modelo MLP. Es importante que el método de estimación para este modelo varía según el tipo de datos a analizar: cuando se trata de datos agrupados, es posible estimar el modelo a través de $\mathrm{MCO}$; cuando los datos son individuales, se debe recurrir a métodos de máxima verosimilitud (Ibid). En el presente trabajo, los valores proporcionados para las variables dependientes están a nivel individual (para cada observación, el valor de la variable dicotómica es conocido).

Después de definir un método para categorizar al encaje y los adeudos, y habiendo escogido un modelo para estimar la relación entre dichas variables (logit), se procederá a realizar el análisis econométrico en el subapartado 3.3 .

\subsubsection{Análisis de la relación entre adeudos con el exterior y el crédito en moneda extranjera}

Para evaluar la relación de largo plazo entre los adeudos y el crédito en moneda extranjera se realizarán dos análisis de cointegración bivariables: en ambos casos la variable dependiente será el crédito, pero en uno la variable independiente será los adeudos totales, y en el otro los adeudos de corto plazo. Se espera que en ambos casos se halle una relación de largo plazo, de manera que puedan expresarse como mecanismos de corrección de errores (MCE) (Engle y Granger, 1987; Granger, 1983). 
Antes de entrar al detalle de la metodología de cointegración se repasarán brevemente algunos conceptos fundamentales de la econometría de series de tiempo: procesos estocásticos, estacionariedad, raíz unitaria y regresiones espurias.

De acuerdo a Gujarati y Porter (2010), “un proceso estocástico o aleatorio es una colección de variables aleatorias ordenadas en el tiempo" ( $p$. 740). Bajo esta definición, tanto los adeudos como el crédito en moneda extranjera son procesos estocásticos, pues cada valor de dichas series (i.e. cada mes) es la realización de una variable aleatoria. De manera puntual, si el crédito en moneda extranjera fue de 8.8 miles de millones de dólares en Enero del 2006, lo que se está observando es el resultado de un conjunto de posibilidades; bien pudo ser $8.7,8.75,8.9$, etc.

Ahora bien, definamos un proceso estocástico estacionario. Técnicamente,

(...) se dice que un proceso estocástico es estacionario si su media y su varianza son constantes en el tiempo, y si el valor de la covarianza entre dos periodos depende sólo de la distancia o rezago entre estos dos periodos, y no del tiempo en el cual se calculó la covarianza.

(Gujarati y Porter, 2010).

La razón más importante de estudiar la estacionariedad (o su ausencia) en las series de tiempo es que, si una serie es no estacionaria, sólo se pueden realizar conclusiones sobre su comportamiento durante el periodo de análisis; los hallazgos no se pueden extrapolar al futuro. Para entender este concepto a mayor detalle, vale la pena analizar el caso más simple de un proceso estocástico no estacionario: la caminata aleatoria sin deriva (MCA), que se puede expresar bajo la siguiente ecuación:

$$
Y_{t}=Y_{t-1}+u_{t}
$$

Donde $Y_{t}$ es una variable aleatororia, $Y_{t-1}$ su primer rezago y $u_{t}$ un termino de error con media 0 y varianza constante $\left(\sigma^{2}\right)$. Esta ecuación se puede re-escribir de la siguiente manera: 


$$
Y_{t}=Y_{0}+\sum_{i=0}^{t-1} u_{t-i}
$$

Donde $Y_{0}$ es el valor que tomo la serie en el momento 0 (i.e. al inicio), y la sumatoria de la derecha indica que el valor actual de la serie está determinado en gran parte por todos los choques aleatorios que han ocurrió hasta el presente. Técnicamente, dicha sumatoria se conoce como tendencia estocástica. Lo más importante a resaltar del modelo presentado es que tiene media constante $\left(Y_{0}\right)$, pero varianza no constante $\left(t \sigma^{2}\right)$, con lo cual se incumple uno de los requisitos de estacionariedad previamente mencionados (Ibíd.).

El siguiente concepto que debe tenerse en consideración para comprender el modelo de cointegración es el proceso estocástico de raíz unitaria. Considérese la siguiente manera de re-expresar la caminata aleatoria sin deriva:

$$
Y_{t}=p Y_{t-1}+u_{t} ;-1 \leq p \leq 1
$$

En el escenario descrito, si $p=1$ entonces el modelo se convierte en MCA; esta situación se conoce como problema de raíz unitaria, e incumple los supuestos de estacionariedad. A partir de este concepto surge una manera de comprobar la estacionariedad en una serie de tiempo: que $|p|<1$. Es importante mencionar que una serie puede ser estacionaria alrededor de una tendencia; por ejemplo, en la siguiente ecuación (extensión del MCA):

$$
Y_{t}=\beta_{0}+\beta_{t} t+p Y_{t-1}+u_{t}
$$

Si $\beta_{0}$ y $\beta_{1}$ son distintos a 0 y $|p|<1$, entonces se dice que la serie $Y_{t}$ es estacionaria alrededor de una tendencia determinista (i.e. tendencia que puede ser predicha, y consecuentemente modelada) (Ibíd.).

Existen varias maneras de identificar la presencia de estacionariedad en una serie de tiempo: análisis gráfico, correlogramas, etc. Sin embargo, la más certera es realizar una prueba de hipótesis que contraste si $|p|<1$. Ese es precisamente el objetivo de la prueba de Dickey-Fuller aumentada (DFA) (Dickey y Fuller, 1979). A continuación se presenta dicha prueba en sus tres tipos de especificación, con las hipótesis respectivas y las decisiones a tomar según sea el caso: 


$$
\Delta Y_{t}=\emptyset_{1} Y_{t-1}+\sum_{i=1}^{t-1} \gamma_{i} \Delta Y_{t-1}+\varepsilon_{t}
$$

Hipótesis nula: $\emptyset_{1}=0$ (la serie es no estacionaria, y debe ser diferenciada)

Hipótesis alternativa: $\emptyset_{1}<0$ (la serie es estacionaria, y no necesita ser diferenciada)

$$
\Delta Y_{t}=\emptyset_{1}+\emptyset_{2} Y_{t-1}+\sum_{i=1}^{t-1} \gamma_{i} \Delta Y_{t-1}+\varepsilon_{t}
$$

Hipótesis nula: $\emptyset_{2}=0$ (la serie es no estacionaria, y debe ser diferenciada)

Hipótesis alternativa: $\emptyset_{2}<0$ (la serie es estacionaria, y no necesita ser diferenciada)

$$
\Delta Y_{t}=\emptyset_{1}+\emptyset_{2} t+\emptyset_{3} Y_{t-1}+\sum_{i=1}^{t-1} \gamma_{i} \Delta Y_{t-1}+\varepsilon_{t}
$$

Hipótesis nula: $\emptyset_{3}=0$ (la serie es no estacionaria, y debe ser diferenciada)

Hipótesis alternativa: $\emptyset_{3}<0$ (la serie es estacionaria alrededor de una tendencia lineal, la cual debe ser extraída en vez de diferenciar la serie para que esta sea estacionaria)

En cada caso, $\Delta$ es un operador de diferencia $\left(\Delta Y_{t}=Y_{t}-Y_{t-1}\right)$. Cuando se dice que la serie debe ser diferenciada, significa que se le debe extraer su primer rezago. Volviendo al ejemplo del MCA:

$$
Y_{t}-Y_{t-1}=u_{t}
$$

En esta ecuación se puede apreciar que, al tomar la primera diferencia, la serie en cuestión se vuelve estacionaria (por definición, $u_{t}$ es estacionaria). Este ejemplo resulta ilustrativo para entender la teoría subyacente de tomar diferencias de una seria en presencia de raíz unitaria. Cuando una serie es estacionaria después de una diferencia, se dice que es integrada de orden 1. 
De manera más general, se dice que una serie de tiempo es integrada de orden $n$ cuando es estacionaria después de $n$ diferencias.

Finalmente, es importante tener en consideración el siguiente riesgo, descubierto inicialmente por Yule (1926): cuando se realiza una regresión (por ejemplo, utilizando el método de mínimos cuadrados ordinarios) entre dos series de tiempo no estacionarias, aunque las pruebas de relevancia individual (estadístico T) señalen que existe una relación significativa, es posible que el resultado sea espurio o sin sentido. Por ello, se debe tener cuidado al interpretar los resultados. Como regla práctica, si la medida de bondad de ajuste $R^{2}$ en un modelo es mayor que el estadístico $d$ (Durbin y Watson, 1951) que mide la presencia de autocorrelación en el término de error, se puede tomar esta evidencia como un buen indicio que la regresión espuria (Granger y Newbold, 1974).

Habiendo expuesto estos conceptos, se puede entrar al detalle de la metodología de cointegración. Considérense dos series de tiempo no estacionarias, $Y_{t}$ y $X_{t}$. Al realizar una regresión entre ambas, es posible que ocurra el fenómeno de la regresión espuria. No obstante, si las series en cuestión son ambas estacionarias después de haber sido diferenciadas (estacionarias en primera diferencia, o integradas de orden 1), es posible que ambas compartan una tendencia estocástica en común. Si esto ocurre, la regresión no será necesariamente espuria; a este hecho se le conoce como cointegración, y la interpretación en términos económicos es que existe una relación de largo plazo entre ambas variables (Gujarati y Porter, 2010; Granger, 1986). Formalmente, la cointegración se expresa bajo la siguiente ecuación:

$$
Y_{t}=\beta_{0}+\beta_{1} X_{t}+u_{t}
$$

Donde $Y_{t}$ y $X_{t}$ son ambas series de tiempo estacionarias en primera diferencia. Si se cumple que $u_{t}$ es estacionaria, entonces se concluye que las series en cuestión están cointegradas, y la relación de largo plazo entre ambas puede ser expresada a través del método de mínimos cuadrados ordinarios. La regresión descrita se conoce como regresión cointegrante, y $\beta_{1}$ es el parámetro cointegrante que determina la relación de largo plazo entre $Y_{t}$ y $X_{t}$. 
Para comprobar si $u_{t}$ es estacionaria, lo más lógico sería utilizar la prueba Dickey-Fulley aumentada. Sin embargo, es importante tener en consideración lo siguiente: como $u_{t}$ se basa en un estimador, $\beta_{1}$, y no en valores reales, los valores críticos de significancia de la prueba DFA no son los más apropiados. Por ello, Engle y Granger (1987) calcularon valores críticos específicos a este caso. Dichos valores serán presentados y utilizados en la etapa de contrastación empírica de los resultados.

Se concluye la presentación teórica del modelo con el siguiente concepto. Si bien la ecuación $Y_{t}=\beta_{0}+\beta_{1} X_{t}+u_{t}$ puede establecer una relación de largo plazo entre las variables, es posible que exista un desequilibro en el corto plazo. Para ello, es útil considerar el término $u_{t}$ como el error de equilibrio; esta variable servirá, para expresar una relación de corto plazo entre las variables $Y_{t}$ y $X_{t}$. De acuerdo al teorema de representación de Granger (Granger, 1983), si dos variables están cointegradas, entonces la relación de corto plazo entre ambas se expresa a través de un mecanismo de corrección de errores (MCE):

$$
\Delta Y_{t}=\delta_{0}+\delta_{1} \Delta X_{t}+\delta_{2} u_{t-1}+\varepsilon_{t}
$$

Donde $u_{t-1}$ es el rezago del error en la ecuación cointegrante, y $\varepsilon_{t}$ es el error del modelo, que se espera sea un proceso estacionario. En el MCE se puede establecer una relación de corto plazo entre las variables a través del estimador $\delta_{1}$. Además, el rezago del error de equilibrio juega un rol importante: si difiere de cero, ello implica que el MCE no está en equilibrio. De manera específica, el estimador $\delta_{2}$ (que se espera sea negativo) determina la rapidez con que la variable dependiente, $Y_{t}$, regresa a su valor de equilibrio.

Recapitulando, el enfoque de la investigación es evaluar si existe una regresión cointegrante entre los adeudos, expresados en dos escenarios (corto plazo y totales), y el crédito en moneda extranjera; de ser así, la relación de corto plazo entre las variables será expresada como un MCE. 


\subsubsection{Descripción de Variables Finales}

Las Tablas 3.3 y 3.4 resumen las variables que serán usadas en la investigación, los acrónimos respectivos, las unidades de medición y las fuentes. Los datos abarcan el periodo Enero 2006 - Diciembre 2013 y son de periodicidad mensual ${ }^{21}$.

\section{Tabla 3.3}

Resumen de variables - relación entre encaje y adeudos

\begin{tabular}{|c|c|c|c|c|}
\hline Definición & Nomenclatura & Tipo & Unidades & Fuente \\
\hline $\begin{array}{c}\text { Ratio Adeudos CP / } \\
\text { Adeudos Totales }\end{array}$ & AEC_AET & Ratio & $\%$ & $\begin{array}{c}\text { Boletín estadístico de la } \\
\text { Banca Múltiple }\end{array}$ \\
\hline $\begin{array}{c}\text { Dummy de Ratio } \\
\text { Adeudos CP / Adeudos } \\
\text { Totales según perc. } 25\end{array}$ & DU_AEC_AET_25 & Binaria & 0 ó 1 & $\begin{array}{c}\text { Boletín estadístico de la } \\
\text { Banca Múltiple }\end{array}$ \\
\hline $\begin{array}{c}\text { Dummy de Ratio } \\
\text { Adeudos CP / Adeudos } \\
\text { Totales según perc. } 50\end{array}$ & DU_AEC_AET_50 & Binaria & 0 ó 1 & $\begin{array}{c}\text { Boletín estadístico de la } \\
\text { Banca Múltiple }\end{array}$ \\
\hline $\begin{array}{c}\text { Dummy de Ratio } \\
\text { Adeudos CP / Adeudos } \\
\text { Totales según perc. } 75\end{array}$ & DU_AEC_AET_75 & Binaria & 0 ó 1 & $\begin{array}{c}\text { Boletín estadístico de la } \\
\text { Banca Múltiple }\end{array}$ \\
\hline $\begin{array}{l}\text { Encaje a los adeudos } \\
\text { de corto plazo }\end{array}$ & ENC & Nominal & $\%$ & $\begin{array}{c}\text { Solicitud de información } \\
\text { al BCRP }\end{array}$ \\
\hline $\begin{array}{l}\text { Dummy de Política de } \\
\text { Encaje }\end{array}$ & DU_ENC & Binaria & 0 ó 1 & $\begin{array}{c}\text { Solicitud de información } \\
\text { al BCRP }\end{array}$ \\
\hline
\end{tabular}

Fuente Elaboración Propia

21 Se consideran sólo las entidades que pertenecen a la Banca Múltiple, según la definición de la SBS. Principalmente se están excluyendo entidades microfinancieras y cajas, pues tienen menor acceso al mercado internacional de capitales, y consecuentemente son menos proclives a endeudarse con el exterior 
Tabla 3.4

Resumen de variables - relación entre adeudos y crédito

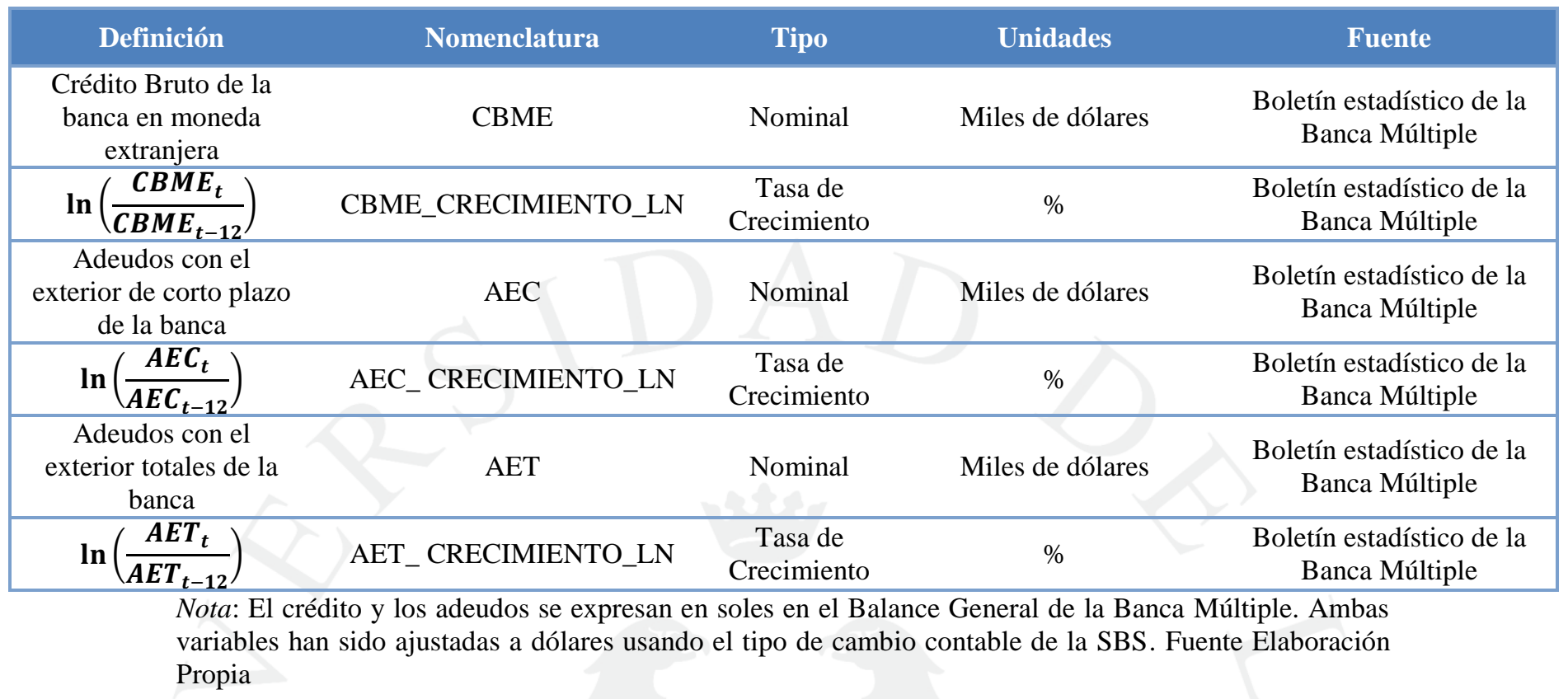

\subsection{Análisis de resultados}

El análisis de los resultados se realizará en tres partes. En primer lugar se evaluará el impacto de la política de encaje sobre los adeudos de corto plazo con el exterior de la banca. Posteriormente se analizará la existencia de una relación de largo plazo entre los adeudos y el crédito. Finalmente, se realizará una simulación que ilustra lo que podría haber sucedido en caso el encaje en cuestión nunca hubiera superado el nivel de $45 \%$.

\subsubsection{Impacto de la política de encaje}

En este sub-apartado se estiman tres modelos logit para evaluar el impacto del encaje sobre el ratio entre adeudos de corto plazo y adeudos totales, bajo los escenarios definidos en el sub-apartado 3.2. Se espera que la relación sea inversa y estadísticamente significativa. Previamente, se analizará de manera general la relación entre las variables en cuestión, antes de ser categorizadas. 
- Análisis gráfico

Antes de realizar el análisis econométrico, se hará una inspección gráfica de las variables en consideración. Ello dará una idea general de la relación entre dichas variables ${ }^{22}$.

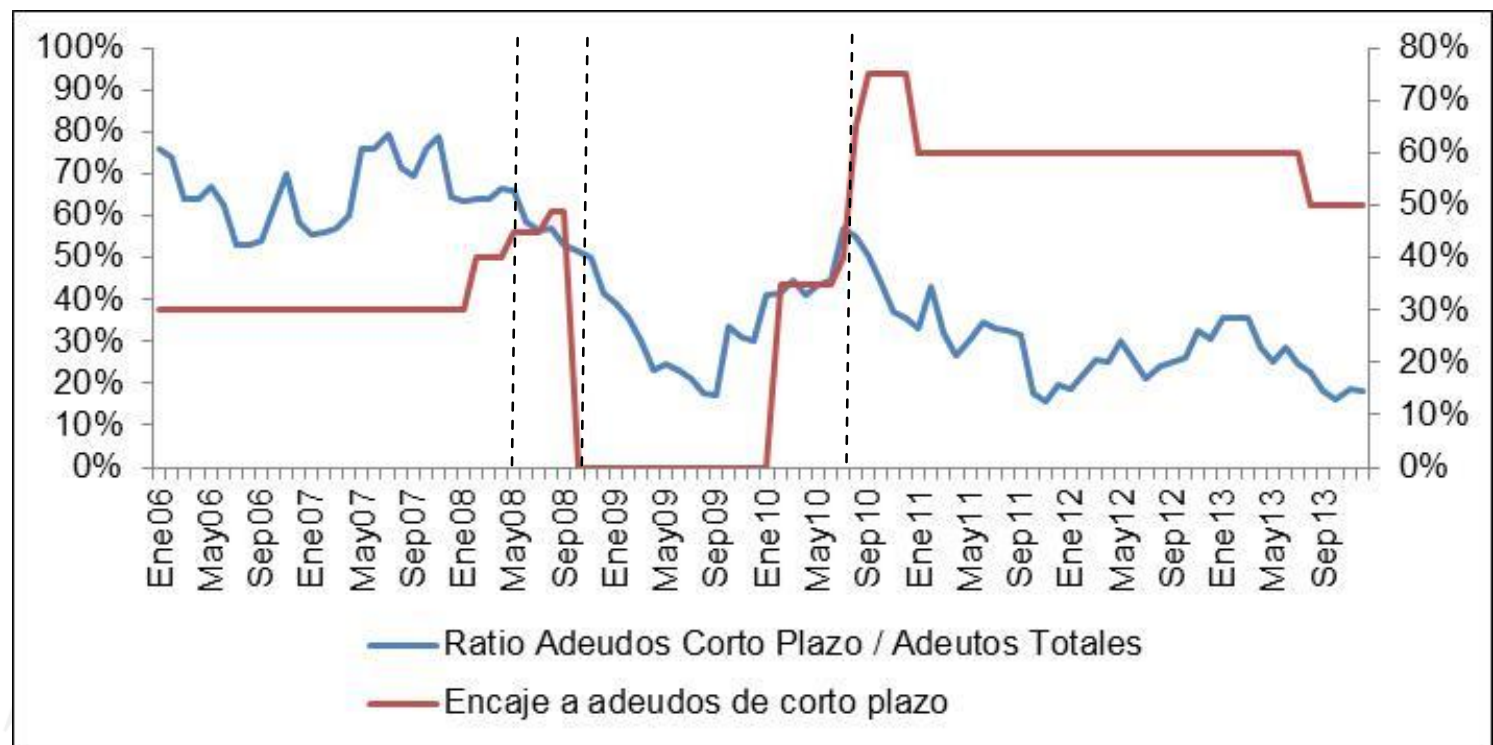

Figura 3.1 Ratio de adeudos de corto plazo entre adeudos totales (eje izquierdo) y encaje a adeudos de corto plazo (eje derecho). Periodo 2006-2013. (En \%) Fuente 1 SBS, Boletín Estadístico de la Banca

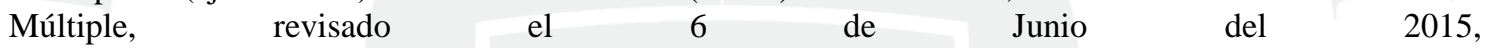
http://www.sbs.gob.pe/app/stats/EstadisticaBoletinEstadistico.asp?p=1. Fuente 2 BCRP, Solicitud de información a la Subgerencia de Política Monetaria, solicitado el 3 de Diciembre del 2016

La Figura 3.1 demuestra la evolución conjunta del ratio y el encaje. Se pueden distinguir 4 periodos. El primer periodo data desde Enero del 2006 hasta Abril del 2008, y se caracteriza porque el ratio se mantiene relativamente estable, en valores cercanos a $65 \%$, y el encaje está prácticamente fijo en $30 \%$.

En Mayo del 2008 se inicia el segundo periodo, con un alza en el encaje a $45 \%{ }^{23}$ y el ratio comenzó a disminuir, pasando de $66 \%$ a $53 \%$ hasta Setiembre de dicho año.

En Setiembre del mismo año se inicia un tercer periodo, con el retiro del encaje a los adeudos, debido a la crisis financiera internacional y para evitar una fuga de capitales. Empero, el ratio siguió cayendo, debido al efecto histéresis por la crisis. Cabe mencionar que durante los meses posteriores a la crisis tanto los adeudos de corto plazo como los de largo

\footnotetext{
22 Un análisis similar ha sido realizado a partir de la Figura 2.5, en el capítulo 2

23 Pocos meses antes, específicamente en Febrero, se había elevado el encaje de 30 a 40\%, pero el impacto sobre el ratio recién se hizo evidente con el alza a $45 \%$
} 
plazo se reducen, aunque los primeros en mayor proporción, lo cual explica la caída en el ratio (ver Figura 2.5). Sin embargo, cuando el nerviosismo por la crisis parece reducirse, los capitales de corto plazo vuelven a ingresar a la economía peruana, y la tendencia del ratio se revierte al alza aproximadamente en Octubre del 2009. En ausencia del encaje, dicho ratio se eleva rápidamente.

El cuarto y último periodo se caracteriza por una nueva alza del encaje en niveles superiores a 45\%, en Agosto del 2010, hecho que detiene (y revierte) la tendencia al alza del ratio, regresando a niveles relativamente bajos en comparación a años anteriores.

El análisis realizado sugiere que existe una relación negativa entre el encaje y el ratio de adeudos de corto plazo y adeudos totales. El siguiente paso es contrastar esta hipótesis usando técnicas econométricas.

- Escenario 1: Variable dependiente categórica DU_AEC_AET_75

En el primer escenario se considera como dependiente la variable categórica DU_AEC_AET_75 definida en la Tabla 3.3, que representa al ratio de adeudos de corto plazo y adeudos totales. Los resultados de la regresión logística se muestran a continuación. 
Tabla 3.5

Resultado de modelo Logit considerando como variable dependiente

DU_AEC_AET_75

\begin{tabular}{|c|c|c|c|c|}
\hline \multicolumn{5}{|c|}{$\begin{array}{l}\text { Dependent Variable: DU_AEC_AET_75 } \\
\text { Method: ML - Binary Logit (Quadratic hill climbing) } \\
\text { Date: 02/12/16 Time: } 21: 41 \\
\text { Sample: 2006M01 2013M12 } \\
\text { Included observations: } 96 \\
\text { Convergence achieved after } 5 \text { iterations } \\
\text { Covariance matrix computed using second derivatives }\end{array}$} \\
\hline \multicolumn{5}{|c|}{$\begin{array}{llll}\text { Variable } & \text { Coefficient } & \text { Std. Error } & \text { z-Statistic } \\
\end{array}$} \\
\hline \begin{tabular}{l}
\multicolumn{1}{|c}{ DU_ENC } \\
\multicolumn{1}{c}{ C } \\
McFadden R- \\
squared \\
S.D. dependent var \\
Akaike info criterion \\
Schwarz criterion \\
Hannan-Quinn criter. \\
Restr. Deviance \\
LR statistic \\
Prob(LR statistic) \\
Obs with Dep=0 \\
Obs with Dep=1
\end{tabular} & $\begin{array}{l}-2.849880 \\
-0.241162\end{array}$ & $\begin{array}{l}0.777108 \\
0.284901\end{array}$ & $\begin{array}{l}-3.667292 \\
-0.846475\end{array}$ & $\begin{array}{l}0.0002 \\
0.3973\end{array}$ \\
\hline $\begin{array}{l}\text { McFadden R- } \\
\text { squared } \\
\text { S.D. dependent var } \\
\text { Akaike info criterion } \\
\text { Schwarz criterion } \\
\text { Hannan-Quinn criter. } \\
\text { Restr. Deviance } \\
\text { LR statistic } \\
\text { Prob(LR statistic) }\end{array}$ & $\begin{array}{ll}0.212300 & \text { Mean dependent var } \\
0.435286 & \text { S.E. of regression } \\
0.927570 & \text { Sum squared resid } \\
0.980994 & \text { Log likelihood } \\
0.949165 & \text { Deviance } \\
107.9683 & \text { Restr. log likelihood } \\
22.92164 & \text { Avg. log likelihood } \\
0.000002 & \\
\end{array}$ & $\begin{array}{l}\text { Mean dependent var } \\
\text { S.E. of regression } \\
\text { Sum squared resid } \\
\text { Log likelihood } \\
\text { Deviance } \\
\text { Restr. log likelihood } \\
\text { Avg. log likelihood }\end{array}$ & \multicolumn{2}{|r|}{$\begin{array}{r}0.250000 \\
0.389121 \\
14.23304 \\
-42.52336 \\
85.04671 \\
-53.98417 \\
-0.442952\end{array}$} \\
\hline $\begin{array}{l}\text { Obs with Dep }=0 \\
\text { Obs with Dep }=1\end{array}$ & \multicolumn{2}{|r|}{ Total obs } & \\
\hline
\end{tabular}

Fuente Elaboración Propia en Eviews 7

A partir de estos resultados, se pueden realizar varias deducciones. En primer lugar, el estadístico asociado a la variable categórica que representa al encaje, DU_ENC, es estadísticamente significativo a un 99\% de confianza, con signo negativo, como era esperado. Con respecto al estadístico de razón de verosimilitud (LR Statistic), si bien es significativo a un $99 \%$ de confianza, es dicha prueba sólo resulta útil cuando se utilizan varias variables independientes en el modelo; en vista que el presente caso sólo considera una variable independiente, resulta redundante analizar dicho estadístico.

Sobre la bondad de ajuste del modelo, Gujarati y Porter (2010) señalan que la medida convencional, el $R^{2}$, tiene un valor limitado; es decir, es probable que el calculo sea muy inferior a 1 en este tipo de modelos. Por 
ello, sugieren algunas medidas alternativas: $R^{2}$ McFadden y Cuenta $R^{2}$. El primero es calculado por el programa econométrico Eviews, mientras el segundo se obtiene bajo la siguiente fórmula:

$$
\text { Cuenta } R^{2}=\frac{\text { Número de predicciones correctas }}{\text { Número de observaciones totales }}
$$

Donde el número de observaciones totales es 96 (número de meses en el periodo de referencia); para el cálculo del número de predicciones correctas, se realiza la siguiente transformación: si la probabilidad pronosticada por el modelo logit es mayor o igual a $50 \%$, se toma como valor 1; caso contario, el valor es 0 . Dicha transformación se compara con los valores originales ( 0 y 1$)$, y en función a ello se determinan las predicciones correctas.

En el modelo presentado en la Tabla 3.5, dichos valores son de $21.2 \%$ y $75 \%$, respectivamente. A grandes rasgos, el segundo indicador señala que la bondad de ajuste del modelo es buena $(>=75 \%)$, y se toma como referencia; sin embargo, “(...) en los modelos con regresada binaria, la bondad del ajuste tiene una importancia secundaria. Lo que interesa son los signos esperados de los coeficientes de la regresión y su importancia práctica y/o estadística" (Ibid).

Los análisis realizados indican que el modelo es consistente en términos estadísticos. El siguiente paso consiste en estimar la razón de probabilidades, propia del modelo logit, y en última instancia las probabilidades puntuales y dar una interpretación económica.

Para estimar la razón de probabilidades, se toma como referencia la siguiente ecuación, especificada en el sub-apartado 3.2:

$$
L_{i}=\ln \left(\frac{P_{i}}{1-P_{i}}\right)=\beta_{1}+\beta_{2} X_{i}+u_{i}
$$

En vista que ya se tienen los valores de los estimadores del modelo, se procede a calcular el ratio de razón de probabilidades, bajo la siguiente ecuación ${ }^{24}$ :

\footnotetext{
24 Se excluye el término de error para estimar las probabilidades puntuales, pues de lo contrario se obtendría siempre el valor observado en cada mes
} 


$$
\left(\frac{P_{i}}{1-P_{i}}\right)=e^{-0.241162-2.849880 X_{i}}
$$

Las probabilidades puntuales se derivan de dicha ecuación, a partir de una transformación algebraica. En la siguiente Tabla se presentan las probabilidades calculadas para cada valor de la variable independiente:

Tabla 3.6

Probabilidades de modelo Logit considerando como variable dependiente DU_AEC_AET_75

\begin{tabular}{|ccc|}
\hline Variable Independiente & $\mathbf{0}$ & $\mathbf{1}$ \\
\hline Razón de probabilidades & 0.79 & 0.05 \\
\hline Prob. condicional (V. Dep=1) & $44.00 \%$ & $4.35 \%$ \\
\hline Prob. condicional (V. Dep=0) & $56.00 \%$ & $95.65 \%$ \\
\hline
\end{tabular}

Fuente Elaboración Propia

La lectura de la Tabla 3.6 es la siguiente: cuando la variable independiente (DU_ENC) toma el valor de 1, la probabilidad que la variable dependiente sea 1 es de sólo $4.35 \%$, mientras que la probabilidad que sea 0 es de 95.65\%; la razón de probabilidades se calcula a partir del ratio de dichas estimaciones, y es de $4.55 \%$. La misma lectura aplica cuando la variable independiente es 0 . En términos económicos, el resultado está alineado a lo esperado con la investigación: cuando el encaje a los adeudos de corto plazo ha sido mayor o igual a $45 \%$, la probabilidad de que el ratio entre adeudos de corto plazo y adeudos totales sea menor o igual a $57.2 \%$ (percentil 75 según Tabla 3.1) es de $95.65 \%$. Si bien esta probabilidad es muy sugerente, es importante comprobar si la magnitud del impacto es realmente alta. Ello se podrá contrastar en los siguientes escenarios, en los cuales la variable dependiente se calcula bajo definiciones más ácidas.

- Escenario 2: Variable dependiente categórica DU_AEC_AET_50

En el segundo escenario se considera como dependiente la variable categórica DU_AEC_AET_50. Se realizarán los mismos análisis que en el escenario previo, razón por la cual algunas definiciones teóricas (ej.: ecuaciones) serán omitidas para evitar redundancia. 
Tabla 3.7

Resultado de modelo Logit considerando como variable dependiente

DU_AEC_AET_50

Dependent Variable: DU_AEC_AET_50

Method: ML - Binary Logit (Quadratic hill climbing)

Date: 02/09/16 Time: 21:57

Sample: 2006M01 2013M12

Included observations: 96

Convergence achieved after 3 iterations

Covariance matrix computed using second derivatives

\begin{tabular}{|crrrr|}
\hline \hline Variable & Coefficient & Std. Error & z-Statistic & Prob. \\
\hline \hline DU_ENC & -2.679360 & 0.504666 & -5.309170 & 0.0000 \\
C & 1.265666 & 0.341394 & 3.707345 & 0.0002 \\
\hline
\end{tabular}

\begin{tabular}{|lrlr|}
\hline \hline McFadden R-squared & 0.262363 & Mean dependent var & 0.500000 \\
S.D. dependent var & 0.502625 & S.E. of regression & 0.410230 \\
Akaike info criterion & 1.064248 & Sum squared resid & 15.81913 \\
Schwarz criterion & 1.117672 & Log likelihood & -49.08392 \\
Hannan-Quinn criter. & 1.085843 & Deviance & 98.16784 \\
Restr. deviance & 133.0843 & Restr. log likelihood & -66.54213 \\
LR statistic & 34.91642 & Avg. log likelihood & -0.511291 \\
Prob(LR statistic) & 0.000000 & & \\
\hline \hline Obs with Dep=0 & 48 & Total obs & \\
Obs with Dep=1 & 48 & & \\
\hline \hline
\end{tabular}

Fuente Elaboración Propia en Eviews 7

El modelo presentado en la Tabla 3.7 indica que la variable independiente, DU_ENC, es estadísticamente significativa a un nivel de confianza de 99\%. Asimismo, los indicadores de bondad de ajuste $R^{2}$ McFadden y Cuenta $R^{2}$ son $26.2 \%$ y $79.1 \%$, respectivamente. En conjunto, estos análisis indican que el modelo está bien especificado.

Con respecto a las probabilidades puntuales y la razón de probabilidades, se presentan en la siguiente Tabla: 
Tabla 3.8

Probabilidades de modelo Logit considerando como variable dependiente DU_AEC_AET_50

\begin{tabular}{|ccc|}
\hline Variable Independiente & 0 & 1 \\
\hline Razón de probabilidades & 3.55 & 0.24 \\
\hline Prob. condicional (V. Dep=1) & $78.00 \%$ & $19.57 \%$ \\
\hline Prob. condicional (V. Dep=0) & $22.00 \%$ & $80.43 \%$ \\
\hline
\end{tabular}

Fuente Elaboración Propia

Los resultados en la Tabla 3.8 indican que la probabilidad de que el ratio entre adeudos de corto plazo y adeudos totales sea menor o igual a $37.1 \%$ (percentil 50 según Tabla 3.1) es de $80.43 \%$ cuando el encaje a los adeudos de corto plazo es mayor o igual a $45 \%$. Este resultado está en línea con lo esperado, tanto en direccionalidad (relación inversa entre las variables del modelo) como en magnitud; si bien la probabilidad de $80 \%$ es alta, es menor en comparación al escenario 1, debido a la definición más ácida de la categorización para la variable dependiente.

- Escenario 3: Variable dependiente categórica DU_AEC_AET_25

En el tercer y último escenario de análisis se considera como dependiente la variable categórica DU_AEC_AET_25. Al igual que en el escenario anterior, los resultados serán presentados de manera más resumida. 
Tabla 3.9

Resultado de modelo Logit considerando como variable dependiente

DU_AEC_AET_25

Dependent Variable: DU_AEC_AET_25

Method: ML - Binary Logit (Quadratic hill climbing)

Date: 02/09/16 Time: 21:57

Sample: 2006M01 2013M12

Included observations: 96

Convergence achieved after 3 iterations

Covariance matrix computed using second derivatives

\begin{tabular}{|crrrr|}
\hline \hline Variable & Coefficient & Std. Error & z-Statistic & Prob. \\
\hline \hline DU_ENC & -1.550597 & 0.529776 & -2.926892 & 0.0034 \\
C & 1.992430 & 0.435193 & 4.578270 & 0.0000 \\
\hline
\end{tabular}

\begin{tabular}{|lrlr|}
\hline \hline McFadden R-squared & 0.089820 & Mean dependent var & 0.750000 \\
S.D. dependent var & 0.435286 & S.E. of regression & 0.415607 \\
Akaike info criterion & 1.065319 & Sum squared resid & 16.23652 \\
Schwarz criterion & 1.118743 & Log likelihood & -49.13534 \\
Hannan-Quinn criter. & 1.086914 & Deviance & 98.27067 \\
Restr. Deviance & 107.9683 & Restr. log likelihood & -53.98417 \\
LR statistic & 9.697676 & Avg. log likelihood & -0.511826 \\
Prob(LR statistic) & 0.001845 & & \\
\hline \hline Obs with Dep $=0$ & 24 & Total obs & \\
Obs with Dep $=1$ & 72 & & \\
\hline \hline
\end{tabular}

Fuente Elaboración Propia en Eviews 7

Los resultados de la Tabla 3.9 indican que la variable independiente es estadísticamente significativa a un nivel de confianza de $99 \%$. Adicionalmente, los indicadores de bondad de ajuste $R^{2}$ McFadden y Cuenta $R^{2}$ son $8.9 \%$ y $75 \%$, respectivamente. En conjunto, estos análisis indican que el modelo (al igual que en los escenarios previos) está bien especificado. 
Tabla 3.10

Probabilidades de modelo Logit considerando como variable dependiente

DU_AEC_AET_25

\begin{tabular}{|ccc|}
\hline Variable Independiente & 0 & 1 \\
\hline Razón de probabilidades & 7.33 & 1.56 \\
\hline Prob. condicional (V. Dep=1) & $88.00 \%$ & $60.87 \%$ \\
\hline Prob. condicional (V. Dep=0) & $12.00 \%$ & $39.13 \%$ \\
\hline
\end{tabular}

Fuente Elaboración Propia

El modelo presentado en este escenario indica que la probabilidad de que el ratio entre adeudos de corto plazo y adeudos totales sea menor o igual a 26\% (percentil 25 según Tabla 3.1) es de 39.43\% cuando el encaje a los adeudos de corto plazo es mayor o igual a $45 \%$. Este resultado es menos impactante en comparación a los escenarios previos, cuando la probabilidad en cuestión era más alta. No obstante, esto se debe a la forma de categorizar la variable dependiente (considerar el percentil 25 es más ácido que los percentiles 50 y 75). Asimismo, el signo del estadístico estimado en la Tabla 3.9 sigue siendo negativo, que es lo más importante del modelo.

\section{- Elección de un escenario}

Se han hecho tres simulaciones del impacto del encaje sobre el ratio de adeudos de corto plazo y adeudos totales, considerando distintas definiciones de la variable categórica que representa a la dependiente. El último paso de este sub-apartado es escoger uno de los escenarios. 
Tabla 3.11

Criterios de selección para escenarios de modelo logit

\begin{tabular}{|cccc|}
\hline $\begin{array}{c}\text { Criterio de } \\
\text { Selección/Escenario }\end{array}$ & Primero & Segundo & Tercero \\
\hline Significancia de DU_ENC & $99 \%$ & $99 \%$ & $99 \%$ \\
\hline Signo de DU_ENC & Negativo & Negativo & Negativo \\
\hline Cuenta R2 & $75 \%$ & $79 \%$ & $75 \%$ \\
\hline R2 McFadden & $21.2 \%$ & $26.2 \%$ & $8.9 \%$ \\
\hline $\begin{array}{c}\text { Probabilidad condicional (V. } \\
\text { Dep=0 dado V. Ind =1) }\end{array}$ & $95.65 \%$ & $80.43 \%$ & $39.13 \%$ \\
\hline
\end{tabular}

Fuente Elaboración Propia

En la Tabla 3.11 se presentan los criterios de selección para escoger un escenario. Las dos primeras filas, la significancia y signo de la variable independiente, son las más importantes para tomar una decisión; no obstante, en este caso resultan inútiles, pues los 3 modelos son igual de buenos en estos aspectos. Asimismo, la Cuenta $R^{2}$ es prácticamente la misma, por lo cual tampoco resulta útil. Por lo tanto, los únicos criterios que son relevantes son los dos últimos: $R^{2}$ McFadden y la probablidad condicional, aunque ambos tienen sus debilidades.

Con respecto a la medida de bondad de ajuste $R^{2}$ McFadden, como ya fue señalado, en los modelos de regresión binaria tiene una importancia secundaria. No obstante, por ser tan bajo para el tercer escenario $(8.9 \%)$, da un indicio de que su especificación no es tan buena como en los otros 2 .

En relación a la probabilidad condicional, en realidad no es directamente comparable entre escenarios, pues se trata de variables dependientes distintas. Sin embargo, dadas las restricciones que se tienen para tomar una decisión, se puede considerar como buen indicador si se interpreta de la siguiente manera: en el primer escenario, la probabilidad condicional es muy elevada, pero no sirve de mucho; el nivel umbral del percentil $75,57.2 \%$, es muy poco exigente, y la última vez que se registró dicho valor fue en Junio el 2008. Por otro lado, el tercer escenario resulta muy útil en términos prácticos; el nivel umbral de 26\% (percentil 25) es exigente, y sería ventajoso concluir que el encaje tiene un impacto tan elevado sobre el ratio de adeudos de corto plazo y adeudos totales. No 
obstante, en la realidad esto no ocurre, pues la probabilidad estimada es de sólo $39.13 \%$. En cambio, el segundo escenario es un punto intermedio; el nivel umbral del percentil 50, 37.1\%, es relativamente exigente ${ }^{25}$, y la probabilidad condicional es elevada, situándose encima de $80 \%$. Por lo antes expuesto, se escoge el escenario 2 sobre los demás ${ }^{26}$.

\subsubsection{Relación entre de los adeudos y el crédito en moneda extranjera}

Como segunda parte de la contrastación empírica se analizará si existe una relación de largo plazo entre los adeudos (totales y de corto plazo) y el crédito en moneda extranjera. Se espera que dicha relación exista bajo ambas definiciones de la variable independiente, en cuyo caso la relación de corto plazo entre las variables se expresaría como un MCE.

Se plantean dos escenarios; en ambos, la variable dependiente será el crédito en moneda extranjera. En el primero, se considerará como variable independiente los adeudos de corto plazo, para los cuales ya se ha demostrado (indirectamente) que el encaje ha tenido un efecto significativo. En el segundo escenario se usarán los adeudos totales como variable independiente. Las variables serán expresadas como tasas de crecimiento interanual, tal como fue detallado en la Tabla 3.4.

\section{- Escenario 1: Variable independiente}

\section{AEC_CRECIMIENTO_LN}

En el primer escenario se analizará la existencia de una relación de largo plazo entre los adeudos de corto plazo y el crédito en moneda extranjera, ambas variables expresadas como tasas de crecimiento. Antes de entrar al análisis econométrico formal, resulta útil una inspección visual de las variables.

\footnotetext{
25 La última vez que se registró dicho valor fue en Febrero del 2011

26 Existen varios aspectos técnicos que pueden ser afinados en los modelos presentados; al respecto, ver la sección RECOMENDACIONES al final de la investigación
} 


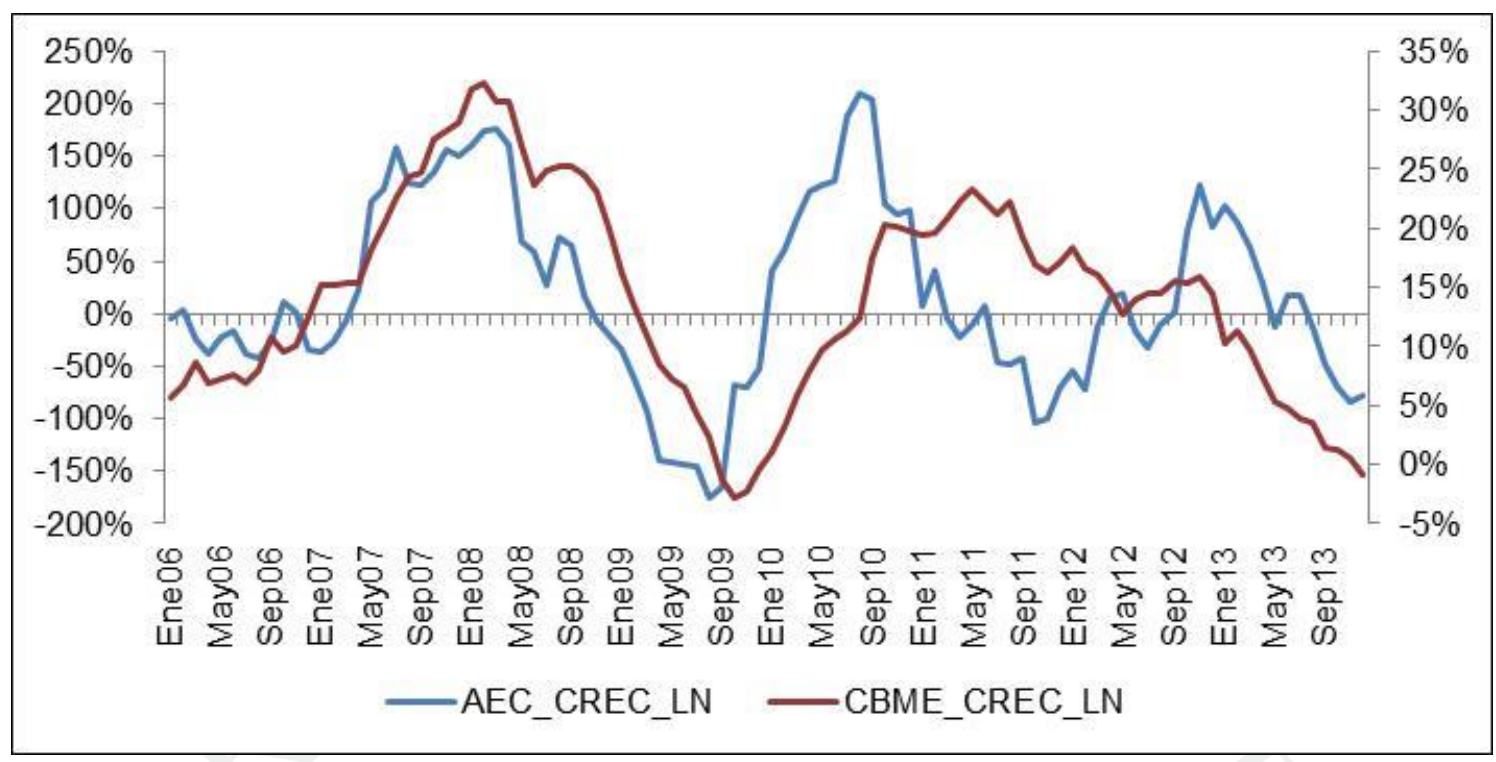

Figura 3.2 Tasa de crecimiento interanual de Adeudos de Corto Plazo (eje izquierdo) y del Crédito Bruto en Moneda Extranjera (eje derecho). Periodo 2006-2013. (En \%). Fuente SBS Boletín Estadístico de la Banca Múltiple, revisado el 6 de Junio del 2015, http://www.sbs.gob.pe/app/stats/EstadisticaBoletinEstadistico.asp?p=1

Tal como puede apreciarse en la Figura 3.2, parece existir una relación entre los adeudos de corto plazo y el crédito en moneda extranjera, al menos hasta Octubre del 2009. A partir de dicho mes, la relación identificada parece perderse; esto resulta más notorio entre Enero del 2011 y Abril de 2012. Esto se confirma al realizar un análisis de correlación: durante el periodo Enero 2006 hasta Octubre del 2009, la correlación entre ambas variables es de $85.6 \%$, mientras que para el resto del periodo es de sólo $8.9 \%$. Los resultados sugieren la existencia de una relación de corto plazo, más de no de largo plazo entre las variables; para confirmarlo, se realizará el análisis de cointegración.

El primer paso para concluir si dos series cointegran según Engle y Granger (1987) es determinar si son del mismo orden (i.e. integradas de orden $n$ ). Para ello, se realizará la prueba DFA sobre las variables seleccionadas. 
Tabla 3.12

Prueba DFA con intercepto y sin tendencia sobre

AEC_CRECIMIENTO_LN. Número de rezagos escogido según criterio de

Schwarz

\begin{tabular}{|c|c|c|c|}
\hline \multicolumn{4}{|c|}{$\begin{array}{l}\text { Null Hypothesis: AEC_CRECIMIENTO_LN has a unit root } \\
\text { Exogenous: Constant } \\
\text { Lag Length: } 0 \text { (Automatic - based on SIC, maxlag=11) }\end{array}$} \\
\hline & & t-Statistic & Prob.* \\
\hline Augmented Dickey- & statistic & -1.797451 & 0.3798 \\
\hline Test critical values: & $\begin{array}{l}1 \% \text { level } \\
5 \% \text { level } \\
10 \% \text { level }\end{array}$ & $\begin{array}{l}-3.500669 \\
-2.892200 \\
-2.583192\end{array}$ & \\
\hline
\end{tabular}

Fuente Elaboración Propia en Eviews 7

Tabla 3.13

Prueba DFA con intercepto y sin tendencia sobre

AEC_CRECIMIENTO_LN en primera diferencia. Número de rezagos escogido según criterio de Schwarz

\begin{tabular}{|c|c|c|c|}
\hline \multicolumn{4}{|c|}{$\begin{array}{l}\text { Null Hypothesis: D(AEC_CRECIMIENTO_LN) has a unit root } \\
\text { Exogenous: Constant } \\
\text { Lag Length: } 0 \text { (Automatic - based on SIC, maxlag=11) }\end{array}$} \\
\hline & & t-Statistic & Prob.* \\
\hline \multicolumn{2}{|c|}{ Augmented Dickey-Fuller test statistic } & -8.119024 & 0.0000 \\
\hline Test critical values: & $\begin{array}{l}1 \% \text { level } \\
5 \% \text { level } \\
10 \% \text { level }\end{array}$ & $\begin{array}{l}-3.501445 \\
-2.892536 \\
-2.583371\end{array}$ & \\
\hline
\end{tabular}

Fuente Elaboración Propia en Eviews 7

De acuerdo a la Tabla 3.12, se falla en rechazar la hipótesis nula que la variable AEC_CRECIMIENTO_LN tiene raíz unitaria. No obstante, al tomar la primera diferencia de dicha variable (Tabla 3.13), se puede apreciar que es estacionaria a un $99 \%$ de confianza. Entonces, se concluye que es una serie integrada de orden 1, o estacionaria en primera diferencia. Para que pueda existir una relación de cointegración con el crédito en moneda extranjera, es requisito que dicha variable también sea integrada de orden 1 . Los siguientes análisis contrastarán esta hipótesis. 
Tabla 3.14

Prueba DFA con intercepto y sin tendencia sobre

CBME_CRECIMIENTO_LN. Número de rezagos escogido según criterio de Schwarz

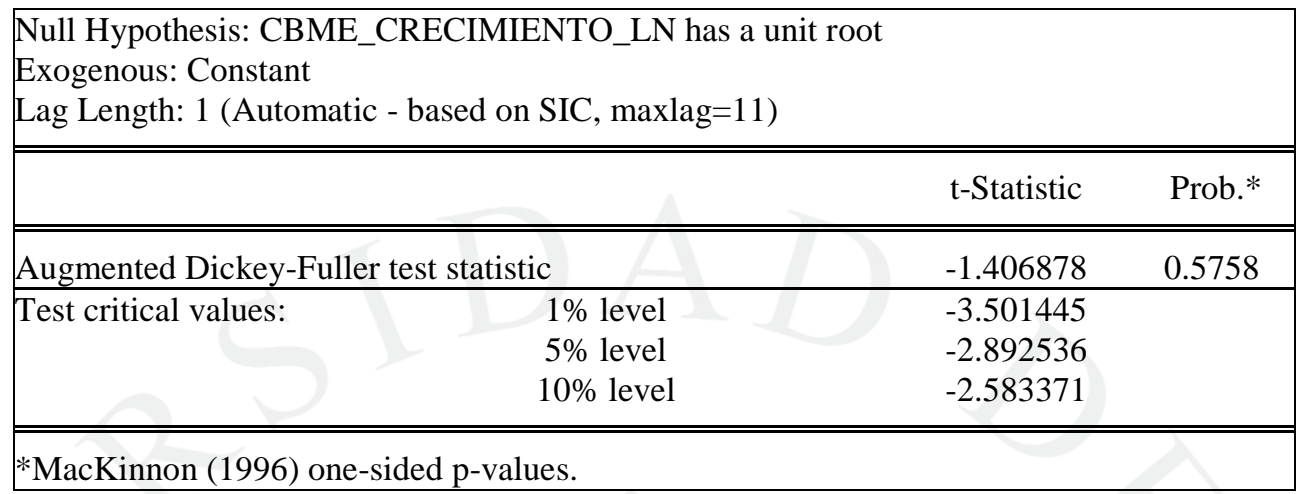

Fuente Elaboración Propia en Eviews 7

Tabla 3.15

Prueba DFA con intercepto y sin tendencia sobre

CBME_CRECIMIENTO_LN en primera diferencia. Número de rezagos escogido según criterio de Schwarz

\begin{tabular}{|c|c|c|c|}
\hline \multicolumn{4}{|c|}{$\begin{array}{l}\text { Null Hypothesis: D(CBME_CRECIMIENTO_LN) has a unit root } \\
\text { Exogenous: Constant } \\
\text { Lag Length: } 0 \text { (Automatic - based on SIC, maxlag=11) }\end{array}$} \\
\hline & & t-Statistic & Prob.* \\
\hline \multicolumn{2}{|c|}{ Augmented Dickey-Fuller test statistic } & -5.362595 & 0.0000 \\
\hline Test critical values: & $\begin{array}{l}1 \% \text { level } \\
5 \% \text { level } \\
10 \% \text { level }\end{array}$ & $\begin{array}{l}-3.501445 \\
-2.892536 \\
-2.583371\end{array}$ & \\
\hline
\end{tabular}

Fuente Elaboración Propia en Eviews 7

Los resultados en las Tablas 3.14 y 3.15 indican que la variable CBME_CRECIMIENTO_LN también es integrada de orden 1, a un nivel de significancia de $99 \%$. Con ello, se cumple el primer requisito para la existencia de una regresión cointegrante entre las variables de análisis. El segundo paso es plantear la potencial ecuación cointegrante:

$$
\text { CBME_CRECIMIENTO_LN } N_{t}=\beta_{0}+\beta_{1} A E C \_C R E C I M I E N T O_{-} L N_{t}+u_{t}
$$


Tabla 3.16

Potencial regresión cointegrante entre AEC_CRECIMIENTO_LN y

CBME_CRECIMIENTO_LN

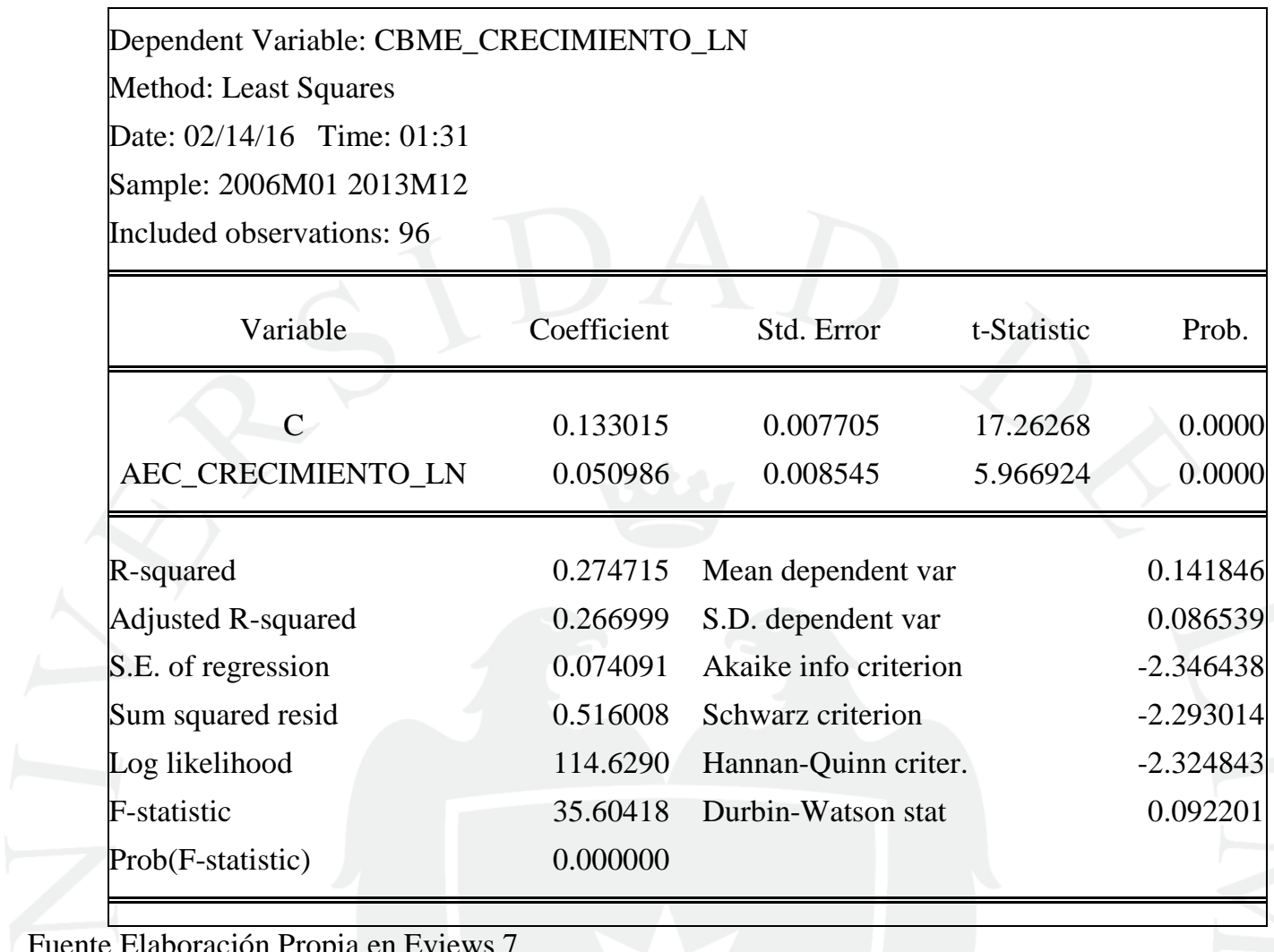

La Tabla 3.16 muestra la regresión mencionada a través del método de MCO. Es importante notar algunos aspectos. En primer lugar, el potencial parámetro cointegrante, $\beta_{1}$, es positivo y con significativo a un nivel de confianza de 99\% (0.050986). Ello podría ser un buen indicio de la existencia de una relación de largo plazo; no obstante, hay que recordar la posibilidad de que la regresión sea espuria. De acuerdo a lo sugerido por Granger y Newbold (1974), una buena regla práctica es cerciorarse que el $R^{2}$ no sea mayor que el estadístico $d$. En este caso, el primer indicador es de 0.27 , mientras que el segundo de 0.09; por ello, podemos sospechar que se trata de una regresión espuria. Retomando la teoría de cointegración presentada en el sub-apartado 3.2, si se comprueba que los residuos de esta regresión son estacionarios, se puede concluir que la regresión es no espuria; al contrario, se trata de una relación de largo plazo entre las variables. Para ello, se aplicará la prueba DFA sobre los residuos obtenidos: 


$$
u_{t}=C B M E_{-} C R E C I M I E N T O_{-} L N_{t}-\beta_{0}-\beta_{1} A E C_{-} C R E C I M I E N T O_{-} L N_{t}
$$

Tabla 3.17

Prueba DFA sin intercepto ni tendencia sobre los residuos de la regresión entre adeudos de corto plazo y crédito en moneda extranjera. Número de rezagos escogido según criterio de Schwarz.

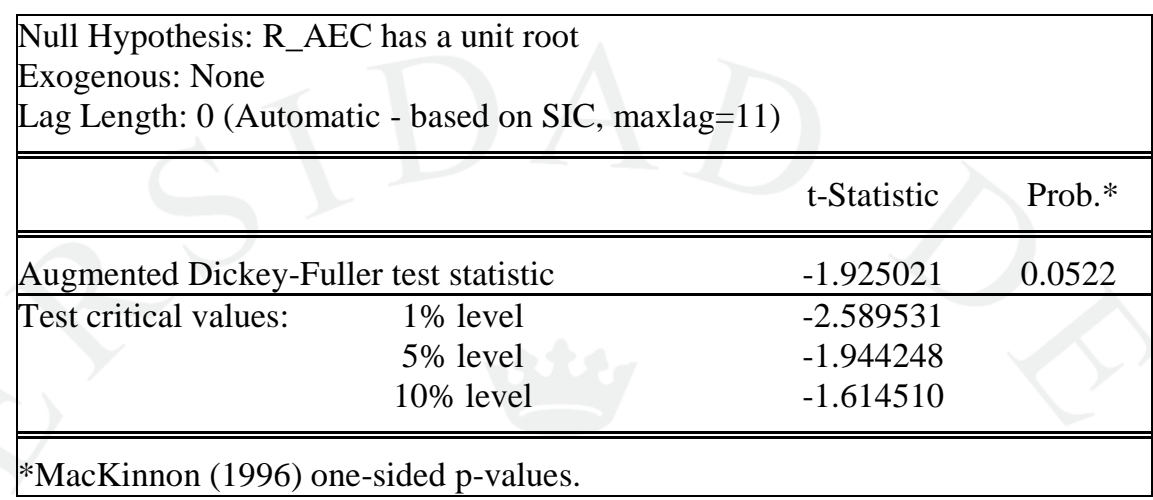

Fuente Elaboración Propia en Eviews 7

De acuerdo a la Tabla 3.17 , los residuos son estacionarios a un nivel de significancia de $94 \%$. No obstante, se debe recordar que los valores críticos propuestos por Dickey y Fuller para esta prueba no son los más apropiados, puesto que los residuos están siendo calculados en función a estimadores en vez de valores reales. Por ello, se utilizará la siguiente tabla de valores críticos, propuesta por Engle y Granger (1987):

Tabla 3.18

Valores críticos de Engle y Granger para prueba DFA sobre residuos de una potencial regresión cointegrante.

\begin{tabular}{|cccc|}
\hline Tipo & $99 \%$ & $95 \%$ & $90 \%$ \\
\hline Sin rezagos & -3.77 & -3.17 & -2.84 \\
\hline Con rezagos $^{27}$ & -3.73 & -3.17 & -2.91 \\
\hline
\end{tabular}

Nota: Las columnas denotan distintos niveles de significancia estadística (99, 95 y 90\%). Fuente Engle y Granger (1987)

Según los valores críticos de la Tabla 3.18, los residuos estimados no son estadísticamente significativos ni siquiera a un nivel de confianza de 90\%. Con ello, se descartaría la existencia de una relación de largo plazo

$27 \quad$ La simulación original de Engle y Granger fue realizada con 4 rezagos. Se asumirá que los valores críticos se mantienen para tantos rezagos sean incluidos en la prueba DFA, en vista que la diferencia entre 0 y 4 rezagos es muy baja 
entre las variables de análisis. No obstante, se ha identificado que la prueba DFA es sensible al número de rezagos incluidos, el cual varía según el criterio de información que sea utilizado (Akaike o Schwarz):

Tabla 3.19

Prueba DFA sin intercepto ni tendencia sobre los residuos de la regresión entre adeudos de corto plazo y crédito en moneda extranjera. Número de rezagos escogido según criterio de Akaike

\begin{tabular}{|c|c|c|c|}
\hline \multicolumn{4}{|c|}{$\begin{array}{l}\text { Null Hypothesis: R_AEC has a unit root } \\
\text { Exogenous: None } \\
\text { Lag Length: } 11 \text { (Automatic - based on AIC, maxlag=11) }\end{array}$} \\
\hline$\gamma$ & & t-Statistic & Prob.* \\
\hline Augmented Dickey & test statistic & -3.742662 & 0.0003 \\
\hline Test critical values: & $\begin{array}{l}1 \% \text { level } \\
5 \% \text { level } \\
10 \% \text { level }\end{array}$ & $\begin{array}{l}-2.592782 \\
-1.944713 \\
-1.614233\end{array}$ & \\
\hline
\end{tabular}

Fuente Elaboración Propia en Eviews 7

La Tabla 3.19 indica que, al incluir rezagos en la prueba DFA según el criterio de Akaike, el estadístico estimado incrementa considerablemente su valor (-3.74). Al contrastar este valor con los propuestos por Engle y Granger, se rechaza la hipótesis nula de raíz unitaria en los residuos a una significancia estadística de 99\%; ello indicaría que los residuos son estacionarios, en cuyo caso existiría una relación de largo plazo entre los adeudos de corto plazo y el crédito en moneda extranjera

Para determinar si la Tabla 3.16 realmente representa una regresión cointegrante, se planteara la relación entre las variables de análisis como un MCE; si este modelo resulta consistente, puede concluirse la existencia de una ecuación de cointegración:

$\triangle C B M E \_C R E C I M I E N T O_{-} L N_{t}=\alpha_{0}+\alpha_{1} \Delta A E C \_C R E C I M I E N T O_{-} L N_{t}+$ $\alpha_{2} u_{t-1}+\varepsilon_{t}$

En esta ecuación, se espera que el estimador $\alpha_{2}$ asociado al supuesto error de equilibrio sea negativo y significativo; que $\alpha_{1}$ sea positivo y significativo (relación de corto plazo entre las variables), y que no exista autocorrelación en el modelo. 
Tabla 3.20

Mecanismo de corrección de Errores entre AEC_CRECIMIENTO_LN y

CBME_CRECIMIENTO_LN

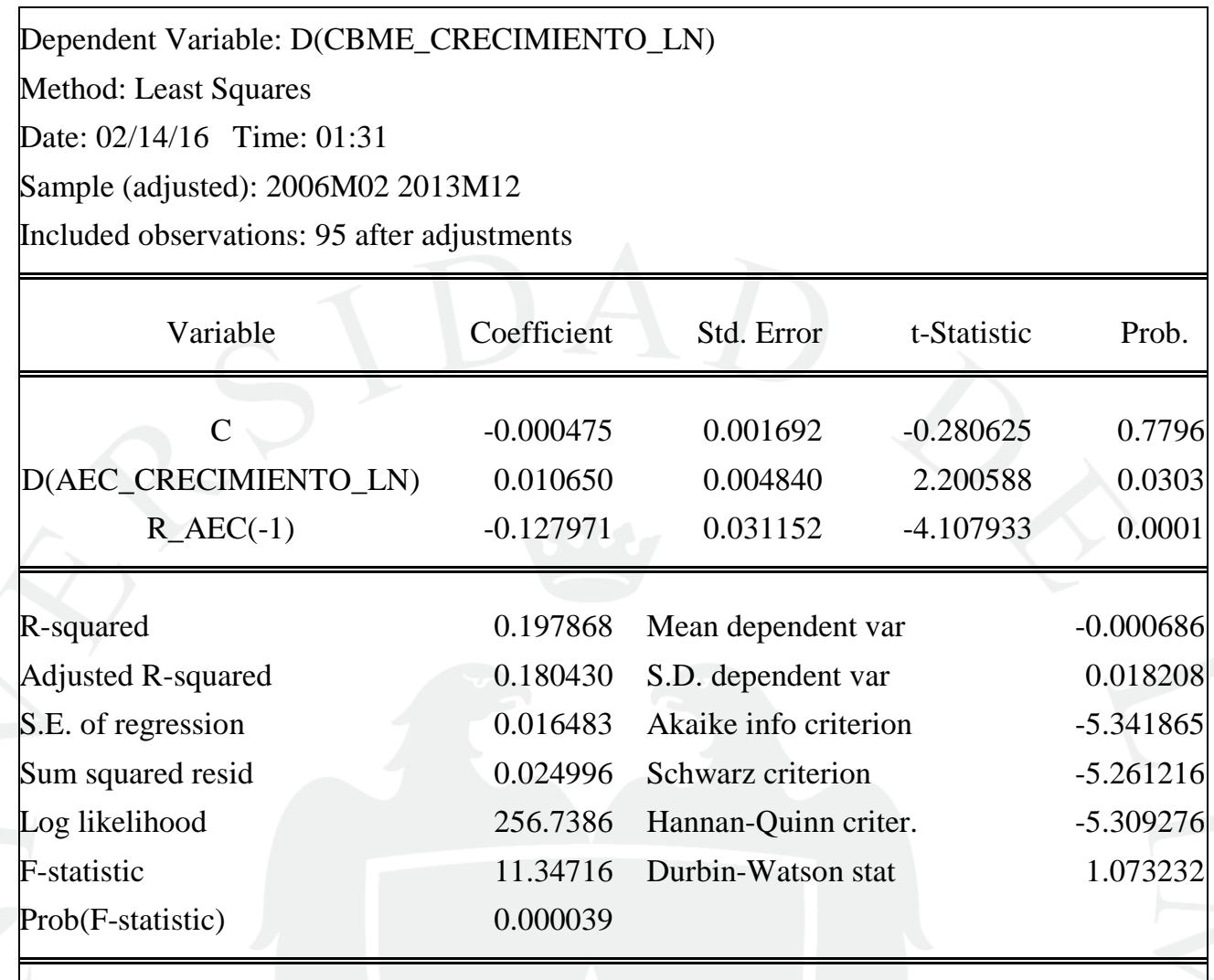

Fuente Elaboración Propia en Eviews 7

El MCE presentado en la Tabla 3.20 indica que el potencial error de equilibrio es significativo y con signo negativo, como era esperado. Si bien la relación de corto plazo entre ambas variables es significativa y con signo positivo, la magnitud es muy baja (0.010650), lo cual sugiere que la relación es tenue. Sin embargo, lo más notorio es el bajo valor del estadístico $d$ (1.07). De acuerdo a los valores críticos de significancia provistos por Gujarati y Porter (2010), existe autocorrelación positiva en el modelo.

En vista de las dudas sobre la presencia de raíz unitaria en el término de error de la ecuación cointegrante y la mala especificación del MCE, se puede concluir que no existe una regresión de cointegración entre los adeudos de corto plazo y el crédito en moneda extranjera. 
- Escenario

2:

Variable

independiente

AET_CRECIMIENTO_LN

El segundo escenario difiere del primero en que considera como variable independiente los adeudos totales de la banca, expresados como tasa de crecimiento. Según la SBS, durante el periodo 2006-2013 la principal fuente de pasivos en moneda extranjera de la banca han sido las obligaciones con el público, con un $67 \%$ de participación promedio, seguido de los adeudos, con un $20 \%$ de participación, y el resto de fuentes con un $13 \%$ de participación. En vista que el crédito en moneda extranjera se financia principalmente con pasivos en la misma moneda, se espera que los adeudos, por constituir una parte considerable de dichos pasivos, mantengan una relación de largo plazo con el crédito. Los análisis y pruebas econométricas a realizar serán los mismos que en el escenario previo.

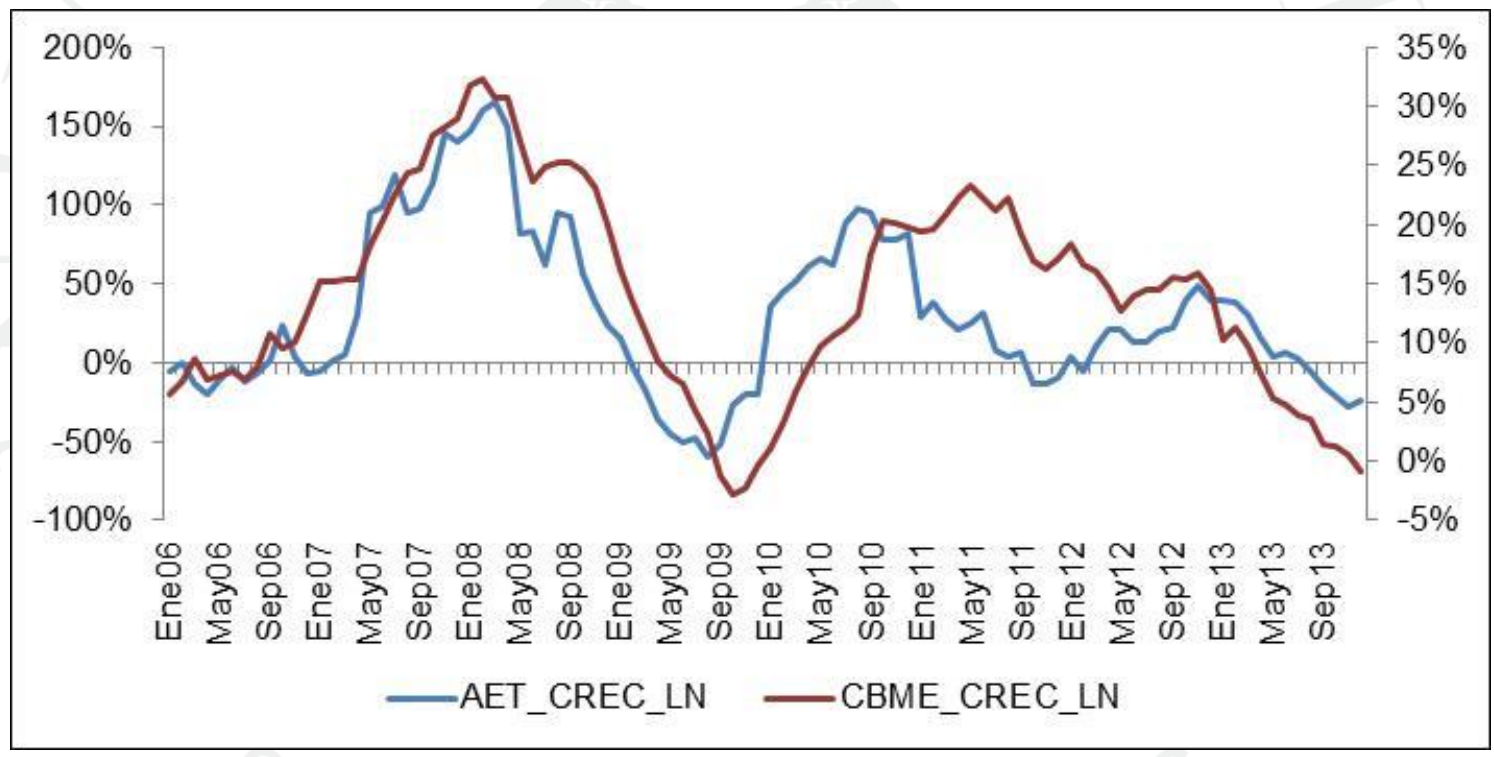

Figura 3.3 Tasa de crecimiento interanual de Adeudos Totales (eje izquierdo) y del Crédito Bruto en Moneda Extranjera (eje derecho). Periodo 2006-2013. (En \%). Fuente SBS Boletín Estadístico de la Banca Múltiple, revisado el 6 de Junio del 2015, http://www.sbs.gob.pe/app/stats/EstadisticaBoletinEstadistico.asp?p=1

La Figura 3.3 muestra un patrón similar a la Figura 3.2, presentada en el escenario previo. No obstante, en este caso la correlación entre las variables es más notoria, incluso después de Octubre del 2009. De manera puntual, el coeficiente de correlación entre el periodo Enero 2006 y Octubre 2009 es de 92.6\%, mientras que para el resto del periodo de análisis es de $33.2 \%$. Ello sugiere que, a pesar de un evidente cambio estructural, se podría esperar una relación de largo plazo entre las variables. 
Tabla 3.21

Prueba DFA con intercepto y sin tendencia sobre

AET_CRECIMIENTO_LN. Número de rezagos escogido según criterio de

Schwarz

\begin{tabular}{|c|c|c|c|}
\hline \multicolumn{4}{|c|}{$\begin{array}{l}\text { Null Hypothesis: AET_CRECIMIENTO_LN has a unit root } \\
\text { Exogenous: Constant } \\
\text { Lag Length: } 0 \text { (Automatic - based on SIC, maxlag=11) }\end{array}$} \\
\hline & & $\mathrm{t}$-Statistic & Prob.* \\
\hline Augmented Dickey- & t statistic & -1.580468 & 0.4886 \\
\hline Test critical values: & $\begin{array}{l}1 \% \text { level } \\
5 \% \text { level } \\
10 \% \text { level }\end{array}$ & $\begin{array}{l}-3.500669 \\
-2.892200 \\
-2.583192\end{array}$ & \\
\hline
\end{tabular}

Fuente Elaboración Propia en Eviews 7

Tabla 3.22

Prueba DFA con intercepto y sin tendencia sobre

AET_CRECIMIENTO_LN en primera diferencia. Número de rezagos escogido según criterio de Schwarz

\begin{tabular}{|c|c|c|c|}
\hline \multicolumn{4}{|c|}{$\begin{array}{l}\text { Null Hypothesis: D(AET_CRECIMIENTO_LN) has a unit root } \\
\text { Exogenous: Constant } \\
\text { Lag Length: } 0 \text { (Automatic - based on SIC, maxlag=11) }\end{array}$} \\
\hline & & t-Statistic & Prob.* \\
\hline \multicolumn{2}{|c|}{ Augmented Dickey-Fuller test statistic } & -8.118935 & 0.0000 \\
\hline Test critical values: & $\begin{array}{l}1 \% \text { level } \\
5 \% \text { level } \\
10 \% \text { level }\end{array}$ & $\begin{array}{l}-3.501445 \\
-2.892536 \\
-2.583371\end{array}$ & \\
\hline
\end{tabular}

Fuente Elaboración Propia en Eviews 7

La Tabla 3.21 indica que se falla en rechazar la hipótesis nula que la variable AET_CRECIMIENTO_LN tiene raíz unitaria. De la misma manera que en el escenario previo, al tomar la primera diferencia de dicha variable (Tabla 3.22), se puede apreciar que es estacionaria a un $99 \%$ de confianza; se concluye que es una serie integrada de orden 1. Por los análisis previos, ya se sabe que el crédito en moneda extranjera, expresado como tasa de crecimiento, también es estacionario en primera diferencias; por ello, se 
cumple el primer requisito para que exista cointegraciòn entre las variables. Se procede entonces a plantear la potencial ecuación cointegrante:

$$
\text { CBME_CRECIMIENTO_LN } N_{t}=\beta_{0}+\beta_{1} A E T \_C R E C I M I E N T O \_L N_{t}+u_{t}
$$

Tabla 3.23

Potencial regresión cointegrante entre AET_CRECIMIENTO_LN y

CBME_CRECIMIENTO_LN

Dependent Variable: CBME_CRECIMIENTO_LN

Method: Least Squares

Date: 02/14/16 Time: 01:31

Sample: 2006M01 2013M12

Included observations: 96

\begin{tabular}{|lcccr|}
\hline \multicolumn{1}{|c}{ Variable } & Coefficient & Std. Error & t-Statistic & Prob. \\
\hline \hline \multicolumn{1}{c}{ C } & 0.103269 & 0.006945 & 14.87038 & 0.0000 \\
AET_CRECIMIENTO_LN & 0.124635 & 0.011591 & 10.75243 & 0.0000 \\
\hline \hline & & & \\
R-squared & 0.551558 & Mean dependent var & \\
Adjusted R-squared & 0.546787 & S.D. dependent var & 0.141846 \\
S.E. of regression & 0.058259 & Akaike info criterion & 0.086539 \\
Sum squared resid & 0.319046 & Schwarz criterion & -2.827224 \\
Log likelihood & 137.7067 & Hannan-Quinn criter. & -2.773800 \\
F-statistic & 115.6147 & Durbin-Watson stat & -2.805629 \\
Prob(F-statistic) & 0.000000 & & 0.164838 \\
\hline \hline
\end{tabular}

Fuente Elaboración Propia en Eviews 7

En la Tabla 3.23 se plantea la potencial regresión cointegrante, utilizando el método de MCO. Al igual que en el escenario previo, el potencial parámetro cointegrante, $\beta_{1}$, es positivo y con significativo a un nivel de confianza de $99 \%$ (0.124635). Sin embargo, el $R^{2}$ es de 0.55 , mayor el es estadístico $d(0.16)$, por lo que puede tratarse de una regresión espuria. Nuevamente, se comprobará si los residuos de esta regresión son estacionarios, a través de la prueba DFA:

$$
u_{t}=C B M E_{-} C R E C I M I E N T O_{-} L N_{t}-\beta_{0}-\beta_{1} A E T T_{-} C R E C I M I E N T O_{-} L N_{t}
$$


Tabla 3.24

Prueba DFA sin intercepto ni tendencia sobre los residuos de la regresión entre adeudos totales y crédito en moneda extranjera. Número de rezagos escogido según criterio de Schwarz

\begin{tabular}{|c|c|c|c|}
\hline \multicolumn{4}{|c|}{$\begin{array}{l}\text { Null Hypothesis: R_AET has a unit root } \\
\text { Exogenous: None } \\
\text { Lag Length: } 0 \text { (Automatic - based on SIC, maxlag=11) }\end{array}$} \\
\hline & & t-Statistic & Prob.* \\
\hline \multicolumn{2}{|c|}{ Augmented Dickey-Fuller test statistic } & -1.830778 & 0.0641 \\
\hline Test critical values: & $\begin{array}{l}1 \% \text { level } \\
5 \% \text { level } \\
10 \% \text { level }\end{array}$ & $\begin{array}{l}-2.589531 \\
-1.944248 \\
-1.614510\end{array}$ & \\
\hline
\end{tabular}

Fuente Elaboración Propia en Eviews 7

Tabla 3.25

Prueba DFA sin intercepto ni tendencia sobre los residuos de la regresión entre adeudos totales y crédito en moneda extranjera. Número de rezagos escogido según criterio de Schwarz

\begin{tabular}{|c|c|c|c|}
\hline \multicolumn{4}{|c|}{$\begin{array}{l}\text { Null Hypothesis: R_AET has a unit root } \\
\text { Exogenous: None } \\
\text { Lag Length: } 11 \text { (Automatic - based on AIC, maxlag=11) }\end{array}$} \\
\hline & & t-Statistic & Prob.* \\
\hline \multicolumn{2}{|c|}{ Augmented Dickey-Fuller test statistic } & -4.286056 & 0.0000 \\
\hline Test critical values: & $\begin{array}{l}1 \% \text { level } \\
5 \% \text { level } \\
10 \% \text { level }\end{array}$ & $\begin{array}{l}-2.592782 \\
-1.944713 \\
-1.614233\end{array}$ & \\
\hline
\end{tabular}

Fuente Elaboración Propia en Eviews 7

Para simplificar espacio, se presentan en seguido las Tablas $3.23 \mathrm{y}$ 3.25, donde se detallan los resultados de la prueba DFA considerando los criterios de información de Schwarz y Akaike para escoger rezagos, respectivamente. Tomando como referencia los valores críticos de Engle y Granger presentados en la Tabla 3.18 para contrastar los estadísticos T, se puede notar que la información no es concluyente en relación a la presencia de raíz unitaria en los residuos. Para determinar si existe una relación de cointegración entre los adeudos totales y el crédito, se volverá a plantear un 
MCE; los resultados serán analizados de la misma manera que en el escenario 1.

$$
\begin{aligned}
& \triangle C B M E \_C R E C I M I E N T O \_L N_{t}=\alpha_{0}+\alpha_{1} \Delta A E T \_C R E C I M I E N T O \_L N_{t}+ \\
& \alpha_{2} u_{t-1}+\varepsilon_{t}
\end{aligned}
$$

Tabla 3.26

\section{Mecanismo de corrección de Errores entre AET_CRECIMIENTO_LN y}

\begin{tabular}{|c|c|c|c|c|}
\hline \multicolumn{5}{|c|}{$\begin{array}{l}\text { Dependent Variable: D(CBME_CRECIMIENTO_LN) } \\
\text { Method: Least Squares } \\
\text { Date: 02/14/16 Time: 01:32 } \\
\text { Sample (adjusted): 2006M02 2013M12 } \\
\text { Included observations: } 95 \text { after adjustments }\end{array}$} \\
\hline Variable & Coefficient & Std. Error & t-Statistic & Prob. \\
\hline 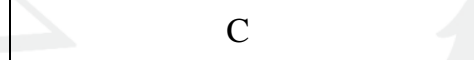 & -0.000537 & 0.001682 & -0.319081 & 0.7504 \\
\hline D(AET_CRECIMIENTO_LN) & 0.030426 & 0.009565 & 3.180974 & 0.0020 \\
\hline R_AET(-1) & -0.101224 & 0.029439 & -3.438373 & 0.0009 \\
\hline R-squared & 0.207045 & Mean dependent var & & -0.000686 \\
\hline Adjusted R-squared & 0.189807 & S.D. dependent var & & 0.018208 \\
\hline S.E. of regression & 0.016389 & Akaike info criterion & & -5.353371 \\
\hline Sum squared resid & 0.024710 & Schwarz criterion & & -5.272723 \\
\hline Log likelihood & 257.2851 & Hannan-Quinn criter. & & -5.320783 \\
\hline F-statistic & 12.01086 & Durbin-Watson stat & & 1.176029 \\
\hline Prob(F-statistic) & 0.000023 & & & \\
\hline
\end{tabular}

CBME_CRECIMIENTO_LN

Fuente Elaboración Propia en Eviews 7

Los resultados no difieren con respecto al escenario previo: de acuerdo al MCE presentado en la Tabla 3.26, el potencial error de equilibrio es significativo y con signo negativo; la relación de corto plazo entre ambas variables es significativa y con signo positivo, con una magnitud baja, aunque mayor que al considerar como variable dependiente AEC_CRECIMIENTO_LN (0.030426); el estadístico $d$ (1.17) sigue siendo bajo, y de acuerdo a los valores críticos de significancia provistos por Gujarati y Porter (2010), existe autocorrelación positiva en el modelo. Por lo tanto, se concluye que tampoco existe una regresión de largo plazo entre los adeudos totales y el crédito en moneda extranjera. 


\subsubsection{Simulación de la política de encaje}

Se ha comprobado que la política de encaje ha influido en la estructura de plazos de los adeudos de la banca, fomentando el reemplazo de adeudos de corto plazo por adeudos de largo plazo. Sin embargo, ¿cómo hubieran evolucionado los adeudos de corto plazo si la política de encaje hubiera sido laxa ${ }^{28}$ durante todo el periodo? Para responder a esta pregunta, se propone el siguiente ejercicio de simulación en base a métodos estadísticos descriptivos:

Tabla 3.27

Ratio de adeudos de corto plazo con el exterior entre adeudos con el exterior totales - Valor promedio durante dos periodos

\begin{tabular}{|cc|}
\hline Periodo & Ratio observado \\
\hline Encaje $<45 \%$ & $52 \%$ \\
\hline Encaje $>=45 \%$ & $32 \%$ \\
\hline
\end{tabular}

Fuente 1 SBS Boletín Estadístico de la Banca Múltiple, revisado el 6 de Junio del 2015, http://www.sbs.gob.pe/app/stats/EstadisticaBoletinEstadistico.asp?p=1. Fuente 2 BCRP, Solicitud de información a la Subgerencia de Política Monetaria, solicitado el 3 de Diciembre del 2016

La Tabla 3.27 indica que durante el periodo cuando el encaje ha sido menor a $45 \%$ el ratio entre adeudos de corto plazo y adeudos totales ha sido en promedio 52\%; en el resto de meses, dicho ratio ha tenido un valor promedio de $32 \%$.

Para simular el impacto de una política de encaje laxa durante todo el periodo, se asumirá que el ratio entre adeudos de corto plazo con el exterior y el total de adeudos hubiera sido 52\% durante los meses en los cuales la política ha sido en realidad contractiva ${ }^{30}$. Se espera que, en ausencia de una política de encaje contractiva, el ratio entre adeudos de corto plazo y adeudos totales hubiera crecido considerablemente. Bajo el escenario descrito, los resultados serían los siguientes:

\footnotetext{
28 Ver definición de políticas de encaje "laxa” y "contractiva" en el acápite 3.2.2

29 La política de encaje ha sido contractiva durante el periodo 200805-200809 y 201008-201312

30 Este es el valor promedio de dicho ratio cuando la política de encaje ha sido laxa (ver Tabla

3.27). Se considera que $52 \%$ es un escenario conservador, ya que si el encaje hubiera sido siempre 0 el ratio en cuestión debería ser incluso superior a $52 \%$
} 


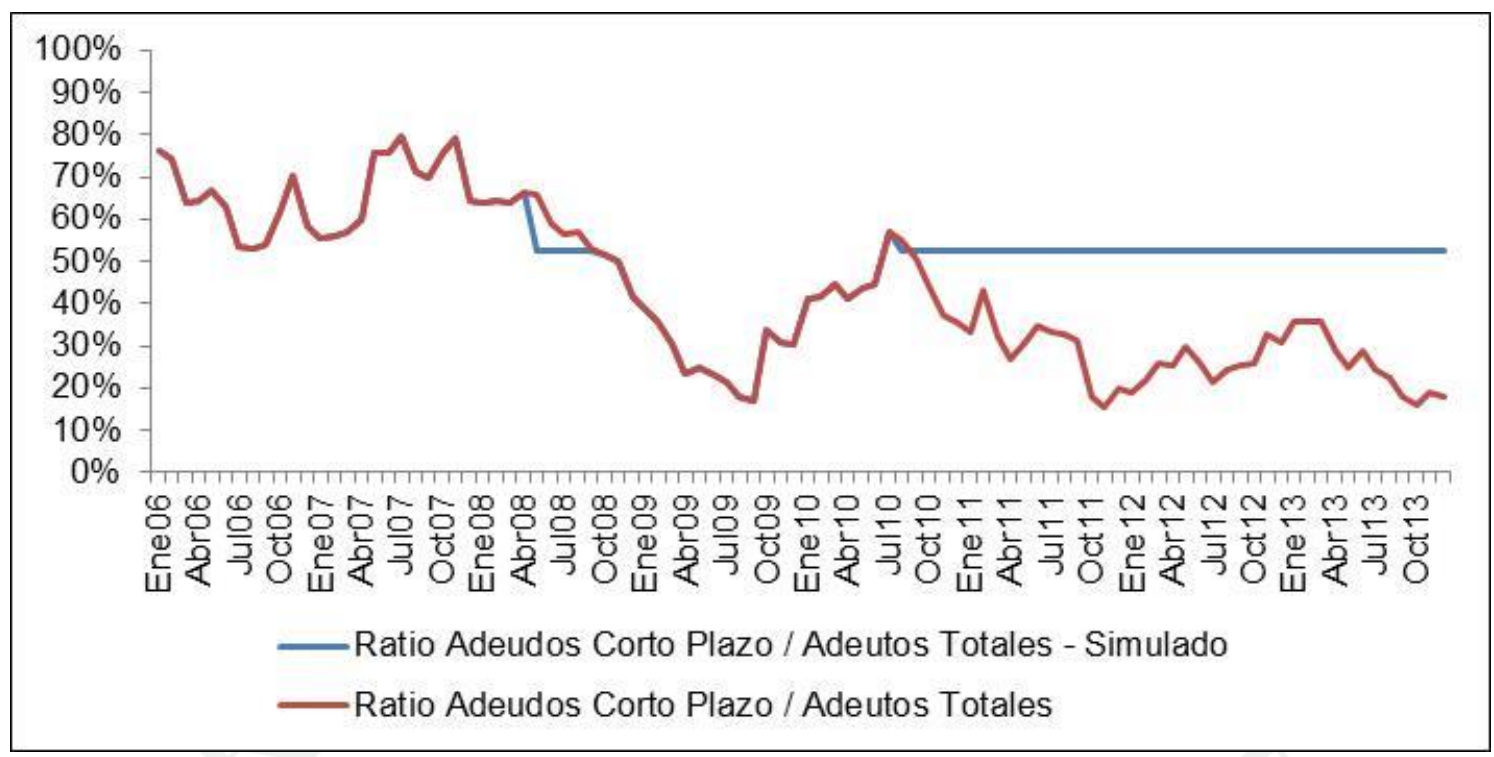

Figura 3.4 Ratio entre adeudos de corto plazo con el exterior y adeudos totales con el exterior - Valores simulados y observados. Periodo 2006-2013. (En \%) Fuente SBS, Boletín Estadístico de la Banca Múltiple, $\quad$ revisado el 6 de $\quad$ Junio http://www.sbs.gob.pe/app/stats/EstadisticaBoletinEstadistico.asp?p=1

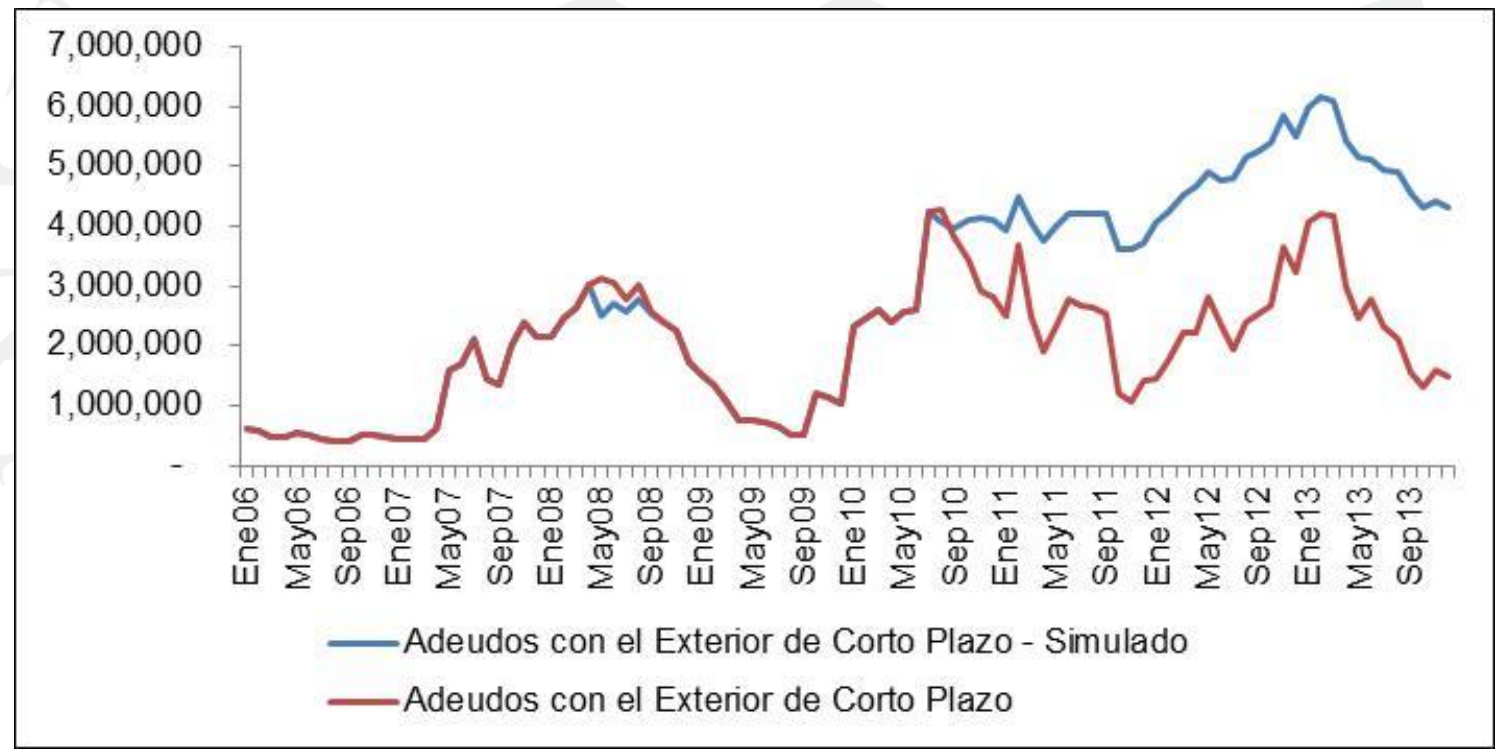

Figura 3.5 Adeudos de corto plazo con el exterior - Valores simulados y observados. Periodo 20062013. (En Miles de dólares) Fuente SBS, Boletín Estadístico de la Banca Múltiple, revisado el 6 de Junio del 2015, http://www.sbs.gob.pe/app/stats/EstadisticaBoletinEstadistico.asp?p=1 


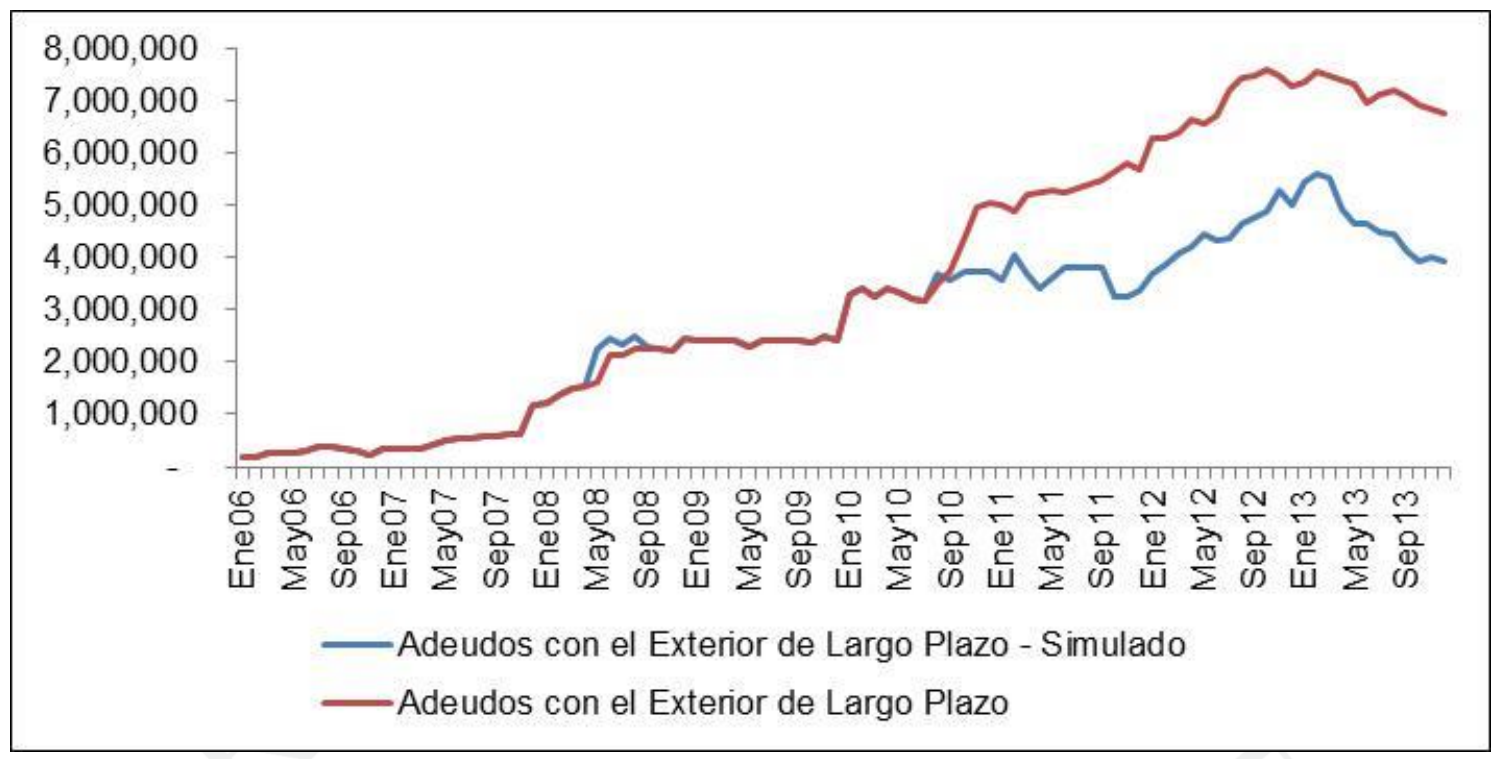

Figura 3.6 Adeudos de largo plazo con el exterior - Valores simulados y observados. Periodo 20062013. (En Miles de dólares) Fuente SBS, Boletín Estadístico de la Banca Múltiple, revisado el 6 de Junio del 2015, http://www.sbs.gob.pe/app/stats/EstadisticaBoletinEstadistico.asp?p=1

Como se puede apreciar en las Figuras 3.4, 3.5 y 3.6, de haber mantenido una política de encaje laxa durante todo el periodo la banca hubiera recurrido a mayor financiamiento con el exterior de corto plazo en comparación al de largo plazo. Si se calcula el ratio entre los adeudos de corto plazo simulados y los observados durante los meses de simulación, el promedio es de $185 \%$, lo cual sugiere que las medidas de encaje implementadas evitaron un crecimiento potencialmente desproporcionado de los adeudos de corto plazo $^{31}$. Ello pudo causar una situación similar a la ocurrida durante la crisis rusa, cuando se dio una sobre-expansión del crédito en moneda extranjera; no obstante, de acuerdo al análisis de cointegración, el impacto habría sido, cuando mucho, de corto plazo, pues las variables en cuestión no mantienen una relación de largo plazo. Queda pendiente analizar si, en ausencia del encaje a los adeudos de corto plazo, las conclusiones de las pruebas de cointegración habrían diferido; empero, esta tarea escapa el alcance de la presente investigación.

\subsection{Conclusiones del análisis empírico}

En relación a las hipótesis planteadas al inicio de la investigación, se ha contrastado que:

\footnotetext{
31 Es importante recalcar que en la simulación no se ven afectados los adeudos totales, sólo las proporciones de corto y largo plazo
} 
- La política de encaje del BCRP ha inducido a la banca peruana a modificar la estructura de plazos de sus adeudos. De manera puntual, el encaje cumplió la función de fomentar un mayor uso de adeudos de largo plazo, en comparación a los de corto plazo.

- Contrario a lo esperado, los adeudos de corto plazo no mantienen una relación de largo plazo (i.e. cointegración) con el crédito en moneda extranjera. Más aún, a pesar de representar (en promedio) el 20\% de los pasivos en moneda extranjera, los adeudos totales tampoco cointegran con el crédito. ¿Qué implica esto en términos económicos? Se está respondiendo una pregunta planteada al inicio de la investigación: el credit crunch que tuvo lugar durante la crisis rusa fue un hecho aislado, y no denota una relación de largo plazo entre los adeudos de la banca y la evolución del crédito. Esta variable tiene otros fundamentos, posiblemente las obligaciones con el público en moneda extranjera, el producto bruto interno o la propia tasa de interés cobrada al público; identificar cuáles son los drivers correctos trasciende el alcance de esta investigación. 


\section{CONCLUSIONES}

La presente investigación surge a partir de dos inquietudes: cuál ha sido el impacto del encaje sobre los flujos de capitales en la economía peruana, específicamente los adeudos de corto plazo de las empresas bancarias, y si existe una relación de largo plazo entre estos adeudos y el crédito de la banca. A través de análisis descriptivos y econométricos, se han contrastado diversas hipótesis relacionadas a estas interrogantes, llegando incluso a identificar hechos que no se tenían contemplados al inicio. A continuación se presentan las conclusiones:

- El encaje a los adeudos de corto plazo de la banca con el exterior ha sido útil en modificar la estructura de plazo de estos pasivos. A través una metodología de categorización a variables binarias, se empleo un modelo logit considerando como variable dependiente el ratio de adeudos de corto plazo y adeudos totales, y el encaje como variable independiente. Los resultados indican que la probabilidad de que el ratio en cuestión este por debajo de 37.1\% (mediana durante el periodo 2006-2013) es de $80.43 \%$ cuando el encaje es mayor o igual a $45 \%$.

- A través de la prueba de cointegración bivariable y el mecanismo de corrección de errores (MCE) propuestos por Engle y Granger (1987) y Granger (1983), se ha comprobado que no existe una relación de largo plazo entre los adeudos de corto plazo y el crédito en moneda extranjera de la banca. Más aún, tampoco existe una regresión cointegrante entre los adeudos totales y el crédito, a pesar de que dichos adeudos constituyen, en promedio, el $20 \%$ de los pasivos totales de la banca en moneda extranjera. Esto sugiere que el credit crunch que tuvo lugar durante la crisis rusa fue un hecho aislado, pues el crédito tiene otros fundamentos, cuya identificación trasciende el alcance de esta investigación

- Al comparar la evolución del crédito entre la crisis rusa y la crisis financiera internacional se ha identificado que en esta última hubo menos deterioro. Específicamente, mientras el crédito en moneda extranjera creció sólo $9 \%$ durante el periodo Enero 1998 - Diciembre 2000, correspondiente a la crisis rusa, la recuperación fue más notoria entre los meses Enero 2008 - Diciembre 2010 (38\%), periodo que 
corresponde a la crisis financiera internacional. Existen diversos factores que pueden explicar la diferencia en esta evolución, tales como una mayor estabilidad de los indicadores macroeconómicos domésticos; sin embargo, es importante resaltar el rol de las políticas implementadas, particularmente el encaje a los adeudos de corto plazo. Pocos meses antes del estallido de la crisis se elevó el encaje a 45\%, lo cual tuvo un impacto directo en la estructura de plazos de los adeudos. Esto no ocurrió durante la crisis rusa y, si bien no se ha comprobado con pruebas econométricas, en definitiva es uno de los factores que ha contribuido a suavizar la evolución del crédito durante la última crisis.

- Con respecto al panorama general de los flujos de capitales hacia Perú, se han identificado cuatro sub-periodos de acuerdo a la tendencia de dichos flujos, los cuáles han estado directamente influenciados por las condiciones de la economía mundial, particularmente la crisis financiera en el 2008 y las políticas monetarias expansivas de los países desarrollados, y las características de la economía doméstica, principalmente la estabilidad de variables macroeconómicas como la inflación.

- Las intervenciones cambiarias del BCRP han contribuido a disminuir la volatilidad del tipo de cambio durante periodos de elevados flujos de capitales, tanto de entrada como salida, de los cuales un porcentaje considerable se refleja en operaciones forward de no residentes con las empresas bancarias. En el caso de compra de dólares, las esterilizaciones mediante el uso de CD-BCRP han permitido retirar el exceso de liquidez, manteniendo de esta manera la estabilidad de la moneda local. 


\section{RECOMENDACIONES}

A continuación se enumeran algunas recomendaciones de política, así como alternativas para profundizar en los análisis realizados, principalmente en las pruebas econométricas.

- El encaje debe ser considerado como un instrumento para alterar la estructura de plazos de los adeudos de la banca, sin obviar su rol tradicional dentro de la política monetaria.

- El modelo logit utilizado para evaluar la relación encaje-adeudos ha cumplido su objetivo. Sin embargo, hay algunos aspectos técnicos que podrían mejorarse. A manera de ejemplo, se puede considerar la inclusión de más variables independientes; categorizar la variable dependiente como ordinal en vez de binaria (en cuyo caso el modelo matemático subyacente también se vuelve más complejo); y utilizar alguna metodología para categorizar variables independientes según umbrales óptimos, pues en el caso de variables aleatorias continuas existen innumerables opciones. Con respecto a este último punto, un método que es ampliamente utilizado para este fin en modelos logit es el Weight of Evidence (WoE); se sugiere usarlo para futuras investigaciones que estén relacionadas.

- Si bien resulta útil monitorear los adeudos con el exterior de la banca para evitar que se repitan escenarios puntuales como el credit crunch durante la crisis rusa, lo cierto es que el crédito, al menos en moneda extranjera, tiene otros fundamentos o drivers. La investigación económica debería orientarse a identificar dichos fundamentos, con el objetivo de hacer un seguimiento más efectivo de los factores que pueden ocasionar volatilidad en el crédito, y en última instancia riesgos de carácter macroprudencial.

- Con la finalidad de incorporar la heterogeneidad de la banca y el efecto diferenciado de los adeudos sobre el crédito, se sugiere elaborar un modelo panel que tenga como unidad de corte transversal a los bancos peruanos. Se espera que en las entidades con mayor exposición al mercado de capitales internacional exista una 
relación significativa, posiblemente de largo plazo (cointegrante), entre los adeudos (totales y de corto plazo) y el crédito en moneda extranjera. 


\section{REFERENCIAS}

Armas, A., Castillo, P., \& Vega, M. (2014). Esquema de metas de inflación y restricción cuantitativa: Los efectos de los requerimientos de encaje en el Perú. (DT. $N^{\circ}$ 2014-03 Serie de Documentos de Trabajo) Recuperado del sitio de Internet del Banco Central de Reserva del Perú: http://www.bcrp.gob.pe/docs/Publicaciones/Documentos-deTrabajo/2014/documento-de-trabajo-03-2014.pdf.

Armas, A., Grippa, F., Quispe, Z., \& Valdivia, L. (2001). De metas monetarias a metas de inflación en una economía con dolarización parcial: el caso peruano. Revista Estudios Económicos del Banco Central de Reserva del Perú, $N^{o} 7$.

Azabache, P. (2011). Decisiones de Inversión en Empresas con Dolarización

Financiera. (DT. N ${ }^{\circ}$ 2011-23 Serie de Documentos de Trabajo) Recuperado del sitio de Internet del Banco Central de Reserva del Perú:

http://www.bcrp.gob.pe/docs/Publicaciones/Documentos-deTrabajo/2011/Documento-de-Trabajo-23-2011.pdf.

Banco Central de Reserva del Perú. (2006-2013). Reportes de Inflación. Lima: Autor.

Banco Central de Reserva del Perú. (2008). Circular 009 del Año 2008. Lima: Autor.

Banco Central de Reserva del Perú. (1 de Mayo de 2016). Glosario de Términos Económicos. Obtenido de http://www.bcrp.gob.pe/publicaciones/glosario.html

Banco Central de Reserva del Perú. (s.f.). Folleto Institucional. Lima: Autor.

Bofinger, P. (2001). Monetary Policy: goals, institutions, strategies and instruments. Nueva York: Oxford University Press.

Carrera, C., \& Cóndor, R. (2011). Los Encajes Bancarios: Reseña Internacional. Revisa Moneda del Banco Central de Reserva del Perú, Volumen N ${ }^{\circ}$ 148, 30-33.

Castillo, P., \& Barco, D. (2010). Respuestas de Política Económica frente al influjo de capitales. Revista Moneda del Banco Central de Reserva del Perú, Volumen $N^{o}$ $145,21-23$.

Choy, M., \& Chang, G. (2014). Medidas Macroprudenciales aplicadas en el Perú. (DT. $\mathrm{N}^{\circ}$ 2014-07 Serie de Documentos de Trabajo) Recuperado del sitio de Internet del Banco Central de Reserva del Perú:

http://www.bcrp.gob.pe/docs/Publicaciones/Documentos-deTrabajo/2014/documento-de-trabajo-07-2014.pdf.

De Gregorio, J. (2010). Regulacion Macroprudencial, estabilidad financiera y flujos de capitales. (DPE. N 37 Serie de Documentos de Política Económica)

Recuperado del sitio de Internet del Banco Central de Chle: 
http://www.bcentral.cl/es/faces/bcentral/investigacion/docinvestigacion/politicae conomica/fichapoliticaeconomica?id=BCCH_PUBLICACI_105633_ES.

Dickey, D., \& Fuller, W. (1979). Distribution of the Estimators for Autoregresive Time Series with a Unit Root. Journal of the American Statistical Association, Volume 74, 427-431.

Durbin, J., \& Watson, G. (1951). Testing for Serial Correlation in Least Squares Regression. Biometrika, Vol. 38, No. 1/2, 159-177.

Engle, R., \& Granger, C. (1987). Co-Integration and Error Correction: Representation, Estimation, and Testing. Econometrica, Vol. 55, No. 2, 251-276.

Ghosh, A., Habermeier, K., Chamon, M., Qureshi, M., Ostry, J., \& Reinhardt, D. (2010). Capital inflows. (Staff Position Note No. 2010/4) Recuperado del Sitio de Internet del Fondo Monetario Internacional: https://www.imf.org/external/pubs/ft/spn/2010/spn1004.pdf.

Granger, C. (1983). Cointegrated Variables and Error Correction Models. San Diego: Trabajo de discución 83-13a de la Universidad de California.

Granger, C. (1986). Developments in the Study of Co-Integrated Economic Variables. Oxford Bulletin of Economics and Statistics, Volume 48, 213-228.

Granger, C., \& Newbold, P. (1974). Spurious Regressions in Econometrics. Journal of Econometrics, 111-120.

Gujarati, D., \& Porter, D. (2010). Econometría. (5a ed.) México D.F.: McGraw Hill.

Herrarte, A. (17 de Febrero de 2016). Obtenido de PdfSR: http://pdfsr.com/pdf/laoferta-monetaria-y-la-politica-monetaria

International Monetary Fund. (2011). Macropudential Policy: An Oranized Framework. Recuperado del sitio de Internet del Fondo Monetario Internacional : https://www.imf.org/external/np/pp/eng/2011/031411.pdf.

Ize, A. (2001). Implicancias de la dolarización parcial para el régimen de meta de inflacion: Un análisis basado en la literatura sobre dolarización. Revista Estudios Económicos del Banco Central de Reserva del Perú, $N^{\circ} 7$.

León, D., \& Quispe, Z. (2010). El encaje como Instrumento no Convencional de Política Monetaria. Revista Moneda del Banco Central de Reserva del Perú, Volumen $N^{o}$ 143, 8-16.

Mankiw, G. (1997). Macroeconomics. (3a ed).

Mishkin, F. (2000). Inflation targeting in emerging market countries. (Working Paper No. 7618) Recuperado del sitio de Internet del National Bureau of Economic Research: http://www.nber.org/papers/w7618.pdf.

Mishkin, F. (2008). Moneda, Banca y Mercados Financieros. (8a ed.) México: Prentice Hall. 
Mishkin, F., \& Savastano, M. (2000). Monetary Policy Strategies for Latin America. (Working Paper No. 7617) Recuperado del sitio de Internet del National Bureau of Economic Research: http://www.nber.org/papers/w7617.pdf.

Molinero, L. (2003). Elección de los puntos de corte para convertir una variable cuantitativa. España: Asociación de la Sociedad Española de Hipertensión.

Montero, A. (Febrero, 2000). Independencia del Banco Central y Credibilidad: Una Retórica Seductora. Documento presentado en la. VII Jornada de economía crítica sobre la fragilidad financiera del capitalismo. Albacete.

Orellana, W. (1999). Estimacion del Circulante y el Multiplicador Monetario en Dólares. Revista de Análisis del Banco Central de Bolivia, Volumen 2, N 1, 6786.

Reinhart, C., \& Reinhart, V. (2008). Capital Flows Bonanzas: An Encompassing View of the Past and the Present. (Working Paper No. 14321) Recuperado del sitio de Internet del National Bureau of Economic Research: http://www.nber.org/papers/w14321.pdf.

Rossini, R., Quispe, Z., \& Rodriguez, D. (2013). Flujo de capitales, política monetaria e intervención cambiaria en el Perú. Revista Estudios Económicos del Banco Central de Reserva del Perú, $N^{\circ} 25,39-50$.

Superintendencia de Banca, Seguros y AFP. (1 de Mayo de 2016). Glosario de Términos e Indicadores Financieros. Obtenido de https://intranet1.sbs.gob.pe/estadistica/financiera/2015/Setiembre/SF-0002se2015.PDF

Taylor, J. (1993). Discretion versus policy rules in practice. Carnegie-Rochester Conference Series on Public Policy, Volume 39, 195-214.

Triveño, L., \& Dorich, J. (2000). Reglas monetarias para el Perú. Revista Estudios Económicos del Banco Central de Reserva del Perú, $N^{\circ} 6$.

Villalobos, L., Torres, C., \& Madrigal, J. (1999). Mecanismo de Transmisión de la Política Monetaria: Marco Conceptual. Recuperado del sitio de Internet del Banco Central de Costa Rica: http://www.bccr.fi.cr/investigacioneseconomicas/politicamonetariaeinflacion/M ecanismo_transmision_credito_bancario_relevancia_caso_Costa_Rica.pdf.

Yule, G. (1926). Why do we sometimes get nonsense correlations between time series? A study in sampling and the nature of time series. Journal of the Royal Statistical Society, Vol. 89, No. 1, 1-63. 